\title{
تاريخ النسوية وتحولاتها عبر الزمن \\ (مصر نموذجًا)
}

\section{The History of Feminism and its Transformations through Time (Egypt as a Model)}

هاني جرجس عياد

"دكتوراه علم الاجتماع - كلية الآداب - جامعة طنطا.

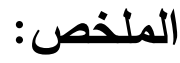

يسعى البحث الراهن إلى تحقيق ثلاثة أهداف رئيسية، هي: أولا، الوقوف على وجهات النظر

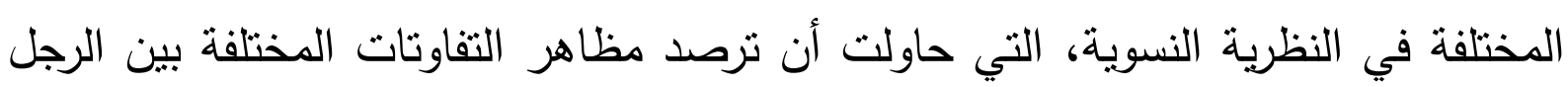

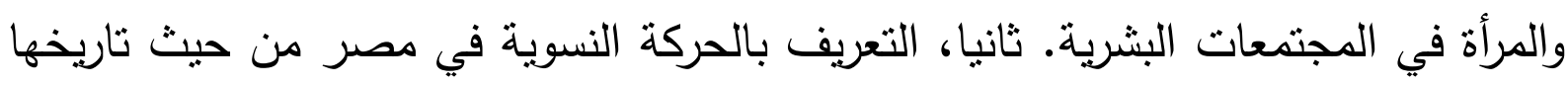

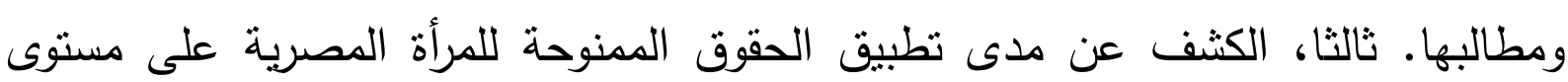
الممارسة الفعلية، وأبرز التحديات التي واجهتها في سياقاتها الاجتماعية والسياسية.

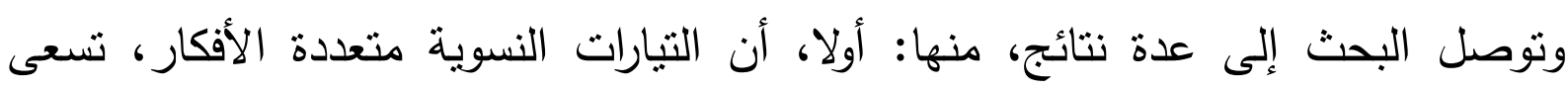

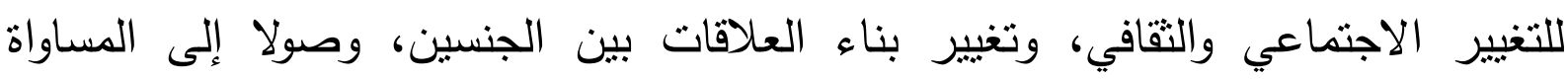

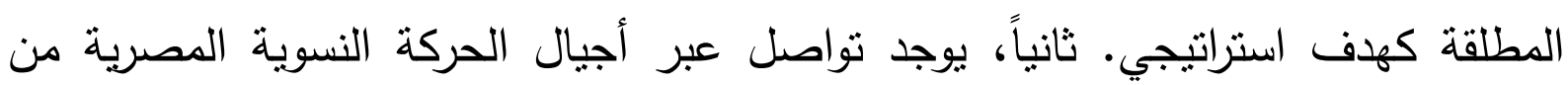
حيث المطالب المرفوعة وأدوات العمل النسوي، فكل موجة من موجات الحركة النسوية

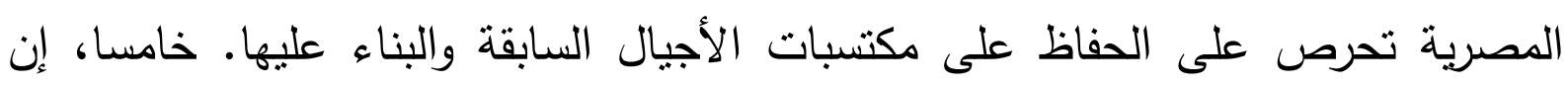

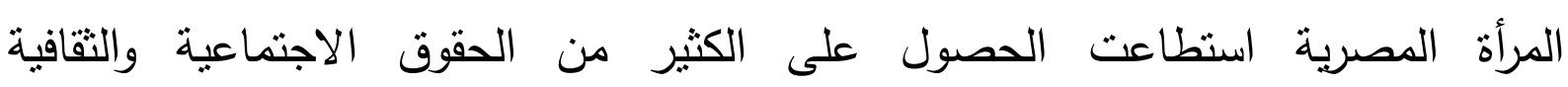

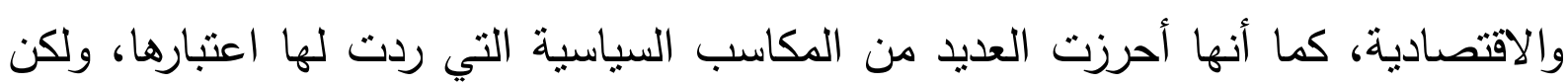

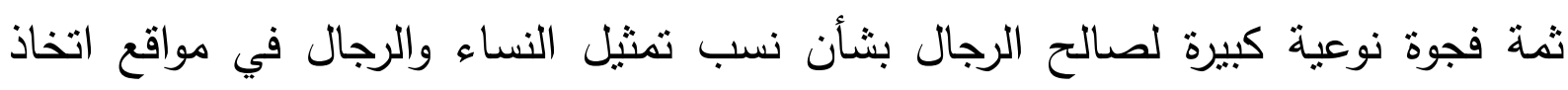

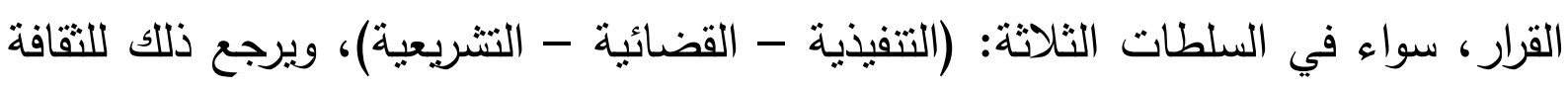

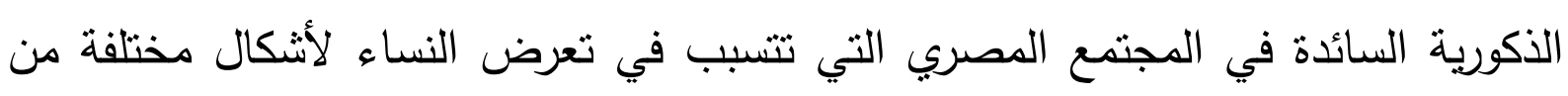
التمييز والعنف في الدجالين الخاص والعام. 
The current study sought to achieve three main goals: First, to understand the different perspectives of feminist theory that attempted to monitor the manifestations of the various differences between men and women in society. Second, the definition of the feminist movement in Egypt in terms of its history and demands. Third, revealing the extent to which the rights granted to Egyptian women are adhered to in practice as well as the level of adherence in actual practice, and the most prominent challenges they faced in their social and political contexts.

This study reached several results, including: First: the diversity of feminist currents that seek social and cultural change, and change the building of gender relations, leading to absolute equality as a strategic goal. Second: there is communication across the generations of the Egyptian feminist movement in terms of raised demands and tools for feminist action. Every wave of the Egyptian feminist movement is keen to preserve and build on the gains of previous generations. Third: Egyptian women have managed to obtain many social, cultural and economic rights, and they have made many political gains that have been rehabilitated, but there is a large qualitative gap in favor of men regarding the proportions of representation of women and men in decision-making positions, whether in the three authorities: (Executive - Judicial - Legislative) This is due to the male culture that prevails in Egyptian society, which causes women to experience various forms of discrimination and violence in the private and public spheres. 
يعدُّ موضوع التفاوتات بين الجنسين من المواضيع التي شغلت تفكير العديد من النسويات،

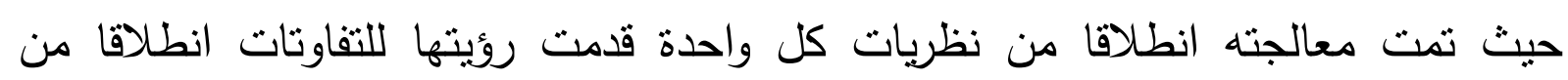
تصورات وتفسيرات مختلفة، رغم اتفاقها على أن المرأة لا تحظى بنفس الوضع داخل المجنمع. تقول الفيلسوفة الفرنسية سيمون دي بوفوار في كتابها (الجنس الآخر): 》المرأة لا تولا امرأة،

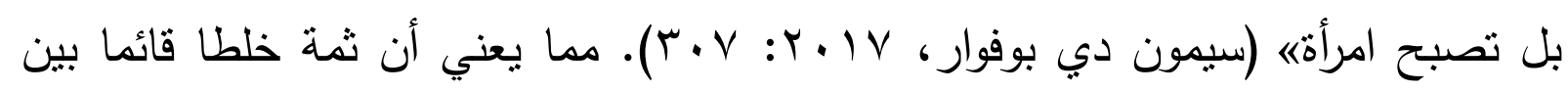

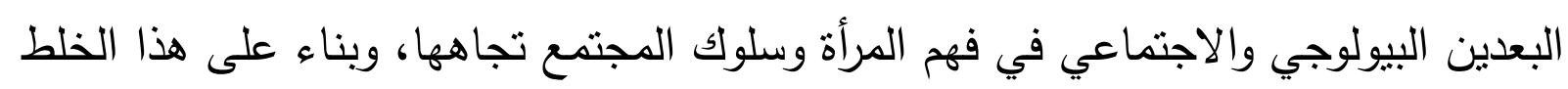
انطلقت النسوية بوصفها حركة لتحرير النساء من الصور النمطية المبنية على البعد البيولوجي، وبدأت معالم حقل معرفي جديد تتبلور ، عنوانه الفكر النسوي. تطورت الفكرة النسوية منذ بدايات القرن التاسع عشر وحتى الآن تطورا كبيرا، وتطورت

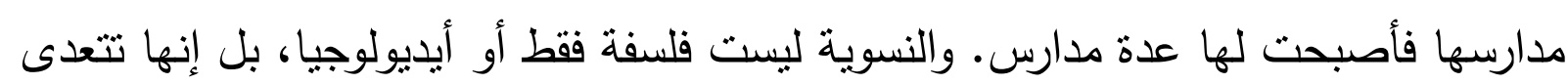
ذلك للممارسة السياسية ثم الاجتماعية ثم وأكثر من هذا الممارسة الثخصية والذاتية، حيث

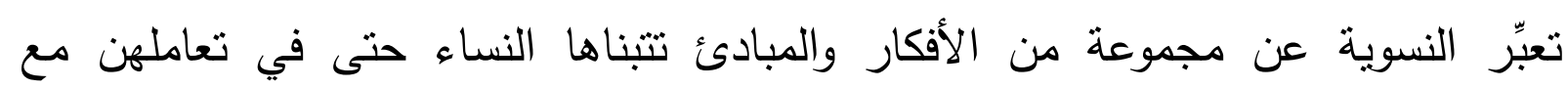
أزواجهن. إن النسوية في أصولها هي حركة سياسية تهدف إلى غايات اجتماعية تتمثل في

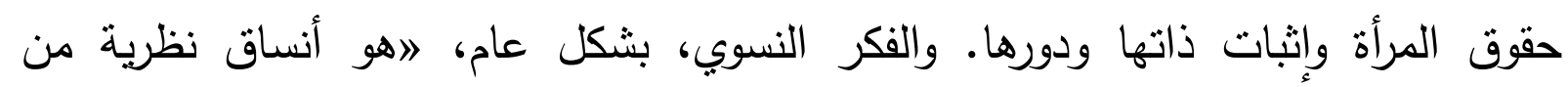

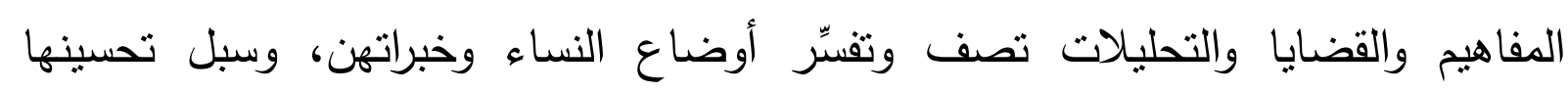

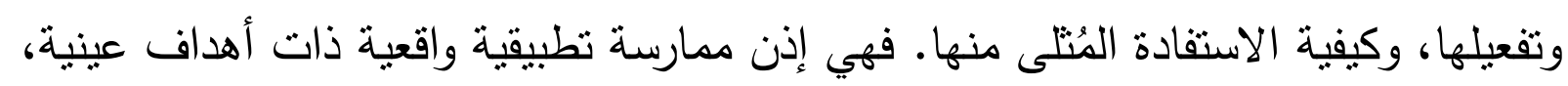

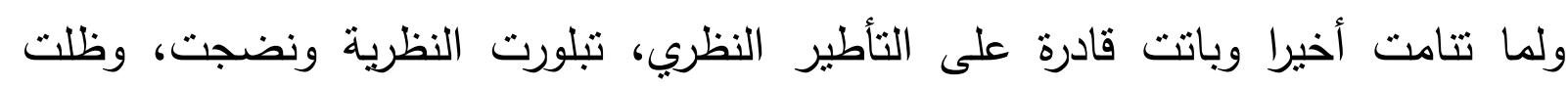

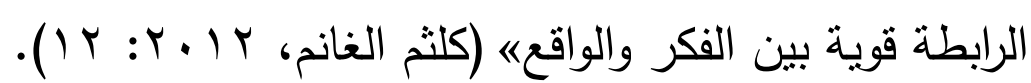
بدأت الحركة النسوية في الفكر الغربي في القرن التاسع عشر، ولثر، وصيغ مصطلح النسوية

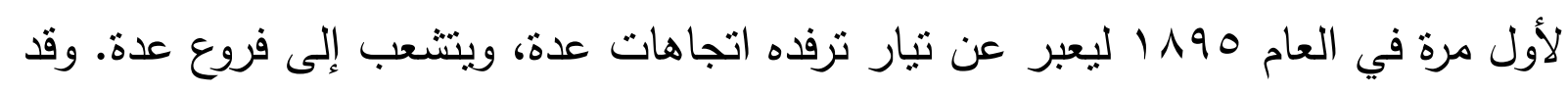

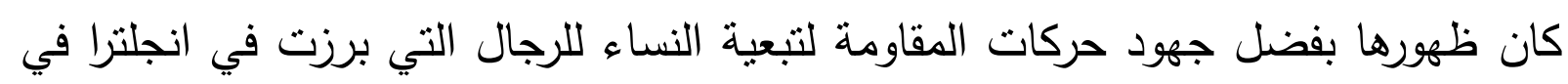
القرن السابع عشر، ثم امتدت في كلٍ من فرنسا والولايات المتحدة. وحدث في هذه الفترة

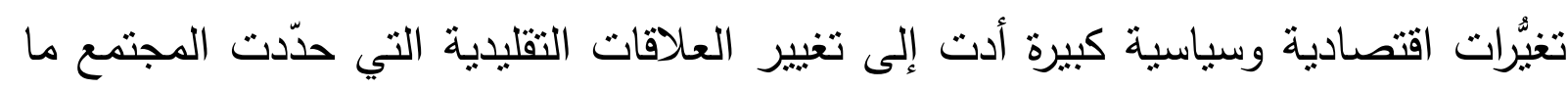


قبل الصناعي. فتطورت الرأسمالية الصناعية في انجلترا، وتبنت كلٌ من فرنسا والولايات المتحدة الأنظمة السياسية القائمة على أساس الديمقراطية التمنيلية، مما أدى إلى تغيير المعنى السياسي والاقتصادي للعائلة التي تبدّلت أحوالها. وتمزّق مركز المرأة التقليدي فيها. حيث فقدت النساء من الطبقات العليا نفوذهن السياسي مع انحدار العائلات الأرستقراطية وانبثاق الحكم الديمقراطي. وتقوّض الأساس الاقتصادي لنساء الطبقات الدنيا حين نقلت لهن التهن

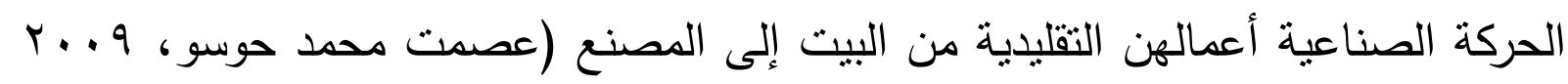
: الفعّالة منل: إنتاج الطعام، وحياكة النسيج، وصناعة الملابس، تزايد اعتمادهن، وخاصة

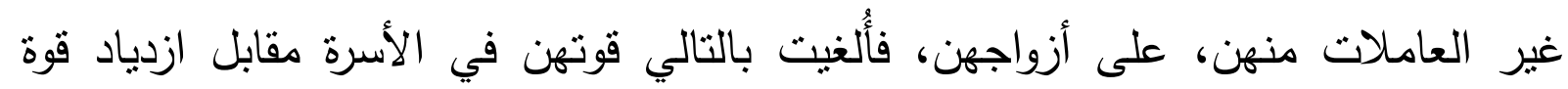

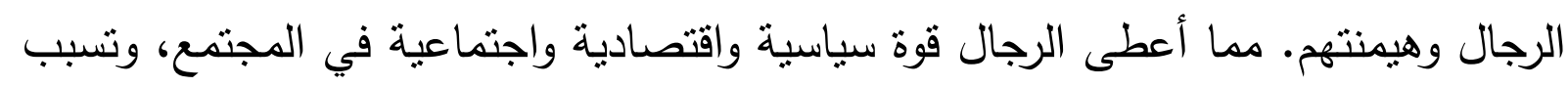
في تتاقص حقوق المرأة سياسيا واقتصاديا واجتماعيا، الأمر الذي أدى إلى تهميشها، ووضعها بمرتبة متدنية عن مرتبة الرجال. وأخيرا ظهرت في تلك الفترة أصوات النساء

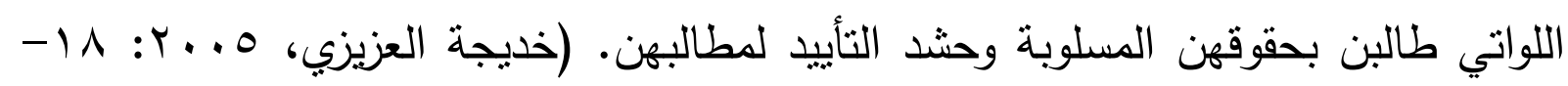
9 (1). وتبلورت هذه المطالب فيما بعد وتطورت الحركة النسوية بموجاتها الثناث. إن الفكر النسوي الغربي، قد تطور، وطوّر معه الأسس الفلسفية لفكر غربي في سياق التغيُر

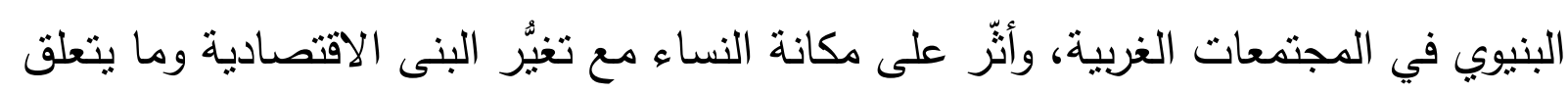
بها من بنى اجتماعية وثقافية. وظهر ذلك من خلال الموجات النسوية المختلفة، التي أعلنت جميعها أن المرأة تتعرض لاضطيهاعهاد وتمبيز ، وانصبت مطالباتها على تحسين واقع المرأة، والحصول على حقوق التعليم والعمل والمشاركة السياسية. ومع تطور الموجات النسوية، تطور الخطاب والمطالبات لتتجاوز الخطابات التقليدية، حتى ثمانينيات القرن العشرين، حيث ظهر ما سُمِي بتيار ما بعد النسوية، الذي اختلف عن الموجات السابقة برفضه

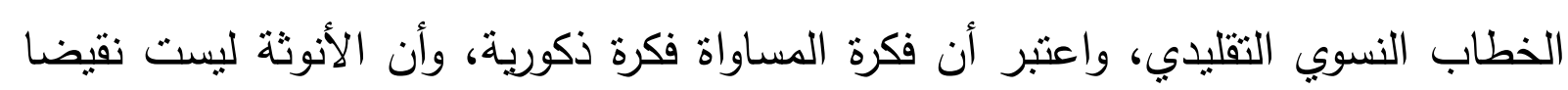
للاككورة، وطالب بضرورة الحفاظ على الهوية الأثنثية. وصلت معالم الفكر النسوي الغربي إلى العالم العربي، فتأثّز به الفكر العربي حيث أدرك مفكروه أن فارقا حضاريا يفصل بين الثرق والغرب يتطلب التأمل والبحث، وبدأت الأسئلة

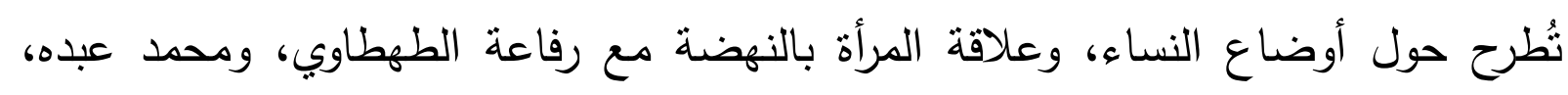

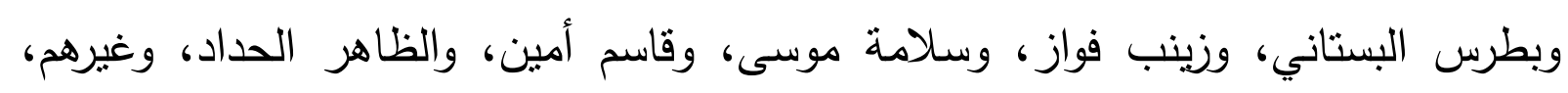


بوصفهم أصحاب مشروع إصلاحي وتجديدي. وتفاوتت خطاباتهم بين مؤيد للاجتهاد والتأويل، وبين مطالب للتماهي الكامل مع الحضارة الغربية، فنشطت الحركة الفكرية،

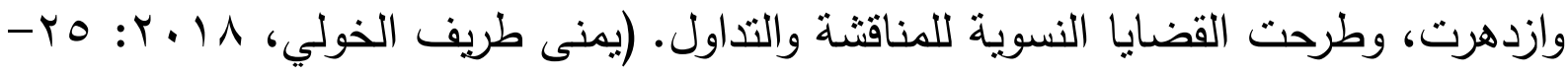

ويمكن النظر إلى تاريخ الحركة النسوية المصرية باعتباره نضالا منواصلا في سبيل العدالة والمساواة في المجالين العام والخاص، وهو نضال يتسم بوضوح الروئية والصوت وخاصة الفئة خلال القرن العشرين ومطلع القرن الحادي والعشرين. ونحن إذ نتحدث عن الحركة النسوية

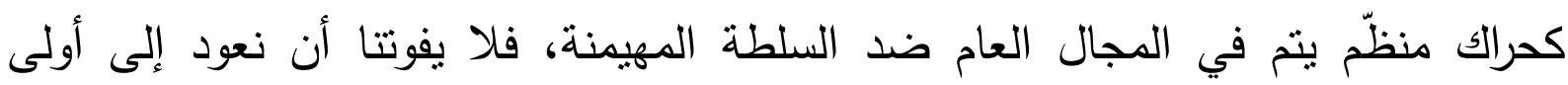
المظاهرات النسائية الصصرية الكبرى التي قامت يوم 17 مارس 1919 في في إطار كفاح

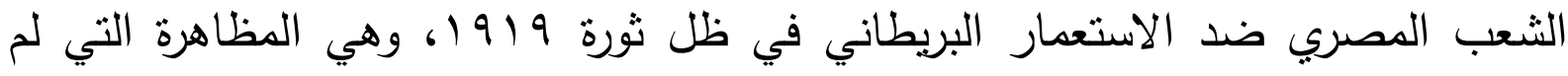

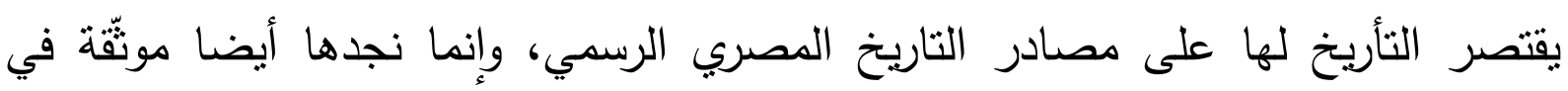
الصحف التي كانت تصدر حينذاك، بل وفي قصيدة حافظ إبراهيم، يصف فيها مسيرة النساء المصريات والمواجهات العنيفة التي واجهنها من قبل قوات الثرطة، مما أدى إلى سقوط أول شهيدة مصرية لثورة 919 19، وهي حميدة خليل، وإصابة العديد من المشاركات (هالة كمال، .$(7: Y \cdot 17$

لقد خسرت البشرية طويلا من هذا الإهدار الجائر لحقوق المرأة ولدورها الحضاري،

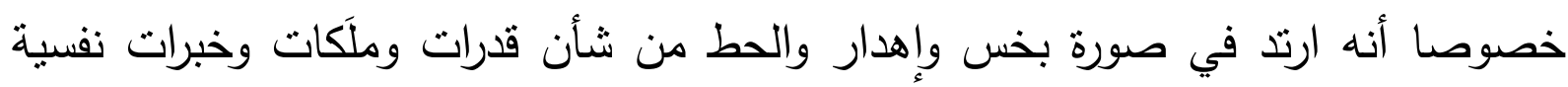

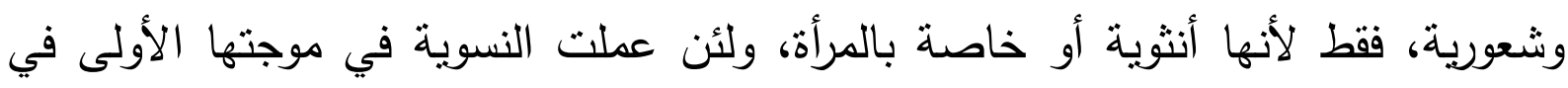

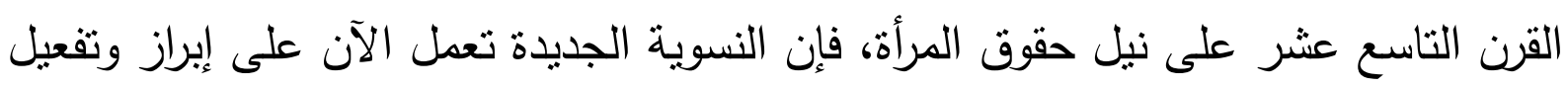

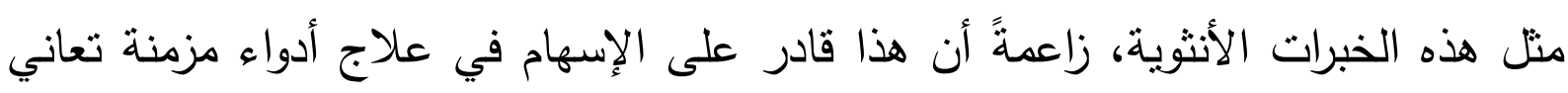

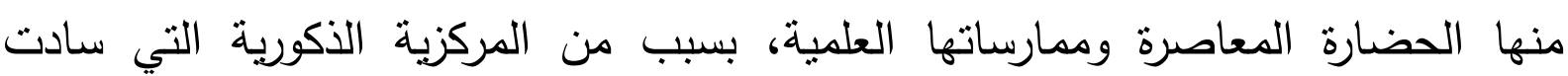
وانفرادها بالفعل الحضاري.

إن النسوية اتجاه ذو مراحل وطيف عريض ومتغيرات وبدائل شتى، وهي، ككل الاتجاهات الفكرية الكبرى، إطار عام يضم فروعا عديدة ورواف شتى، أوجه الاختلاف بينها كثيرة، لكنها

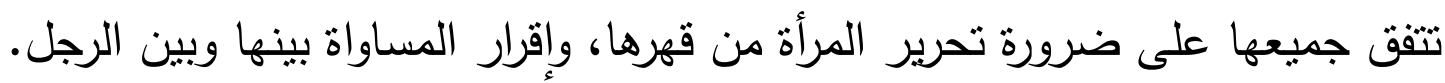

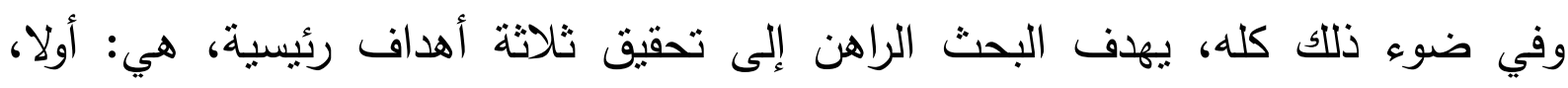
الوقوف على وجهات النظر المختلفة في النظرية النسوية، الني حاولت أن ترصد مظاهر النها 
التفاوتات بين الرجل والمرأة في ضوء المحدات النظرية التي تنطوي عليها، وفي ضوء ما تقدمه من رؤى تساعد على تفسير وتحليل الأوضاع الاجتماعية المقيّدة لها والداعمة لاستغلالها. ثانيا، التعريف بالحركة النسوية في مصر وقراءة لتاريخها، متتبعة أشنكال العمل النسوي والمطالب التي رفعتها النسويات المصريات على مدار القرن العشرين ومطلع القرن الحالي، وإنجازاتها، والتحديات التي واجهتها في سياقاتها الاجتماعية والسياسية. ثالثا، استعراض بعض المؤشرات والإحصاءات والحقائق والأرقام عن الأوضاع الحالية للمرأة المصرية، ومدى مشاركتها في الحياة العامة. ويتم ذلك من خلال عدة محاور رئيسية، هي: التمكين السياسي وتعزيز الأدوار القيادية للمرأة، والتمكين الاقتصادي، والتمكين الاجتماعي، ولني، والحماية. القسم الأول: النظرية النسوية ودراسة أشكال التمييز ضد النساء أولا: مفهوم النسوية

طرح مفهوم النسوية Feminism لأول مرة في مؤتمر النساء العالمي الأول الذي عُقِّ في باريس عام 1991، وعُرف المفهوم حينذاك على أنه: 》الإيمان بالمرأة، وتأييد حقوقها، وسيادة نفوذها《. أما معجم أوكسفورد Oxford فقد عرّفه على أنه: ضآراء ومبادئ

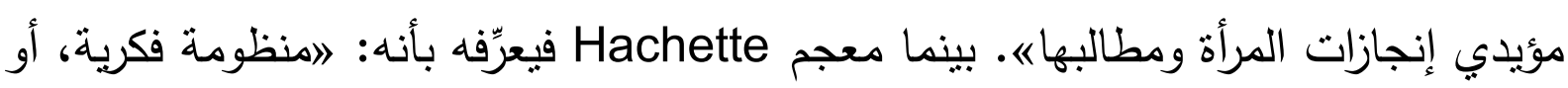
مسلكية مدافعة عن مصالح النساء، وداعية إلى توسيع حقوقهنه . في حين أن معجم ويبستر Webster واجتماعيا، وتسعى كحركة سياسية إلى تحقيق حقوق المرأة واهتماماتها، وإلى إزالة التمييز

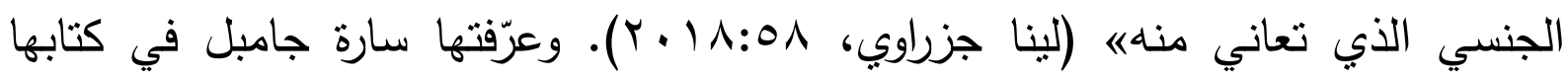
(النسوية وما بعد النسوية) بأنها: "حركة سعت إلى تغيير المواقف من المرأة كامرأة، قبل تغيير الظروف القائمة، وما تتعرض له النساء من إجحاف كمواطنات على المسنويات القانونية والحقوقية في العمل والعلم، والنتارك في السلطة السياسية والمدنيةه (سارة جامبل،

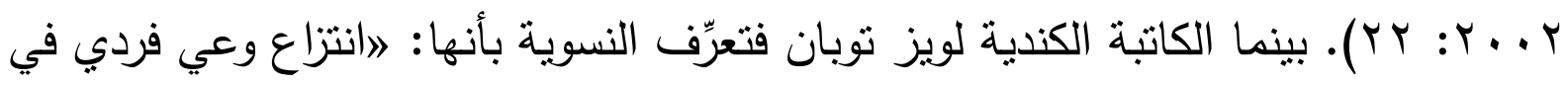
البداية، ومن ثم وعي جمعي ثتبعه ثثرة ضد موازين القوى الجنسية، والتهميش الكامل للنساء

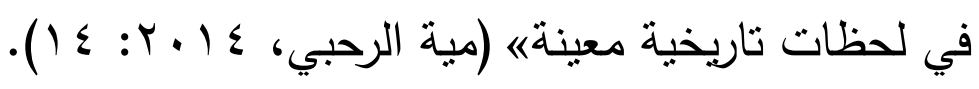

وربما تعرّف على أنها: "حركة تسعى إلى إعادة تنظيم العالم على أساس المساواة بين الجنسين (ذكر/أنثى)، في جميع العلاقات الإنسانية، إنها حركة ترفض كل تمييز بين الأفراد 
على أساس الجنس، وتلغي جميع الامتيازات والأعباء الجنسية، وتسعى جاهدة لإقامة اعتراف بالإنسانية المشتركة للمرأة والرجل باعتبارها أساس القانون والعرفه (ويندي كيه

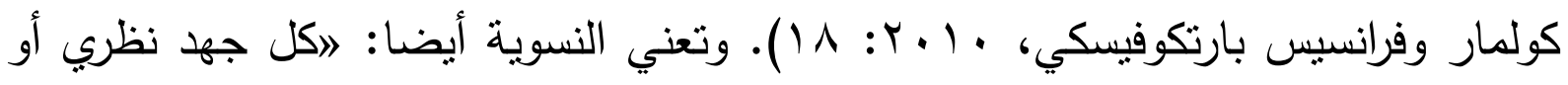

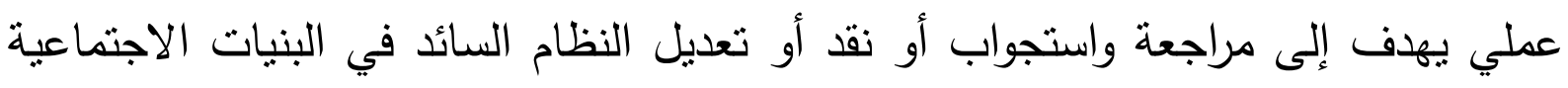

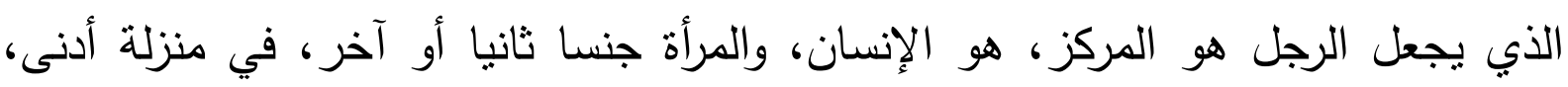

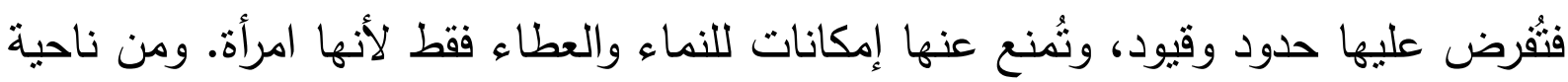

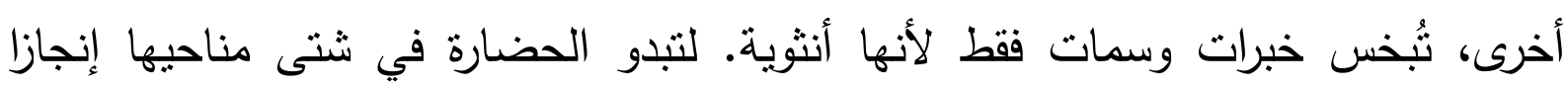

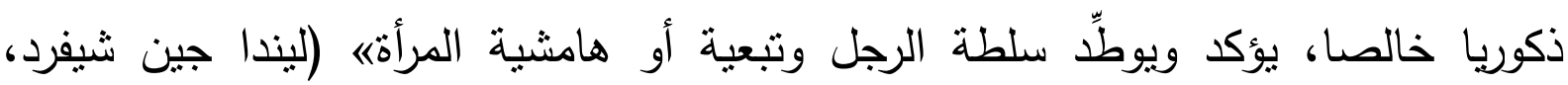

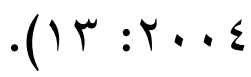

هي إذن حركة اجتماعية وسياسية تتبنى قضية النساء في المجتمع من منطلق القناعة بوجود خلل في ميزان القوى الاجتماعية والسياسية بين الرجال والنساء، وتقوم على الوعي والفعل.

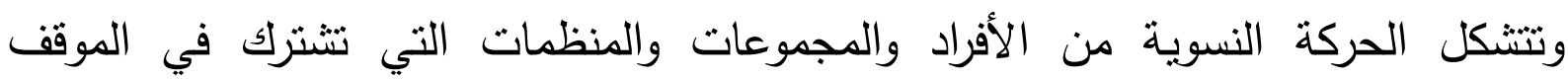
والهدف، وتعبِّر عن ذلك بالفكر والعمل. وكاتجاه عام، فإن الدصطلح يثير إلى التقرقة بين الذكر والأنثى على أساس الدور

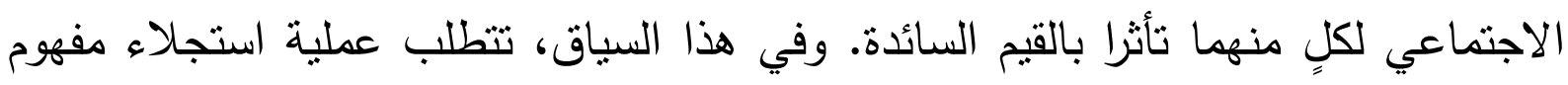

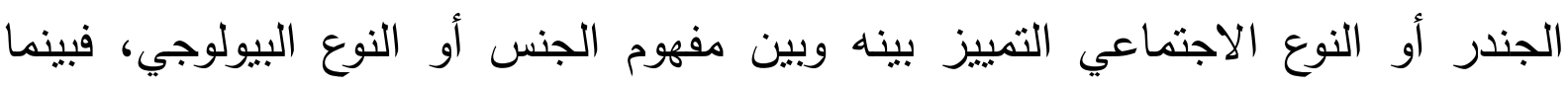

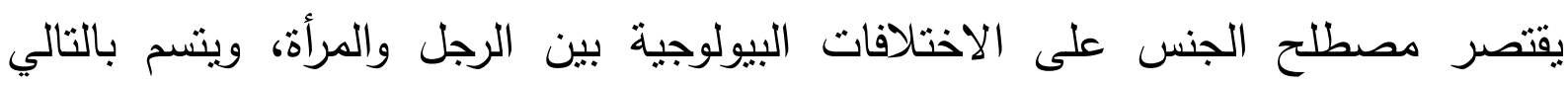
بالجبرية والاستاتيكية، كون الفروق الجسدية بين الرجل والمرأة فروقا ثابتة وأبدية، نجد أن النان مصطلح الجندر مفهوم دينامي، حيث تتفاوت الأدوار التي يلعبها الرجال والنساء تفاوتا كبيرا بين ثقافة وأخرى، ومن جماعة اجتماعية إلى أخرى في إطار الثقافة نفسها. فالعرق، والطبقة

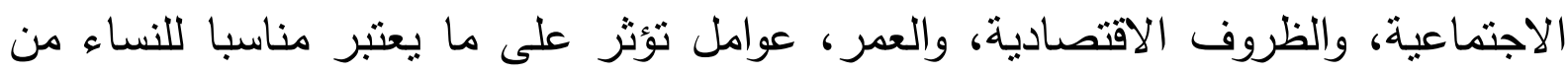

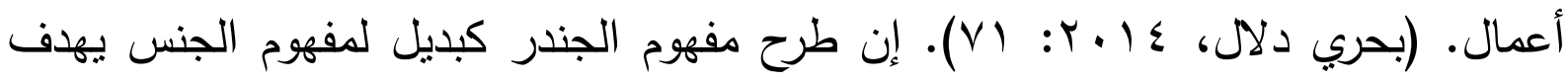

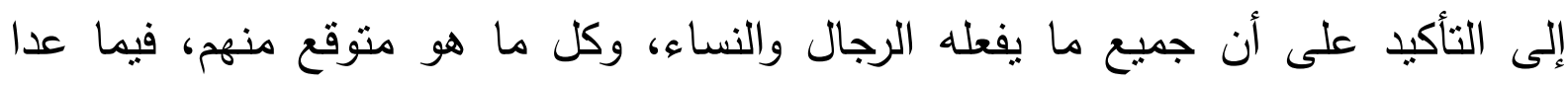

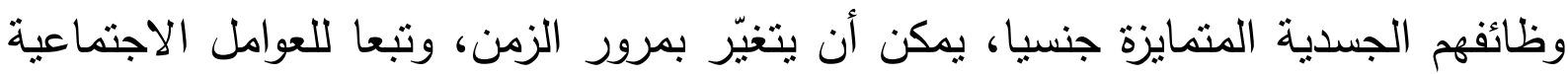
والثقافية المنتوعة.

تتحور معظم نقاثات الحركة النسوية حول مفهوم الدور الاجتماعي، فتعمل على نقده أو

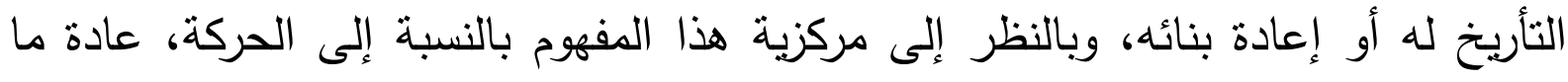


بدور نقدها كذلك في فلكه، وهو النقد الذي أدى إلى انتقال الحركة من موجة إلى موجة، وربما يؤدي إلى انتقالها لثيء جديد في المستقبل كذلك. من كل ما سبق، فإن النسوية هي مجموعة من التصورات الفكرية والفلسفية التي تسعى لفهم

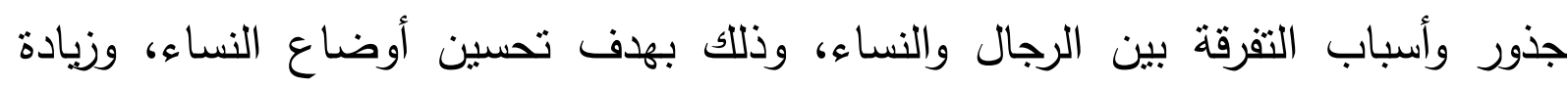
فرصهن في كافة المجالات. إن النسوية ليست فقط أفكارا نظرية وتصورات فكرية مؤسسة

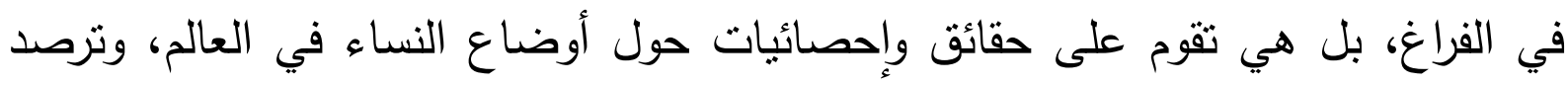
التمييز الواقع عليهن سواء من حيث توزيع الثروة أو المناصب أو الفرص وأحيانا حتى التى

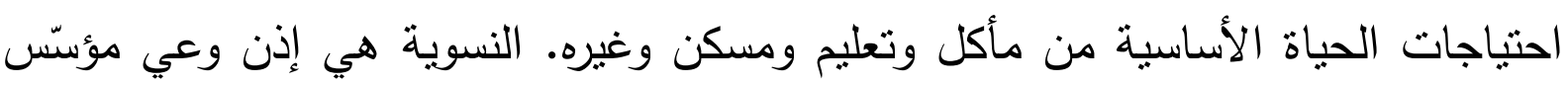
على حقائق مادية، وليست مجرد هوية. ثانيا: الموجات النسوية الثُلاث (نبذة تاريخية) مرت الحركة النسوية في العالم بمراحل عدة، يصعب اختصارها في هذه العجالة، لكن هذا لا لا

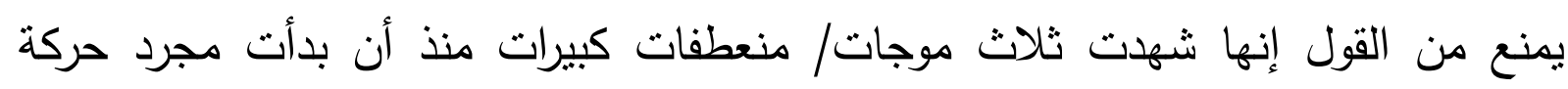

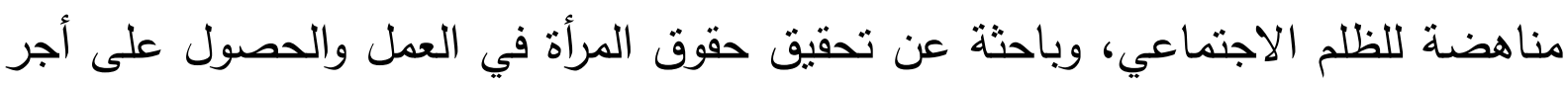

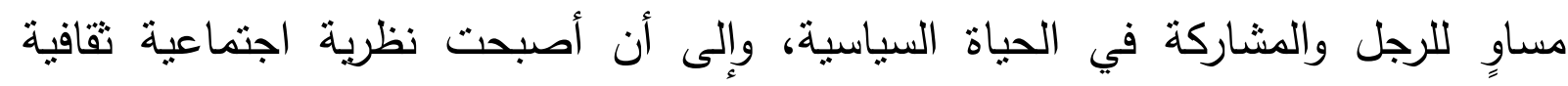

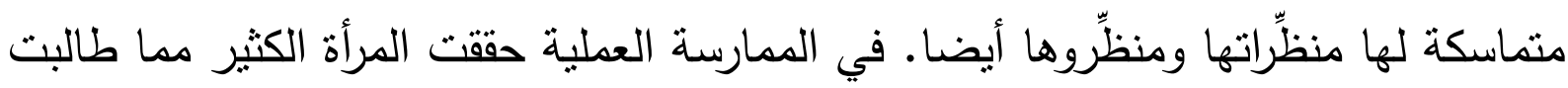

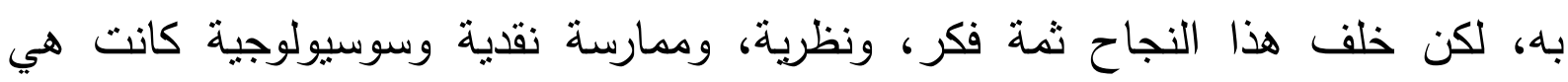
المرجع الفكري الذي تستتد إليه الحركات النسوية ومؤسساتها، لا سيما في أوروبا. ومثل كل

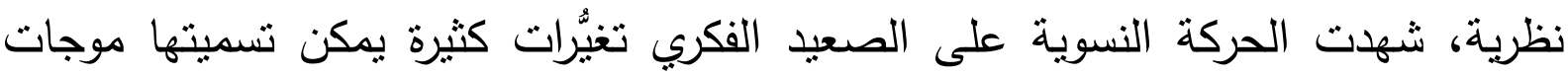
كبيرة.

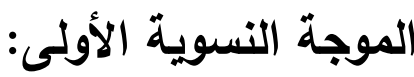

ارتبطت النسوية المبكرة ارتباطا مبانشرا بصدور كتاب (دفاع عن حقوق المرأة) عام IV9

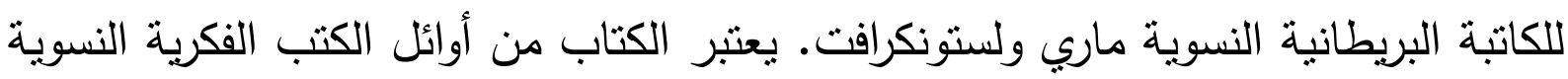
في العالم، وأبرز كتب مدرسة النسوية اللييرالية. ينقسم الكتاب لثناثة عثر فصلا، تنتاول فيه الثيه

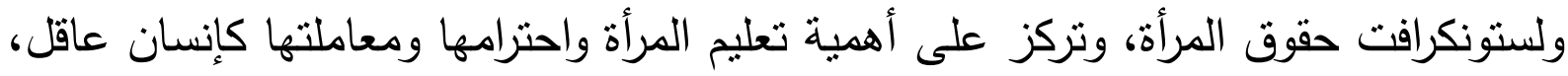
وليس ككائن عاطفي. كتبت ولستونكرافت الكتاب كرد على بعض فلاسفة القرن الثامن عشر، الذين نادوا بعدم أحقية المرأة في التعليم. وكان من بينهم شارل موريس ناليران، الذي

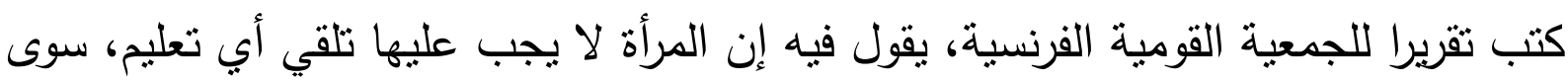


هذا الذي يساعدها على تأدية دورها في المنزل. في كتابها، أكدت ولستونكرافت على ضرورة

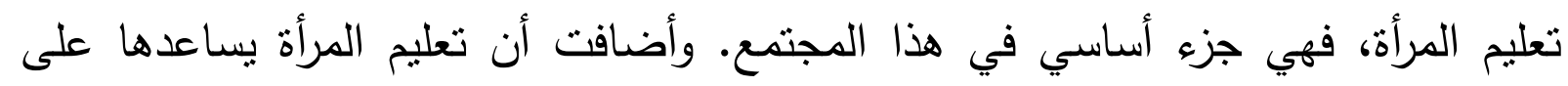

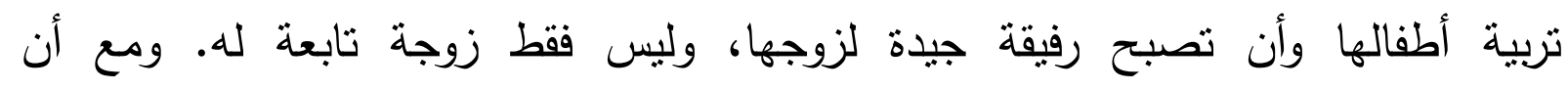
ولستونكرافت لم تستخدم مصطلح الأدوار الجندرية إلا أنها رفضت الفكرة التي تقول إن المرأة بطبيعتها غير عقلانية وعاطفية لا تهنم سوى بالمتع، وأثنارت إلى أنه يتم التعامل مع النساء كما لو أنهن دمى، وبالنتيجة تتمو شخصياتهن بهذا النمط وتتركز اهتماماتهن في أثنياء تافهة. وأضافت أنه إذا تم التعامل مع الرجال بنفس الطريقة، فستتشكل شخصياتهم واهتماماتهم على نفس النمط. وأكدت ولستونكرافت على ضرورة احترام المجتمع للمرأة ومعاملتها ككائن بشري عاقل له حقوقه الإنسانية، وليس كثيء عاطفي يمكن امتلاكه وبيعه

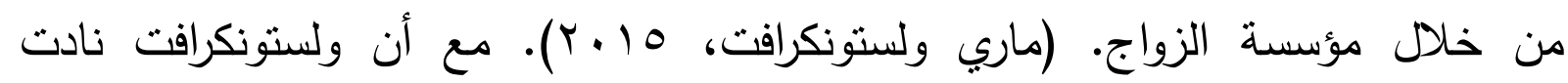

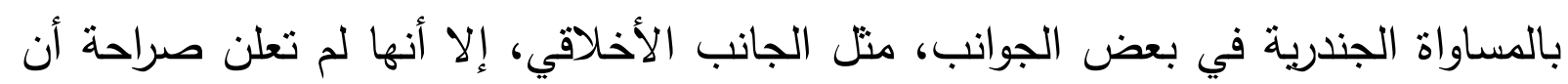
النساء والرجال منساوون على كافة المستويات، كما أنها دعت لتعليم المرأة لتكون رفيقة وأمًا جيدة، متجاهلة الدور الاجتماعي والسياسي للمرأة. كانت الغاية النهائية للنسوية في موجتها الأولى هي نيل المرأة بعضا من الحقوقي واندي العامة التي يتمتع بها الرجل، لذلك دأبت على تأكيد المساواة بين الجنسين، وأن الفوارق النوعية للمرأة هامشية لا تجعلها أقل، ولا تحول دون تلقيّها العلم وممارستها العمل والحياة السياسية

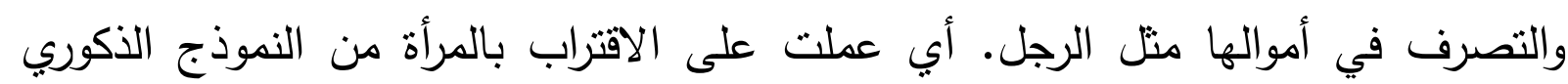
السائد كنموذج حضاري للإنسان، وسارت في مسار التحجيم والطمس للخصائص الأنثوية الميزة، وكان هذا هو السبيل الأوحد لفك إسار المرأة. احتدم الجدال في طيات هذه الموجة، ووصل صداه إلى المشرق العربي على يد الرواد أمثال: رفاعة الطهطاوي وقاسم أمين ونظيرة زين الدين وهدى شعراوي ... إلخ، وجرى وهى

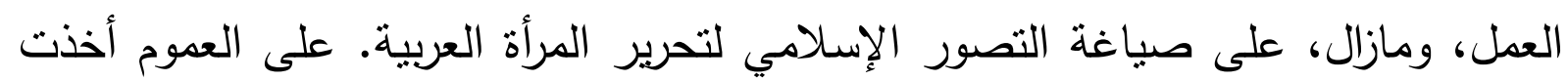

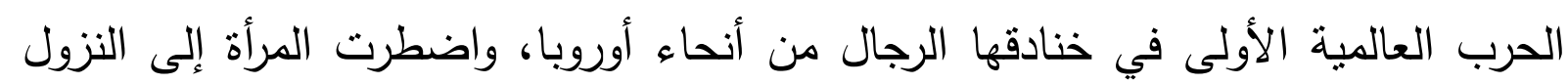
إلى مواقع العمل التي خلت منهم، وأدته على أكمل وجه، فيما يمكن اعتباره حسما للجدل في التي الفكر الغربي، وظفرت المرأة بحقوق المواطنة في انجلترا ونيوزيلندا والولايات المتحدة والاتحاد السوفيتي ... إلخ، وبدا الطريق ممهدا لكي تتالها في البقاع الأخرى. وارتفع حق تعليم المرأة كمثال أعلى في أنحاء شتى في العالم بدرجات متفاوتة. (ليندا جين شيفرد، ع . . ب: ع ( ). 
هذه الموجة النسوية الأولى في الفكر الغربي حركة اجتماعية سياسية أولا وأخيرا، غير ذات

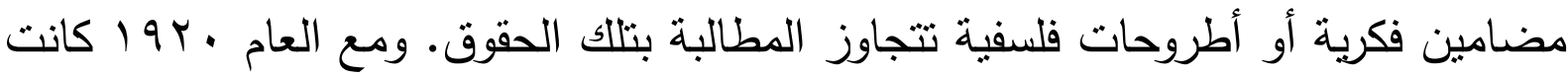

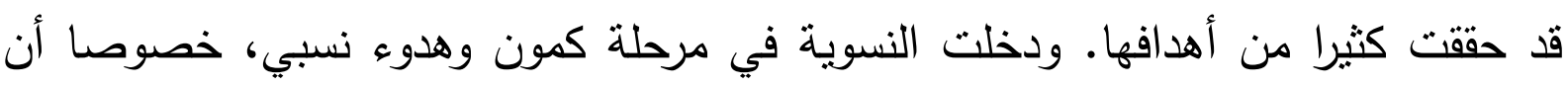
العالم الغربي كان منشخلا آنذاك ببوادر الحرب العالمية الثانية المقبلة ثم عواقبها، ويواجه الكفاح الباسل ضد الاستعمار الممهِّ لحركات التحرر القومي في العالم الثالث.

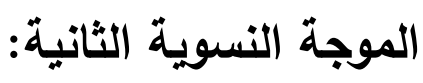
أما الموجة الثانية فقد بدأت في الستينيات والسبعينيات من القرن العشرين، وفيها انتقلت الحركات النسوية من الكفاح الميداني إلى الاهتمام ببناء النظرية النسوية التي تركز على هلى تفكيك التقافة البطريركية ونقدها، وهنا تحضر سيمون دي بوفوار كرمز لهذه المرحلة بكتابها

(الجنس الآخر ) الذي اعثُبر عمدة المؤلفات الخاصة بالحركات النسوية في هذه الفترة.

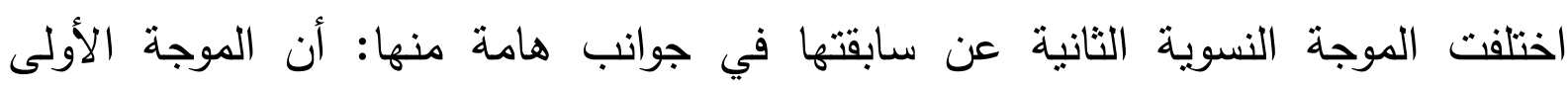
اقتصرت على النضال المطلبي سعيا وراء تحقيق هدفها في إنجاز مبدأ الحقوق المتساوية، بما في ذلك حق الاقتراع، وحق الملكية، وحق المواطنة الكاملة. أما الموجة الثانية فقد نقلت

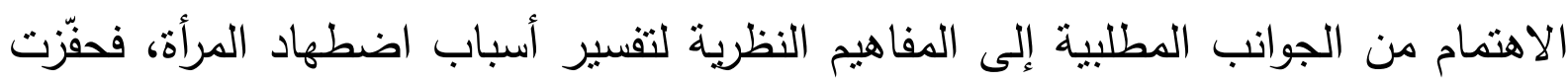
بذلك ظهور مؤلفات وتتظيرات في كتب ودوريات عديدة في مجال الأنثروبولوجيا والإنسانيات؛ ومنها علم الاجتماع (الذي لم يعر اهتماما لموضوع المرأة في دراساته

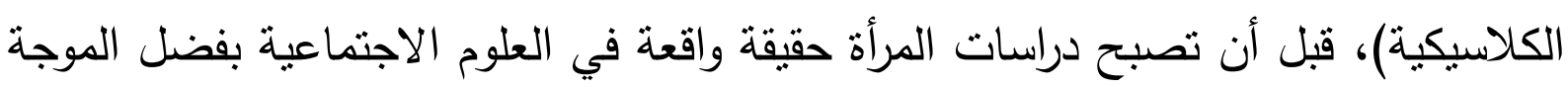

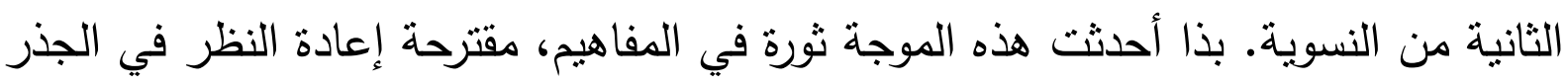
الذكوري لمناهج المعرفة، ساعدها في ذلك تأثرها بالظرف السياسي الذي ميّز سنتينيات وسبعينيات القرن الماضي، حيث عارضت نسويات الموجة الثانية حرب فيتتام، وشاركن في

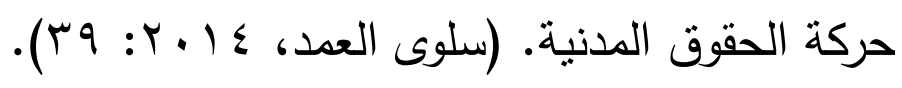
ركزت هذه الموجة اهتمامها على تحرير المرأة من قمع المضامين الاجتماعية والثقافية للنظام الأبوي المهيمن، فسلّطت الضوء على ماهية الجسد الأنثوي، بما يمثلك من معانٍ

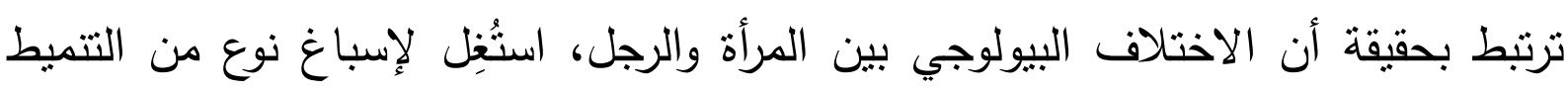

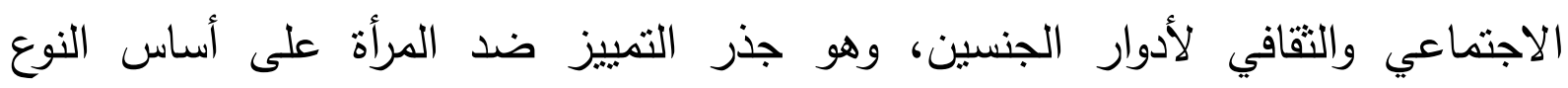
البيولوجي. في كتابها (الجنس الآخر) كتبت سيمون دي بوفوار عبارتها الثهيرة: الالمرأة لا تولد امرأة، بل تصبح امرأةه. هذه العبارة المفعمة بالمعاني المكثقة، حفّزت على ظهور فكر لئري 1. 
جديد حول طريقة النظر للاختلاف الجندري من حيث المكانة، والدور الاجماعي المُعطى

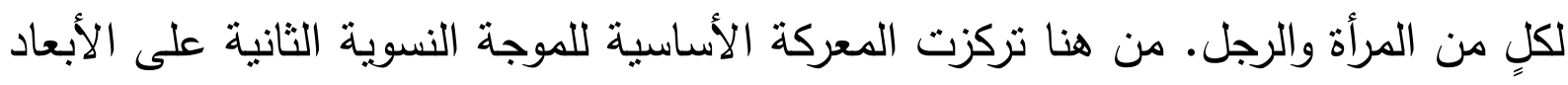

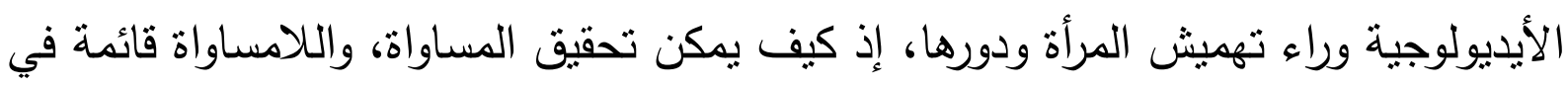
نوليفة البناء الأيديولوجي، والاجتماعي، والثقافي، واللغوي، وجميعها يحدد مسبقا مكانة ودورا

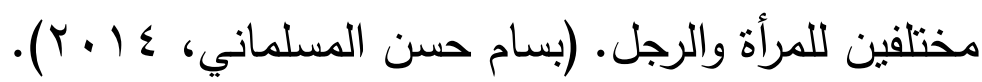

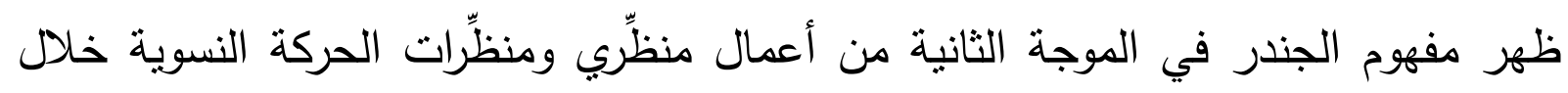
تحليلهن للعلاقات الاجتماعية، وبحثهن عن أسباب هيمنة الذكور على الإناث. فكانت نلك الكاتل

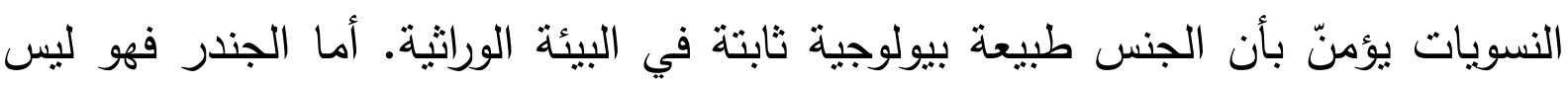

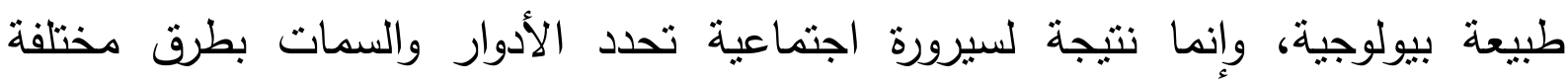
باختلاف النقافة. ففي هذه المرحلة انتقد فلاسفة الحركات النسوية، التتريعات القانونية الدجفة بحق النساء. وقد أدى استخدام مفهوم الجندر إلى انبثاق نوعين من النتظبر : الأول

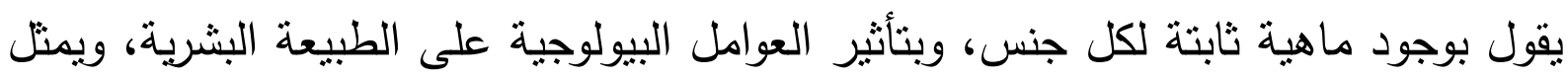

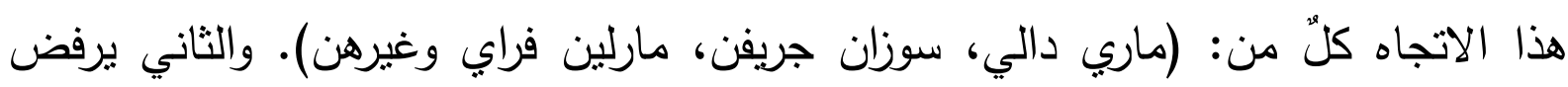

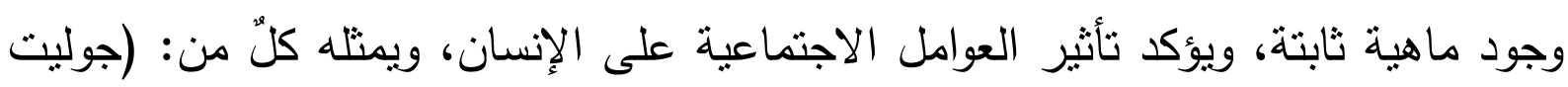
ميتشيل، ساندرا بارتكي، بيتي فرايدن، كيت ميايت وغيرهن). وقد غالى كل اتجاه في تقديره

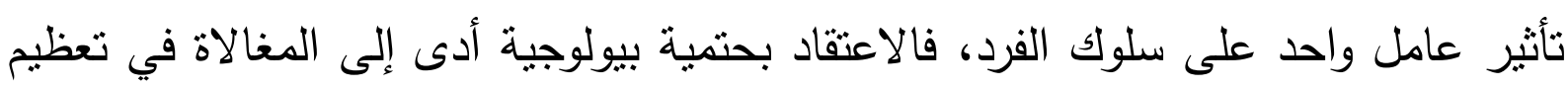

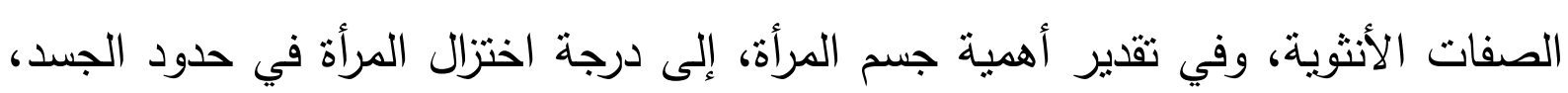
واختزال الجسد في حدود بعده الجنسي. والثاني بالغ في تقدير العامل الاجتماعي، وفي التاني تفسير الفروق الطبيعية، والنفسية، والفيزيولوجية، والبيولوجية بين الجنسين بالاختلافات فئات

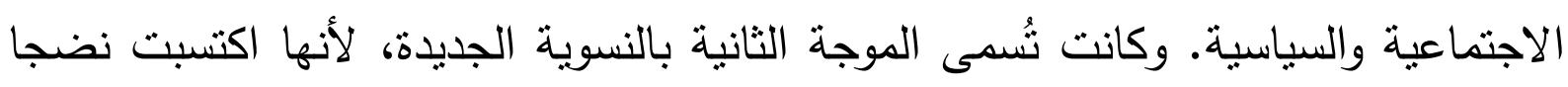

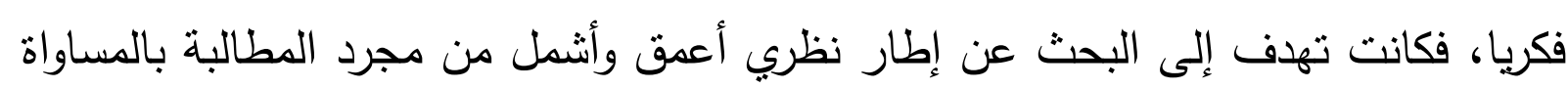

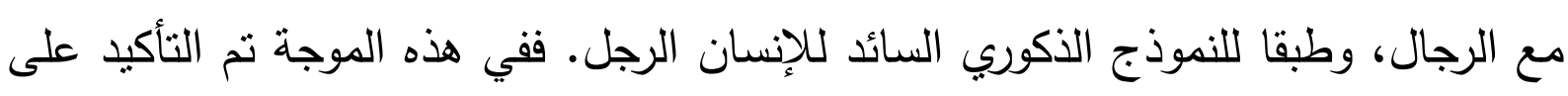

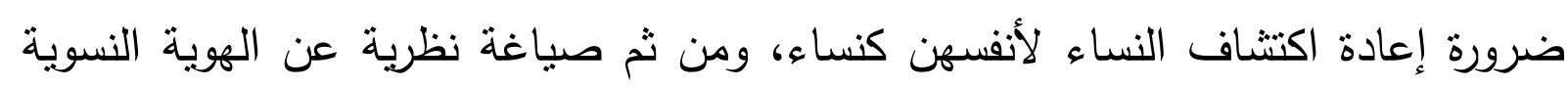

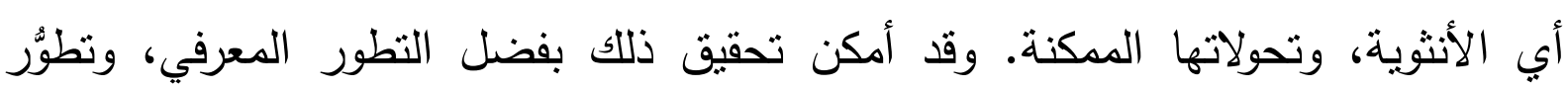

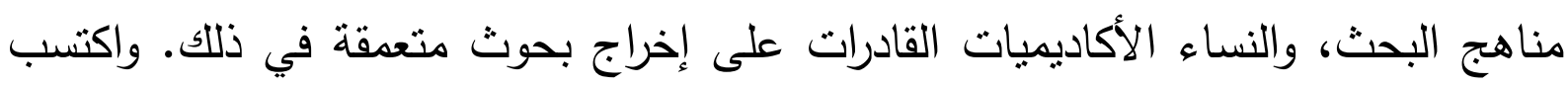

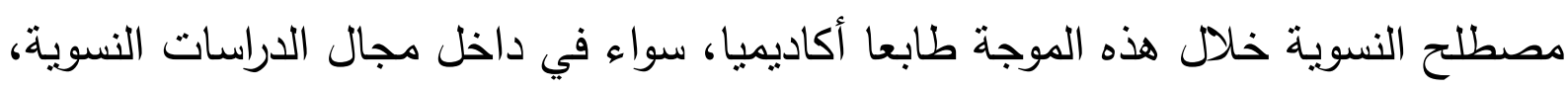

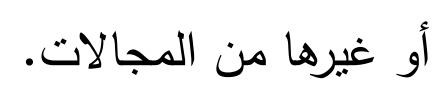


وبعد ما حققت الموجة الثانية من الحركة النسوية الغربية بعضا من مطالبها، بدأ استخدام

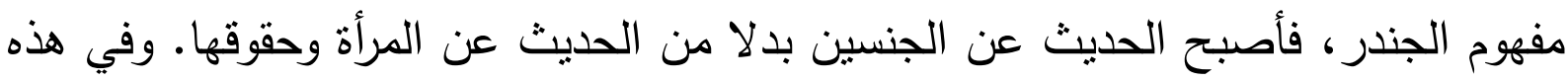
المرحلة لعبت مقولة الجندر دورا مهما في التحليل والنقد النسوي.

\section{الموجة النسوية الثالثة:}

أما الموجة الثالثة فبدأت منذ الثمانينيات من القرن العشرين، وهي مستمرة إلى اليوم. وتركز اهتمامها بشكل خاص على طرح مسألة الاختلاف بين الجنسين، والهوية الأنثوية، وتمثلها حاليا المحلّة النفسية والفيلسوفة لوس إريجاراي.

وإذا ما تجاوزنا المرحلة الأولى التي كانت نضالية وسياسية أكثر مما هي تتظيرية، فان مجمل تاريخ الحركات النسوية يكمن في الانتقال من مرحلة محو الاختلافات بين الرجل

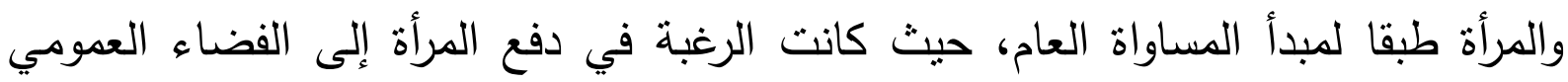
وفرض ذاتها في ميدان الفعل والعمل، تقتضي بالضرورة تجاوز القول باختلاف الجنسين إلى مرحلة الاعتراف بالاختلاف الجذري الموجود بين النوعين والدفاع عنه.

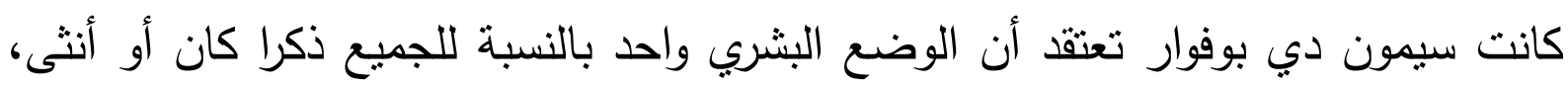
وكانت تدافع عن ضرورة تجاوز الاختلافات التي لم يصنعها سوى السياق الثقافي والتاريخي،

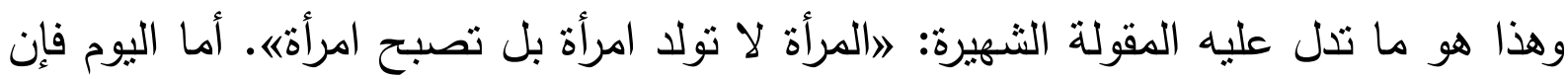
المقاربات الجديدة تميل أكثر إلى الاعتراف بالنوع، وإلى إبراز مفهوم الأنوثة كهوية ضرورية اهنهاه للنسوية، وكما ترى إريجاراي فإن فكرة المساواة ذاتها هي فكرة ذكورية، لأنها تعني بكل وضوح أن المرأة ينقصها شيء يمتلكه الرجل، وأن من حقها الحصول عليه لأنها تستحقه.

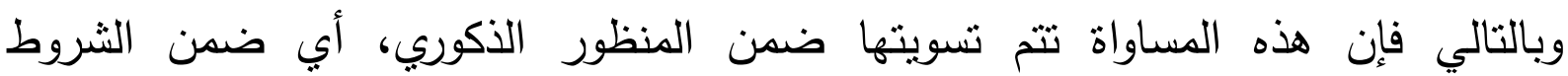
والمقاييس التي يفرضها الرجل. فترى إريجاراي أن المرأة عليها أن تضع رهانها من أجل أن لن لهن تصير امرأة، فالأمر يتعلق ببناء الذات، وتأسيسها في هذا الاتجاه، تقول: \أنا أولد امرأة، لكن يجب عليّ مع ذلك أن أصبح هذه المرأة التي أكونها بالطبيعةه. (الفاهم محمد، 1 • ب). وكيفما كان الحال نستطيع أن نقول إن المساواة لا تعني أن يلتحق الرجل بالمرأة،

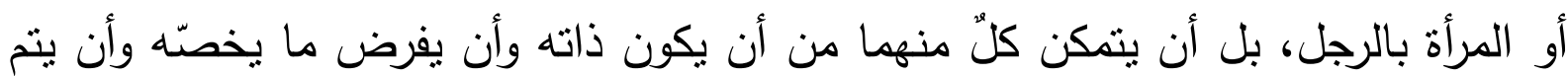
الاعتراف به من طرف الآخر على أنه آخر غير قابل للاختزال في هوية واحدة أو تطابق 
كان المنطق الأساسي الذي تأسست عليه الموجة الثالثة، نقد الموجتين الأوليين باعتبارهما ذكوريتي التوجه، إذ هدفت الحركة النسوية قبل الموجة الثالثة، إلى توسيع حقوق النساء لمساواتهن بالرجال، لكن الحركة كانت تعترف في هذا النشاط بتفوق نمط الحياة الذكوري ومعياريته، كما لو كان تحرير النساء يتمنل في تحويلهن إلى رجال، على النقيض من ذللك، بذلت الموجة الثالثة جها كبيرا في الاحتفاء بتجارب النساء كما يعشنها فعلا، وتمكينهن من الفخر بجنسهن ومشاعرهن وخبراتهن باعتبارهن نساء.

تميزت حركة ما بعد النسوية أو الموجة الثالثة من الحركة النسوية، بتأثير فلاسفة الحركات باتئن النسوية، بآراء فلاسفة ما بعد الحداثة من منل فوكو ودريدا، حيث شكل نقد هؤلاء الفلاسفة لمفهوم العقلانية، ولمركزية العقل، وللتعريف الواحد للحقيقة، حلقة الوصل بين الفكر النسوي، وفكر ما بعد الحداثة. وحفّزت آراء فوكو المفكرات على تقديم المذهب النسوي على أنه علم مواجهة يتحدى حصر الإنسانية بالذكر والتعريف الجندري للأكورة. ووجدت بعض المفكرات في آراء دريدا التي تحمل فكرا نسويا وموضوعات تتعلق بالنساء عناصر مناسبة لبناء النظرية النسوية. وتعتبر ما بعد النسوية أحدث حلقة من حلقات النتوع في ملامح الفكر النسوي الذي يتسم بالتحول والتغيرٌ المستمرين. وتسير هذه الحركة على النهج النظري للموجة النسوية الثانية في دراسة العلاقات المثمرة عن مرحلة ما بعد الحداثة، بقصد الجمع بين مختلف طرق صياغة، وتتكيل شخصية ودور المرأة في أي مجتمع. (عصدت محمد درده

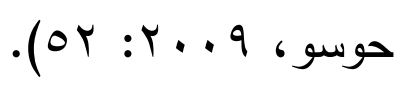
عمل الجيل الثالث على نقد منظومة التضاد الثنائية، وبنية التفكير البطريركي التي تقوم على التعارض والتراتب، وليس على الندية والاختلاف والتنوُّع والتلوُّن. هكذا نلحظ استخدام النسوية المعاصرة استراتيجيات تفكيكية لكي تزعزع استقرار النظام الثنائي الكامن في ثنائية المذكر/ المؤنث، وتخلخل الهياكل الأساسية التي تقوم عليها هذه الثنائية، منعا للتمبيز بينهما، ذلك يتيح للرجال والنساء المشاركة في التوصل إلى طرق جديدة لصياغة الذات المعاصرة.

إن تعبير ما بعد النسوية قد جاء ليقول بأن المرأة هي قضية مجتمع، وأن حقوقها ليست معزولة عن حقوق المجتمع ككل، فتيار ما بعد النسوية رد على بعض أفكار الموجات النسوية السابقة، التي جعلت من الرجل المنتهك الوحيد لحقوق المرأة، واعتباره الخصم والغريم الذي يجب انتزاع الحقوق منه، حيث حلّت مصطلحات جديدة فيما بعد النسوية، 
متلك: العدالة الاجتماعية، وحقوق الفرد، وتحرر المجتمع، فحقوق المرأة هي حقوق البشر كافة.

\section{النسوية الإكترونية (مواقع التواصل الاجتماعي وخلق مناخ نسوي جديد):}

أما حديثا جدا، فقد بدأت الموجة الرابعة، التي مازالت الأدبيات حولها قليلة لأنها لم تتبلور بعد، ترتبط ارتباطا وثيقا بمواقع التواصل الاجتماعي. ويربط كثيرات من الناشطات بداية الترائ

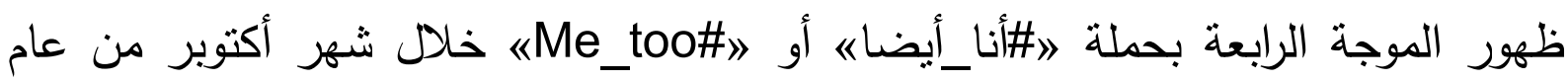

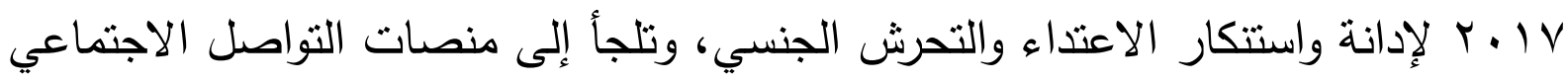

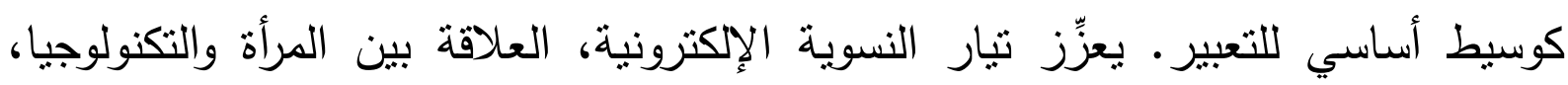
بهدف البحث وفلك شفرات والهيمنة والسيطرة على الثقافة النكنولوجية، مستخلات بذلك القدرة التجرييية والإمكانات التي يقدما الفضاء الإلكتروني لخلق تتكيلات اجتماعية وهويات أخرى، مع إعطاء طابع آخر مختلف للنشاط السياسي. قبل ظهور النسوية الإلكترونية، كانت الدراسات النسوية تهتم بدراسة التكنولوجيا وتأثيراتها في الحياة الاجتماعية والثقافية، وتتظر للتكنولوجيا على اعتبار أنها تعبر عن النقافة الذكورية،

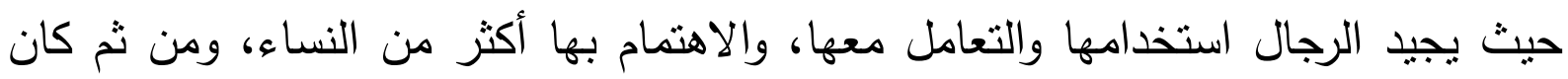

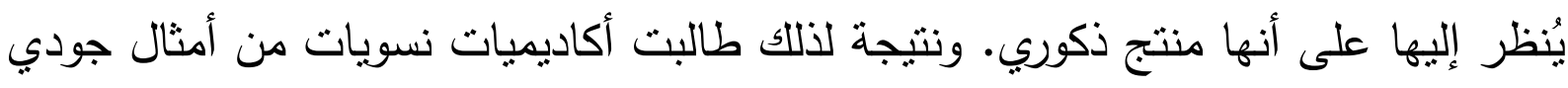
واكجمان، بضرورة أن تصبح المرأة أكثر نشاطا في المجالات التكنولوجية، وأن يتم إعادة التهاد صياغة النقافة التكنولوجية في إطار النوع الاجتماعي. (2-12:1)

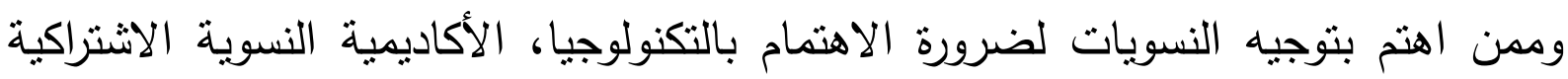
دونا هاراواي، من خلال مقالها (بيان ساييورج)، وتستخدم هاراواي نظرية السايبورج (اندماج

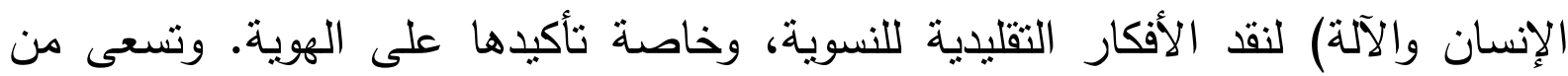

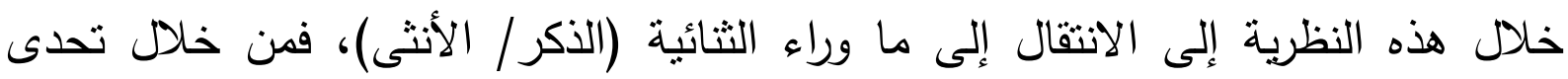

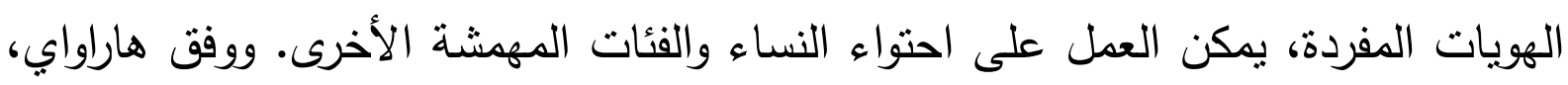
فإن النساء بحاجة لأن يصبحن أكثر كفاءة من الناحية التكنولوجية، وأكثر قدرة على التعامل

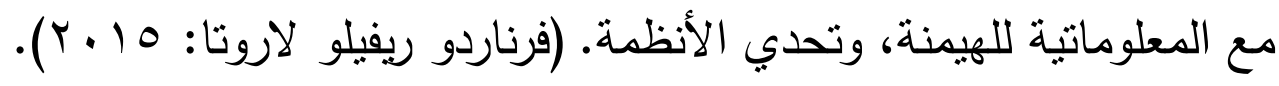

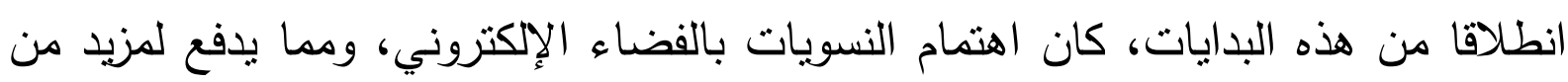
الاهتمام النسوي بالإنترنت كأماكن للمرأة لكي تنثارك في أثنكال جديدة من العمل، التحرر

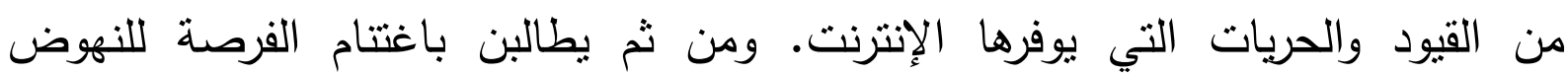


بأنفسهن، وتحدي السلطة الذكورية. ومن ثم كان الاهتمام بإنشاء مواقع على الثبكة العنكبوتية، وتكوين المجموعات الحوارية وغيرها من الأدوات التي يوفرها الإنترنت.

ثالثا: اتجاهات فكرية في النظرية النسوية ونكية توجد العديد من النظريات النسوية المختلفة التي حاولت أن ترصد مظاهر التفاوتات المختلفة بين الرجل والمرأة في المجتمعات البشرية، وبشكل خاص أوضاع المرأة في الغرب. واللافت للنظر أن معظم هذه النظريات ظهرت في العالم الغربي منذ الثورة الصناعية وحتى الآن، وبمعنى آخر إن هذه النظريات ارتبطت بالأساس بالسياقات الغربية ودرجة التطور الذي وصلت إليه مجتمعاتها. وتتسم هذه النظريات بشكل عام بمحاولة تشخيص أوجه التفاوت التي تواجه المرأة، وبشكل خاص في مجال العمل، بالرغم من الفرص الهائلة التي حصلت الته عليها في مختلف المجالات بما في ذلك المجالات التي لم يكن من المتصوّر أن تلتحق بها. وما تهدف إليه هذه النظريات هو التركيز على أوضاع المرأة وجعلها في الواجهة من لن المشكلات الاجتماعية التي تواجهها المجتمعات البشرية، بحيث لا يتم التعامل معها كقضية فرعية ضمن النظريات الاجنماعية، الأمر الذي يجعلها تكتسب الاهتمام الذي يليق بمكانة المرأة في المجتمعات الإنسانية.

النسوية الليبرالية:

تعتبر النسوية اللييرالية نمطا فردانيا من النظرية النسوية، وتركز على قدرة النساء على صون مساواتهن من خلال أفعالهن وخياراتهن الخاصة، وتؤكد على جعل الحقوق القانونية والسياسية للنساء متساوية مع الرجال، ويناقش النسويون الليبراليون والنسويات اللييراليات اعتقاد المجتمع الخاطئ بأن النساء يمتلكن بالطبيعة إمكانات فكرية وجسدية أقل من الرجال، وبالتالي ميل هذا المجتمع للتمبيز ضدهن في المجالات الأكاديمية والنقاشية وسوق العمل، كما يعتقد مؤيدو ومؤيدات النسوية الليبرالية أن تبعية الأنثى متجذرة في مجموعة من القيود القانونية والعرفية التي تعيق دخول المرأة لما يُسمى العالم العام والنجاح فيه، ويسعون اليه

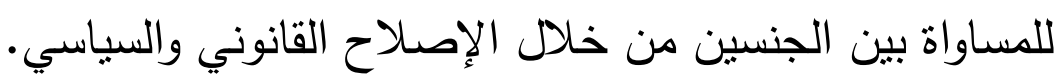
(Wikipedia The Free Encyclopedia, Liberal Feminism).

تتنقد النظرية الليبرالية التفاوتات القائمة على الاختلافات البيولوجية بين الرجل والمرأة. وترى هذه النظرية أن الاختلافات بينهما ليست كبيرة بما يستدعي تأسيس اختلافات في الحقوق الخاصة بهما، ومن ثم تكريس أنماط من التفاوتات المجحفة للمرأة مقارنة بما يحصل عليه 
الرجل مجتمعيا. وتدحض هذه النظرية الاختلافات القائمة على الجنس بين الرجل والمرأة،

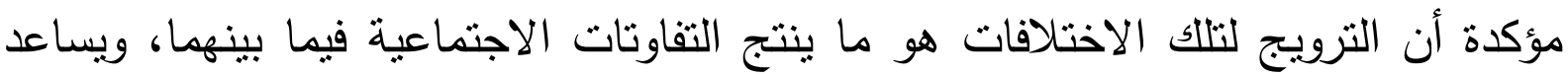
في القبول الاجتماعي لها. ومن منطلق رفض هذه النظرية اعتماد الفروق الجنسية بين الرجل والمرأة فإنها تدعو للتخلص من كافة أثنكال التمييز الاجتماعي بين الرجل والمرأة، وبشكل خاص في مجالي التعليم والعمل. اعتمدت السياسات الليبرالية النسوية على حركة الحقوق المدنية في الولايات المنحدة التي ارتكزت في عملها على التثريعات المناوئة للتمييز وبرامج العمل الإيجابي لمواجهة

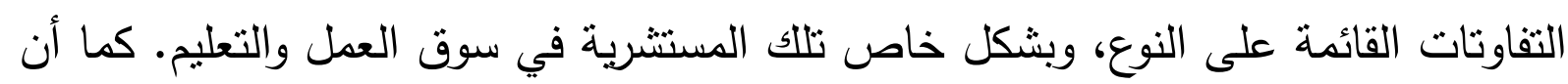
العديد من القضايا المحورية التي ظهرت من خلال الحركة النسوية في سبعينيات القرن

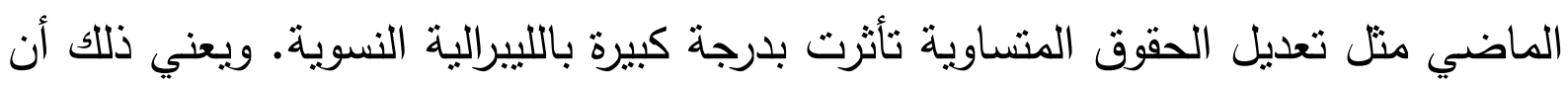
النظرية اللييرالية النسوية لم تتفصل عن حركة المجتمع المدني في الولايات المتحدة التي

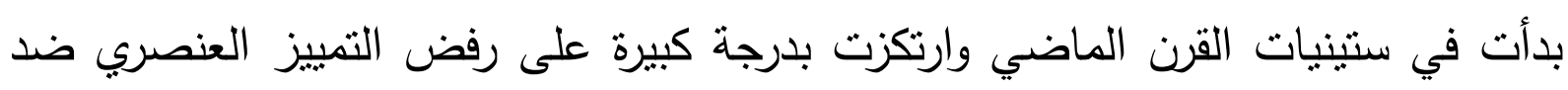

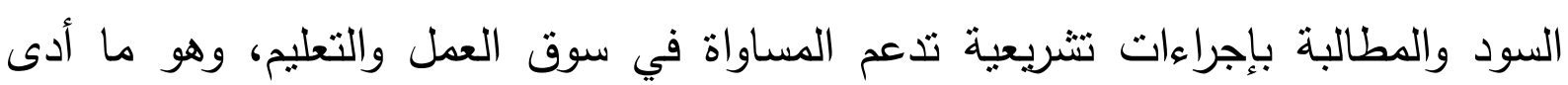

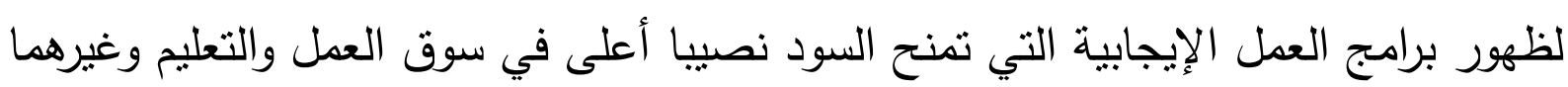

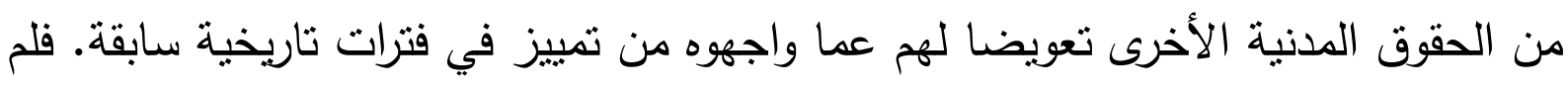

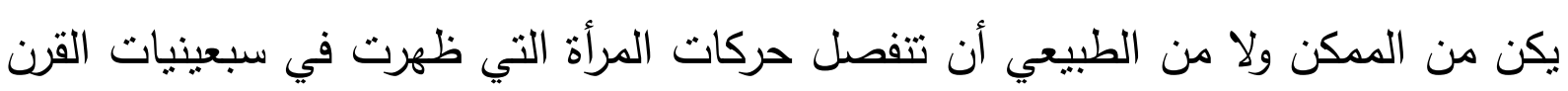
الماضي عن السياق القائم على نبذ التمييز العنصري ضد الند السود والاستفادة من توجهاته

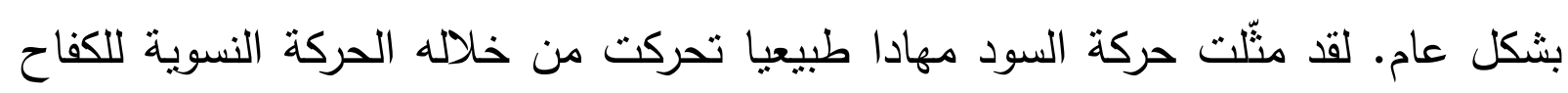
ضد التمييز القائم على النوع، ودعما معنويا لها. (فرانسيس فوكوياما، 9 (بץ).

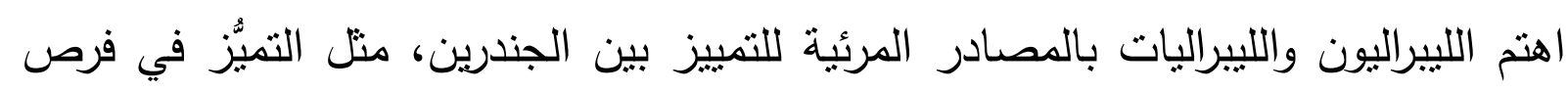

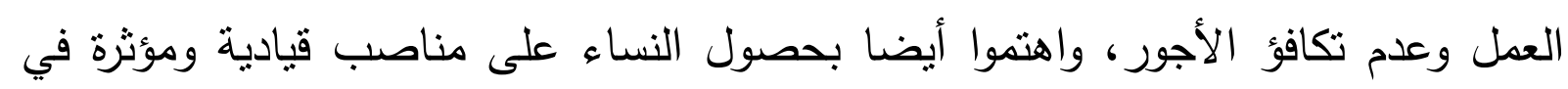

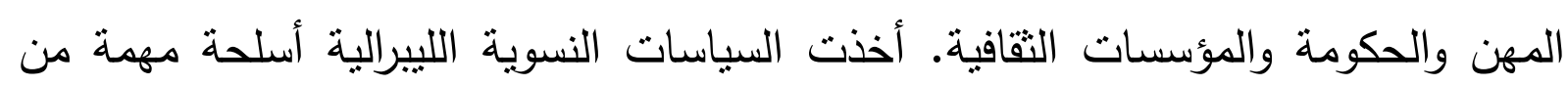

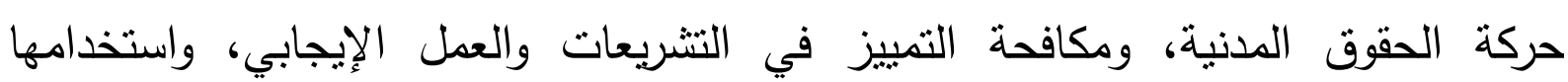

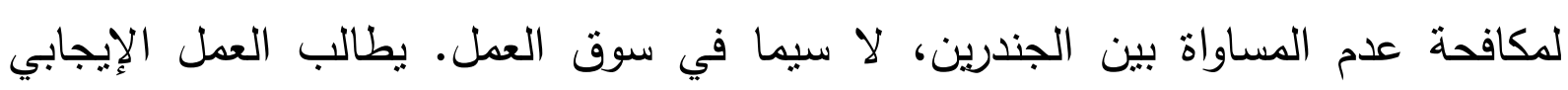

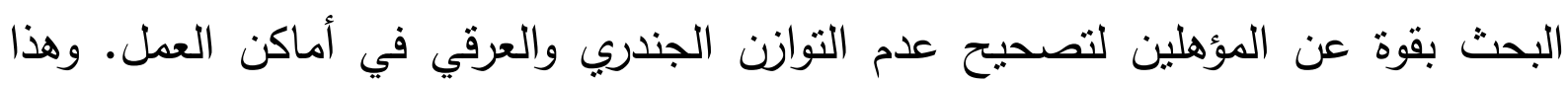
يعني نتجيع الرجال على التنريب للحصول على وظائف مثل: التمريض والتنريس والسكرتارية، والنساء في مجالات منل: الهندسة، والبناء، والثرطة. 
على الرغم من النجاحات التي حققتها النظرية الليبرالية في دعم المرأة على الدخول لسوق العمل، وهو إنجاز ساعد في النيل من هيمنة الرجال وتحكمهم في فرص العمل المتاحة، فإنها كانت أقل نجاحا في القضاء على أثكال التمبيز الأخرى غير المعلنة في مؤسسات العمل، التي تمنع المرأة من تحقيق تقدمها وارتقاء مناصب أعلى أسوة بما بحصل عليه الرجل. فهناك سقف زجاجي غير مرئي يمنع المرأة من الترقي والحصول على مناصب أعلى نهاء في مؤسسات العمل التي تلتحق بها، وهو الثيء نفسه الذي بمكن الحديث عنه بالنسبة للسود في الولايات المتحدة. فقد قبلت هذه المؤسسات دخول المرأة للعمل على مضض، ولى ولم يكن أمامها ما تسنطيع به تقويض سعيها للحصول على حقوقها، وبالرغم من ذللك فإنها فرضت قيودا صارمة لا نستطيع من خلالها الترقي أو الحصول على الأجر ذاته الذي نهي يحصل عليه الرجل الذي يقوم بالمهام ذاتها التي تقوم بها. (صالح سليمان عبدالعظيم، $\cdot(T \leq): T \cdot) \varepsilon$

هذا لا يعني أن ما حققته النظرية الليبرالية لم يكن شيئا مهما، العكس هو الصحيح، فقد

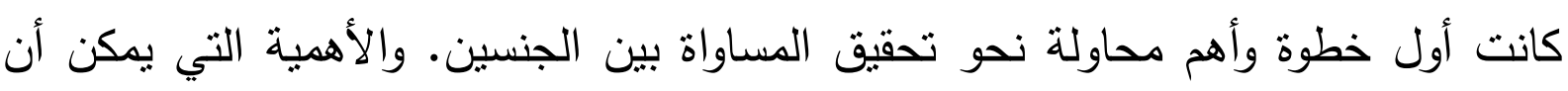
تعزى إلى النظرية لا تكمن فقط فيما حققته، بقرر ما تكمن أيضا في أنها لفتت الأنظار

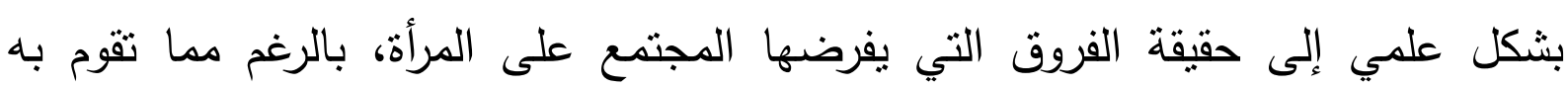
الأخيرة من جهود تتساوى مع ما يقوم به الرجل إن لم تكن تتفوق عليه، فقد قبلت البنيات الاجتماعية التفاوتات المختلفة بينهما كحقيقة واقعية لا يمكن مواجهتها أو الجدل بشأنها، وهى مسألة دحضنها النظرية الليبرالية بالعديد من الأعمال الفكرية والكثير من الجهود السياسية.

يتمثل الانتقاد الأساسي لفلسفات النسوية الليبرالية في تركيزها بشكل مفرط على المساواة مع

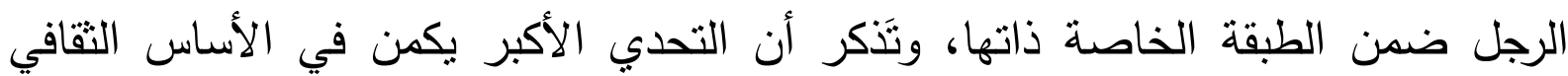
للاضطهاد الجماعي، الذي يميل مؤيدو ومؤيدات النسوية الليبرالية لتجاهله. ولكن كانت النسوية اللييرالية أكثر نجاحا إلى حد ما في إثبات أنه حتى لو كانت المرأة مختلفة عن وند

$$
\begin{aligned}
& \text { الرجل، إلا أنها ليست أدنى درجة. } \\
& \text { النسوية الماركسية: }
\end{aligned}
$$

يعتبر نسويو هذا التيار أن قمع المرأة وقهرها بدآ مع ظهور الملكية الخاصة. فنقل الملكية بالإرث سبب مأسسة للعلاقات غير المتوازنة وتوزيع للمهام والأعمال على أساس من التمييز 
الجنسي. وقد شيدت الرأسمالية نظاما للعمل يميّز ما بين المجالين الخاص والعام: فللرجل

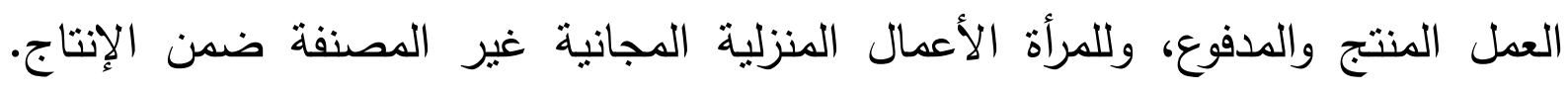

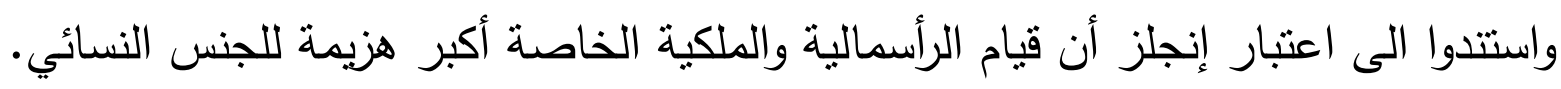

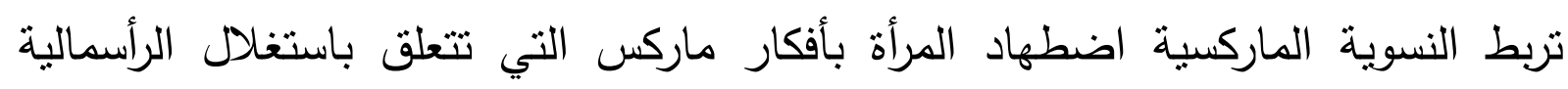

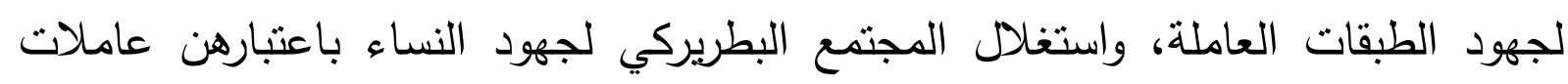

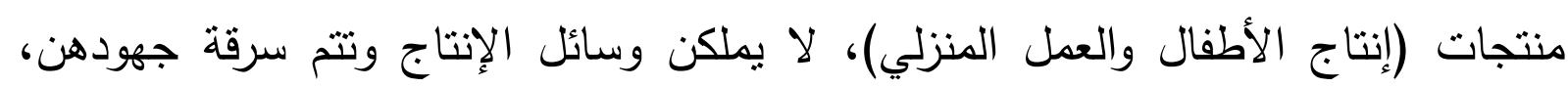

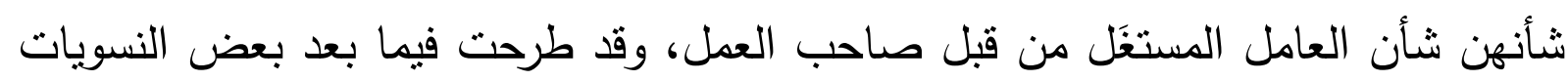

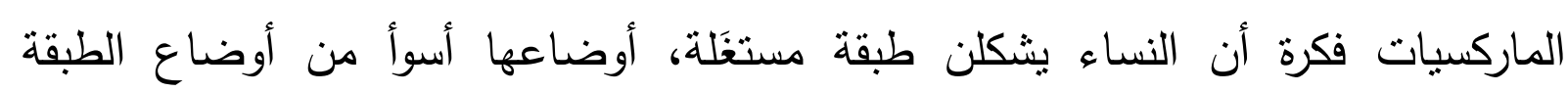

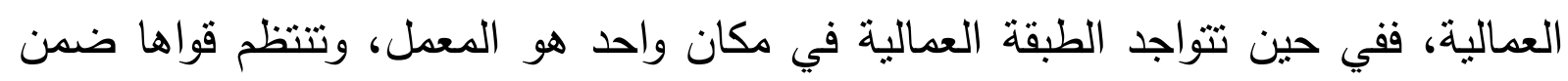

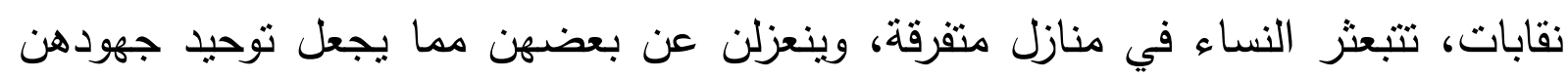
على درجة كبيرة من الصعوبة. وتركز النسوية الماركسية على إحداث تغيير مجتمعي شامل، لا على تغيير الفرد المكوّن لهذه المجتمعات. فبتحويل وسائل الإنتاج إلى ملكية عامة الهية

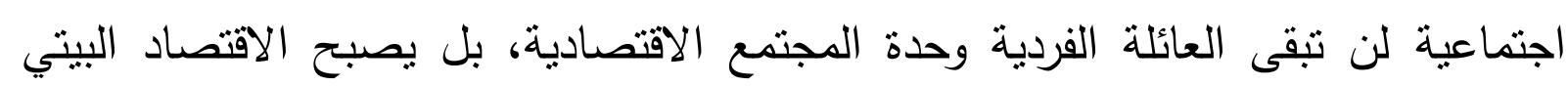

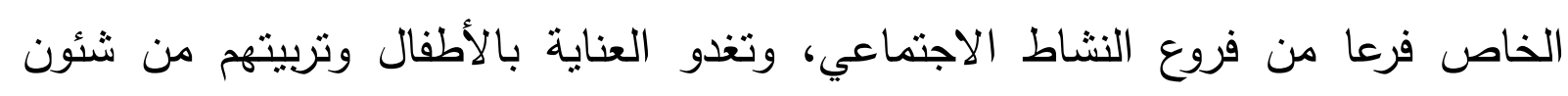

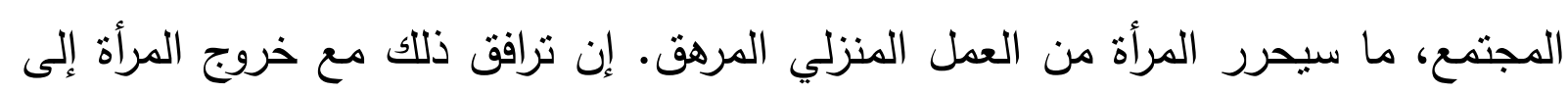

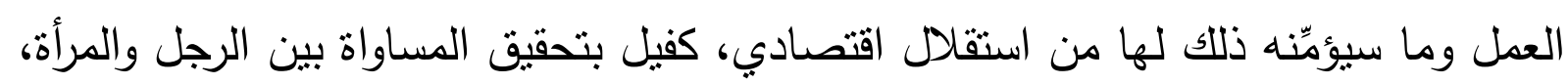

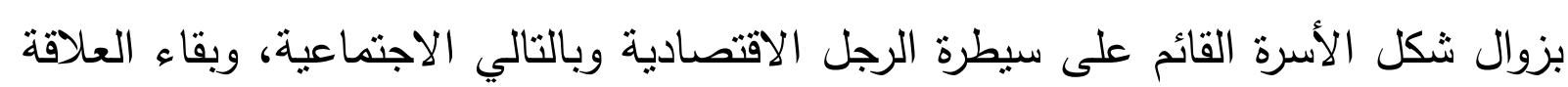

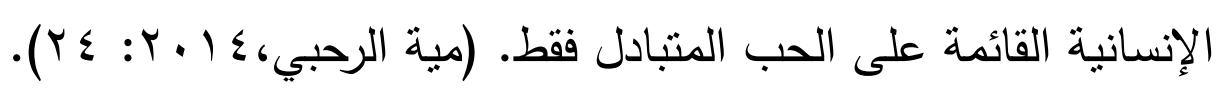

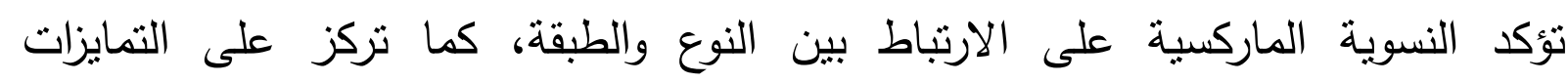

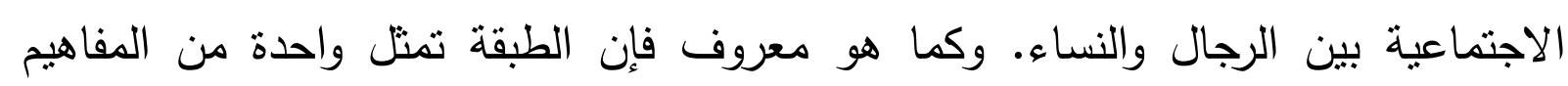

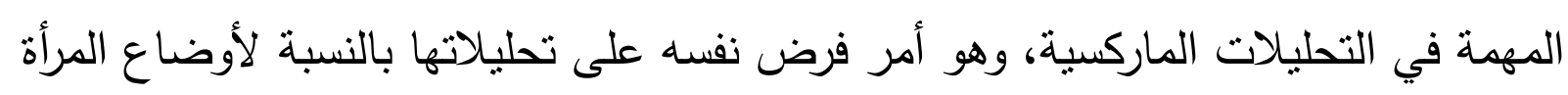

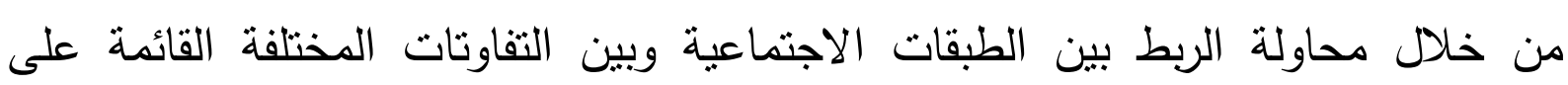

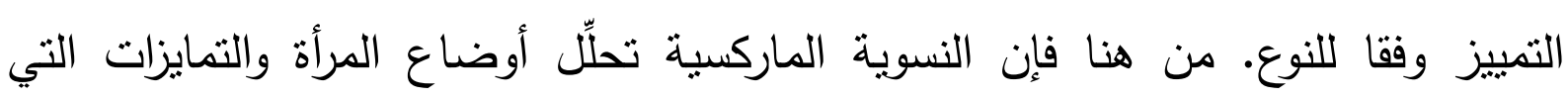

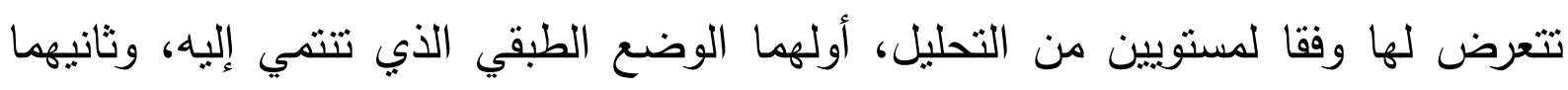

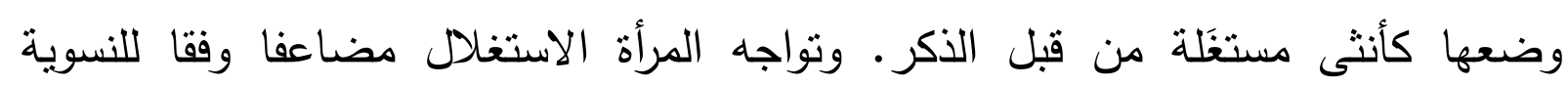

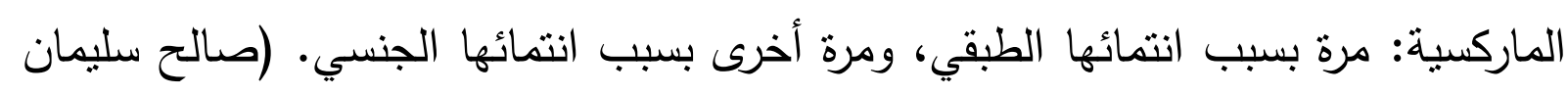

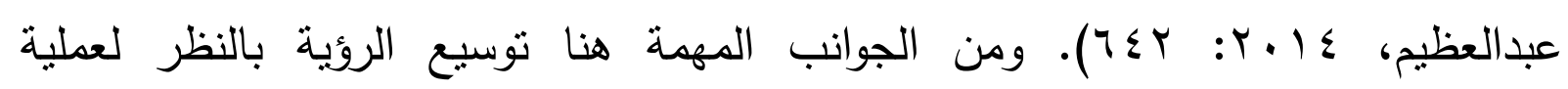


الاستغلال المجتمعي الذي تتعرض له بعض الثرائح الاجتماعية، ففي النسوية الماركسية بساعد استخدام مفهوم الطبقة في الدمج بين الرجل والمرأة دون التمييز بينهما طالما أنهما

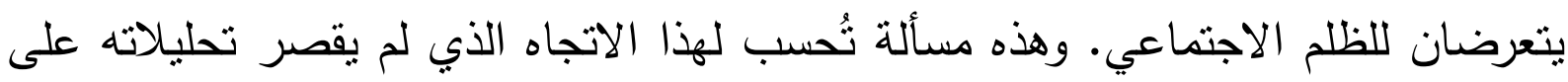

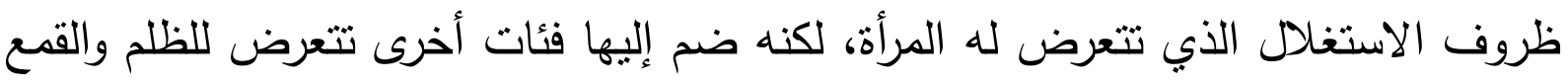

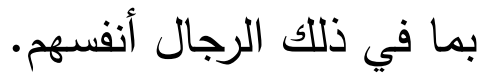
وفقا للنحليلات النسوية الماركسية، فإن الاستغلال الذي تتعرض له المرأة في الييت وسوق العمل هو المصدر الرئيسي للتفاوتات القائمة على النوع. وارتباطا بذلك فإن هناك مؤسستين

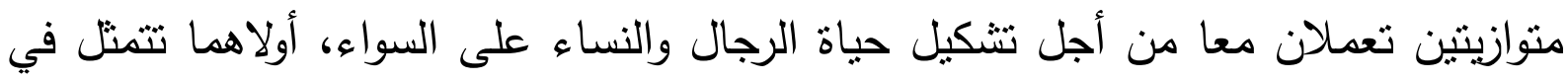

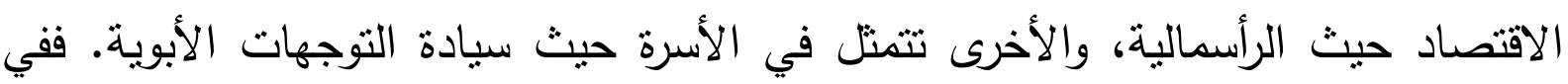

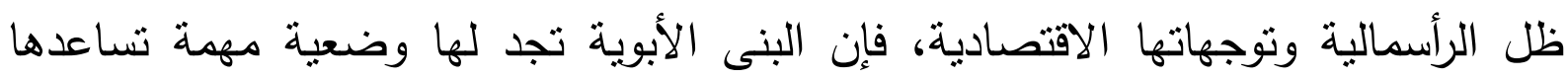

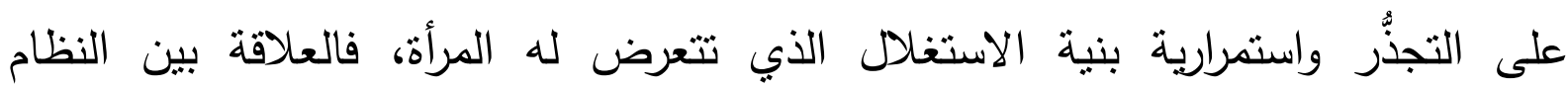
الرأسمالي والبنية الأبوية علاقة تعاضدية بساهم من خلالها كل طرف في تدعيم الآخر ومساندته. (Chafetz, Janet Saltzman, 1997:97). فمن خلال الجمع بين البنية الأبوية والبنية الرأسمالية، وفقا للنسوية الماركسية، فإن المرأة تعاني من استغلالين مضاعفين، أولهما ذو علاقة بوضعينها كزوجة، وثانيهما ذو علاقة بموقعها في سوق العمل

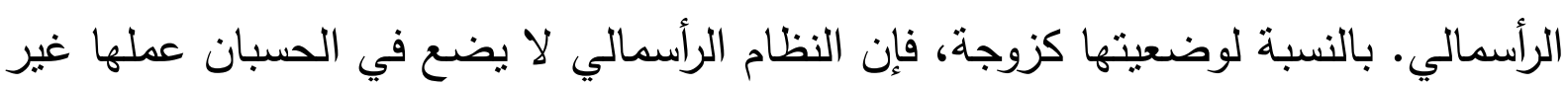

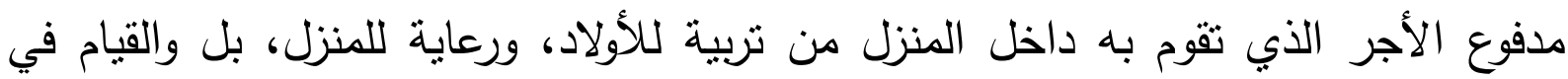

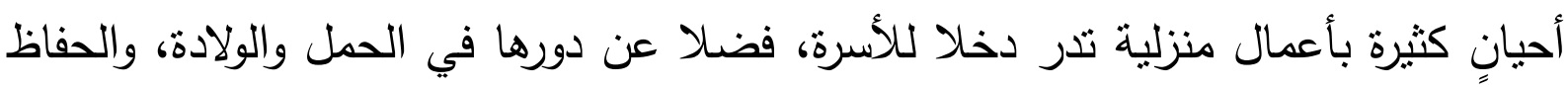
على قوة العمل الآنية والمستقبلية على السواء. لا يقوم المجتمع الرأسمالي بحساب قيمة ما لثال

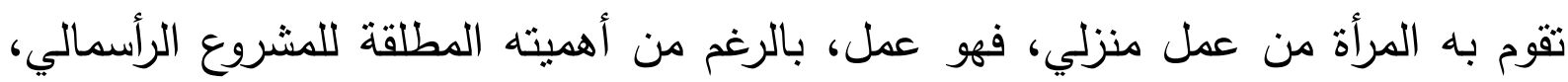

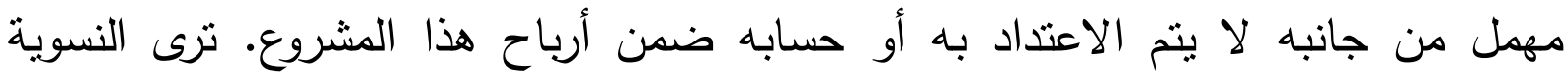

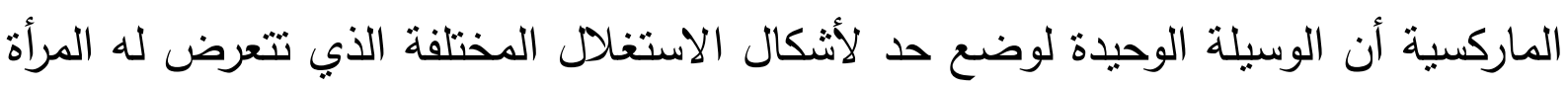

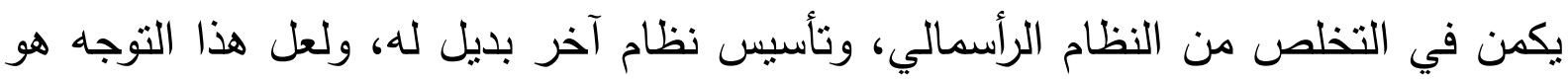

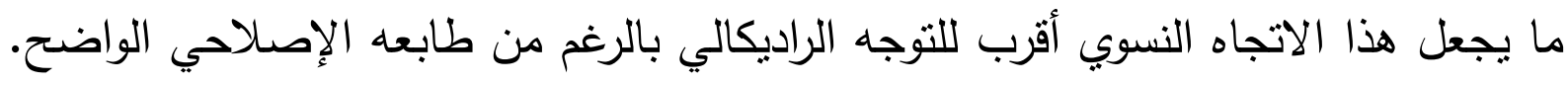

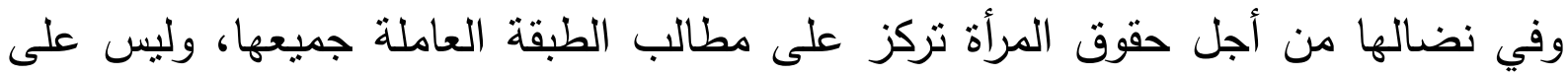

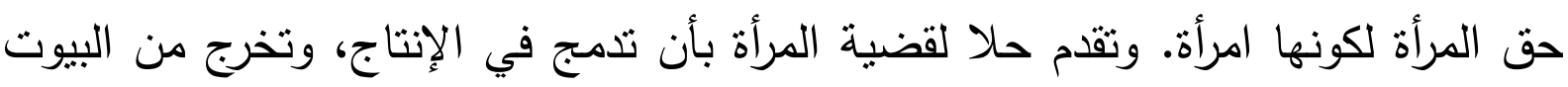


انتقدت بعض النسويات النظرية النسوية الماركسية، فرأت جين بينكي إلثتاين أن العديد من

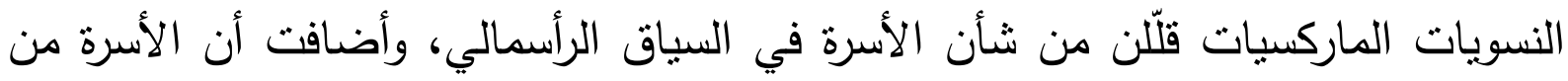

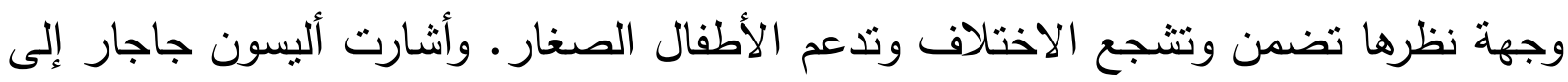
أن النسوية الماركسية عمدت إلى ضم الرجال والنساء، كون كليهما يتم اضطهادهما من قبل الإن الأنظمة الرأسمالية، ولم توضح كيف يتم اضطهاد النساء عن طريق الرجال تحديدا من النماءله خلال وسائل ومؤسسات اقتصادية مثل مؤسسة الزواج مثنا (ويكي الجندر، نسوية ماركسية).

النسوية الراديكالية:

يرى التيار النسوي الراديكالي أن الرجل هو المتحكم بهرمية رأس المال، وهذا ما يفسر الأدوار الجندرية ويفرز اضطهاد الرجل للمرأة، وأن وضع المرأة الحالي هو نتاج عن سيطرة

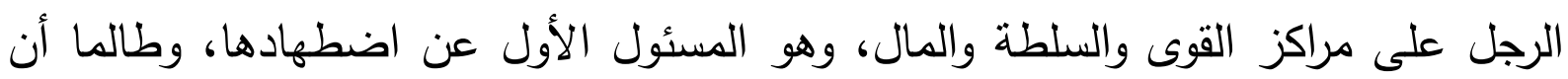
هذا النظام وهذه القيم هي التي تحكم المجتمع فإن المرأة لن تتمكن من إنجاز أي تغيير هام في مسيرتها نحو المساواة. يهدف هذا التيار إلى سد الثغرات في تناري النسوية الليبرالية والماركسية من خلال التأكيد على الطابع العام للتمييز ضد النساء بوصفه عابرا للمناطق والتقافات، مستقلا عن الطبقات. وتعتبر النسويات الراديكاليات أن البطريركية هي أساس بـاء بهاء التمييز ضد النساء والسيطرة عليهن، وينسحب ذللك على ميادين الحياة الاجتماعية والسياسية والاقتصادية والجنسية كافة، ويخلق نظام تتميط للجنسين من خلال نقافتنن: واحدة ذكورية

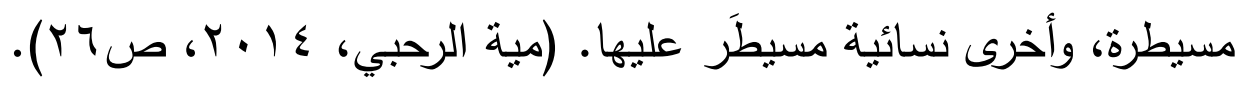
دافعت الكاتبة الأمريكية كيت ميليت عن هذا التيار في كتابها (السياسة الجنسية) عام 979 19، الذي يسلِّط الضوء علي الدور الذي يلعبه الجنس في تبعية المرأة وإنزالها إلي درجة كونها مجرد منتجات. يبرز المنتمون لهذا التيار التأسيس الاجنماعي للجنس بوصفه مصدرا لاضطهاد المرأة وليس النظام الاقتصادي، بمعنى أن سبب تبعية المرأة هو مؤسسة الأبوية

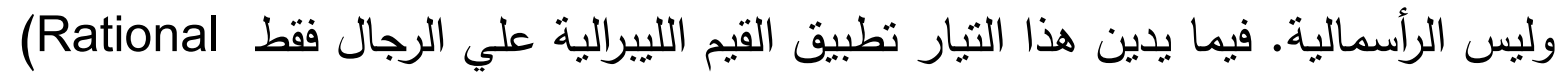

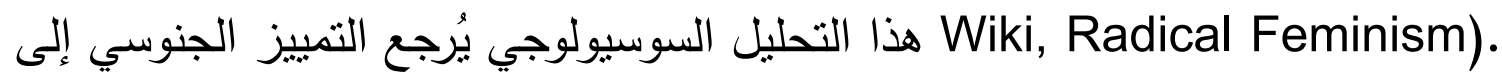
مشكل بنوي بالأساس، حيث يتم استغلال المرأة منذ الوهلة الأولى من قبل الأب والأخ والزوج، في البداية من خلال العمل المنزلي المجاني وسلب إرادتها والاختيار مكانها، ولاحقا 
مع الزوج عبر استنزافها جنسيا في عملية الإنجاب وتربية الأبناء مع العمل على قطع جميع العابع الإمدادات إليها والإجهاز على فرص وصولها الي السلطة ومواقع الثأثير في المجتمع. من بين استراتيجيات هذا التيار ، الهادفة إلى تغيير المعادلة الاجتماعية القائمة، استعادة

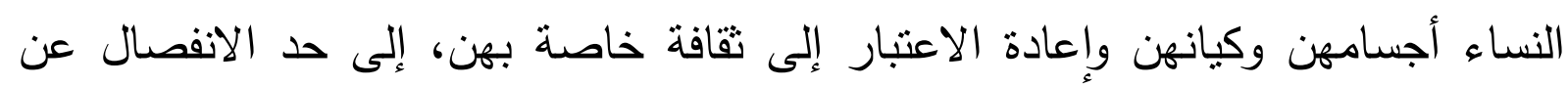

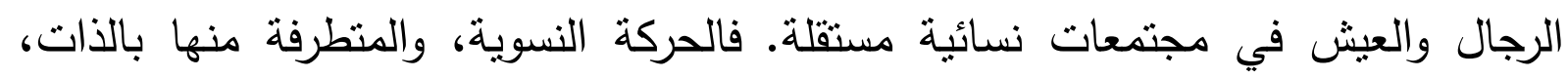
تتطلق من نظرية صراع تجاه الرجل كونه هو السبب الأول فيما تعانيه المرأة من تحئز واضطهاد ونظرة دونية، جعلتها تعيش على هامش المجتمع الإنساني، كما قالت جيل

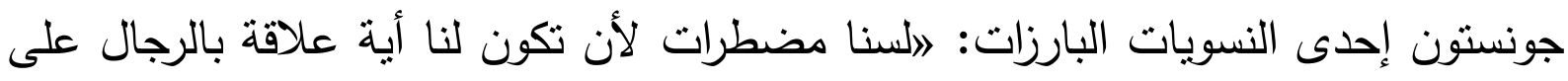

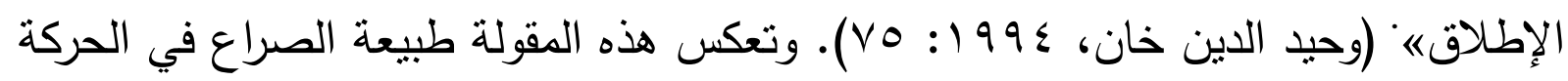

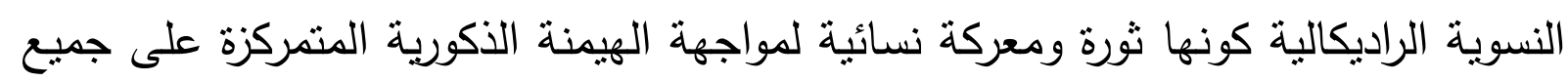

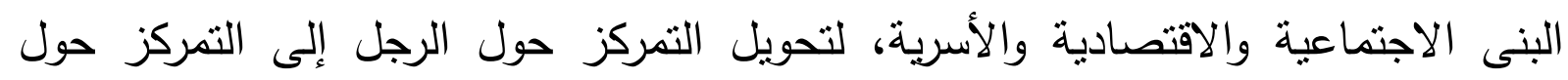

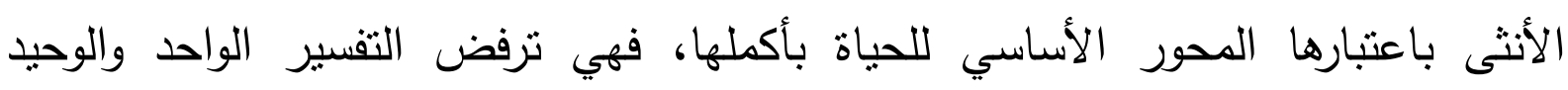

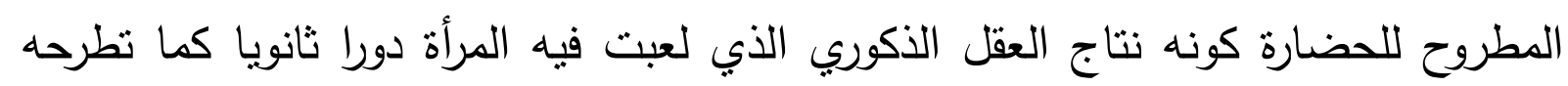

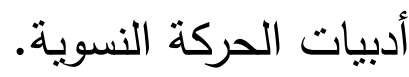
لذلاك لا تقتصر الحركة النسوية على تغيير نظام المرأة فقط والتعامل مع قضاياها بثكل

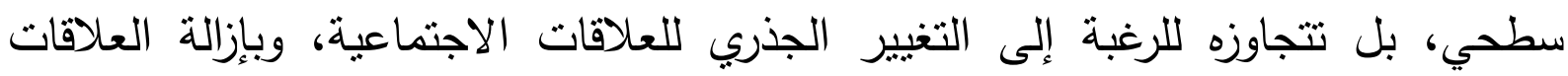

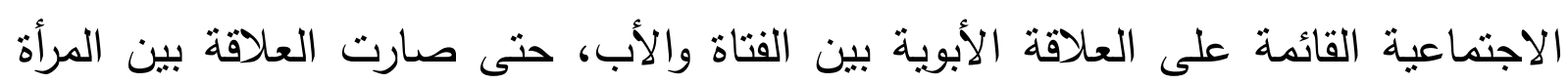

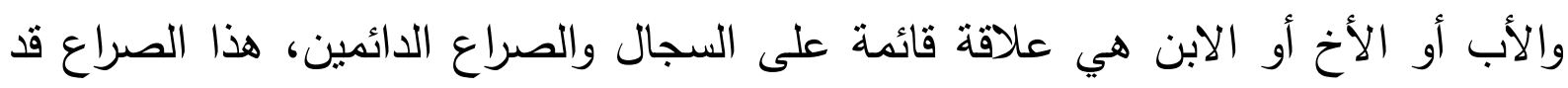

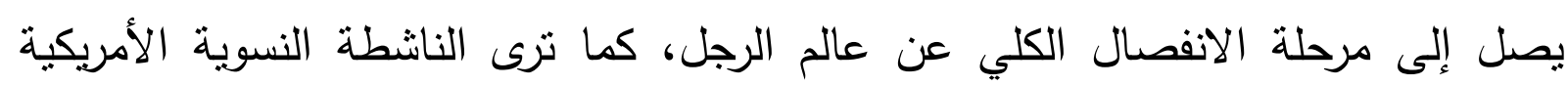

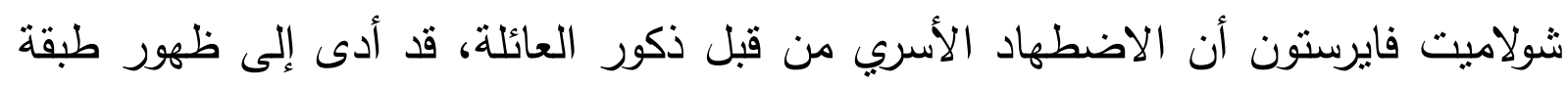

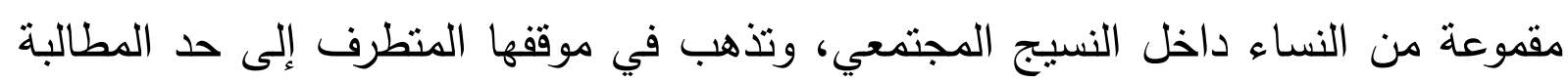

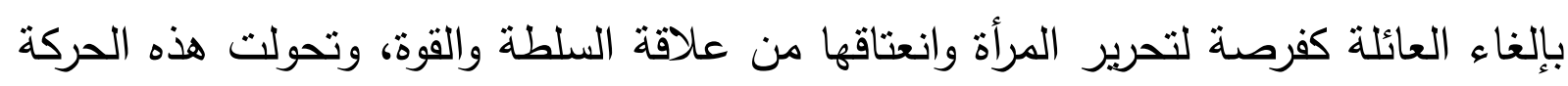

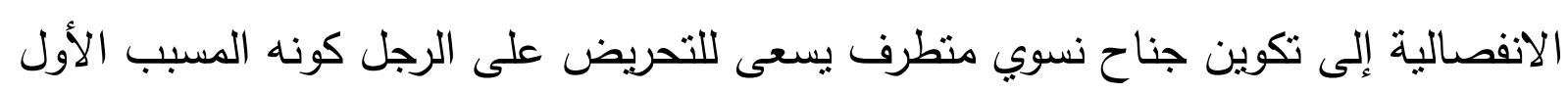

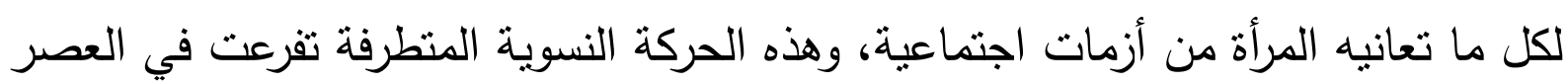

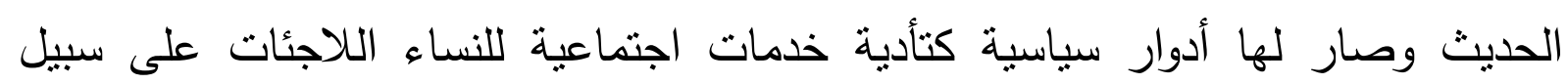

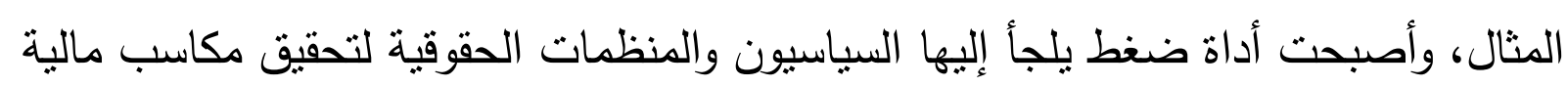
أو سياسية ليس لها علاقة بهموم المرأة. 
أول وأهم ضحايا هذه الحركة هي الأسرة، فقد سعت لنقويض وهدم أساس الأسرة كأول قبد

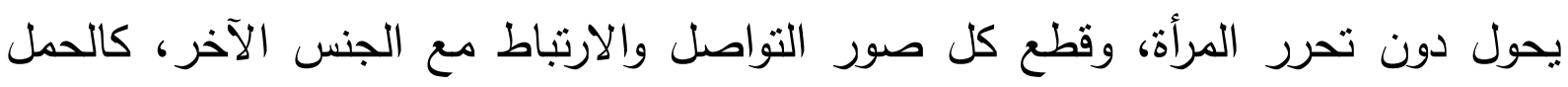

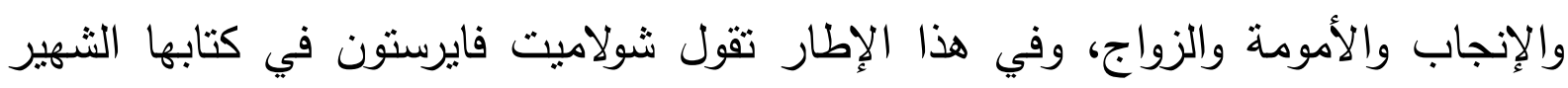

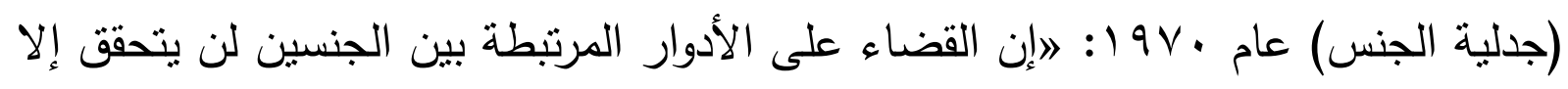

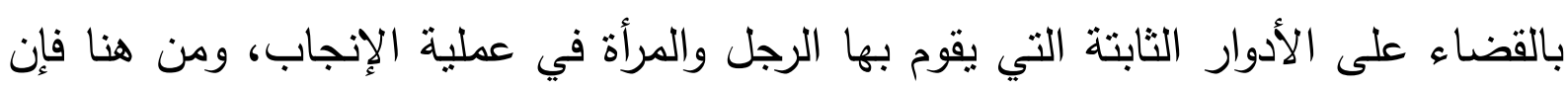
منع الحمل والتعقيم والإجهاض، ثم التلقيح الاصطناعي كلها وسائل تساعد على تقليل التمييز البيولوجي، ومن ثم الحد من التمييز بين الجنسين في مجال السلطةه. (يمنى طريف

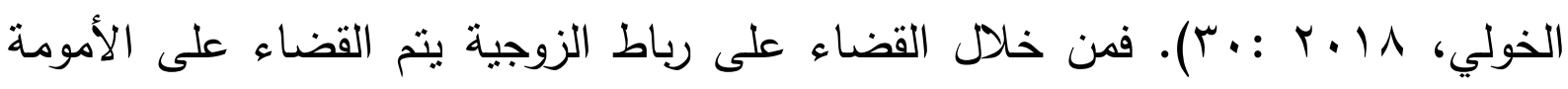
التي تعتبر من العوائق التي يجب إزالتها من وجهة نظر النسويات الراديكاليات، وطرح التلقيح الصناعي محل التلقيح الطبيعي كبديل تتحقق من خلاله المساواة، وهذه الخطوة

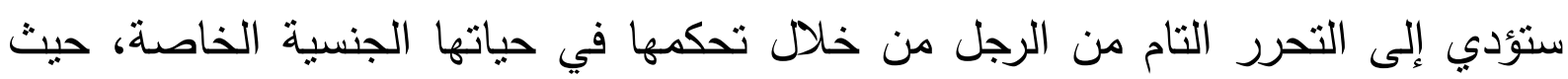

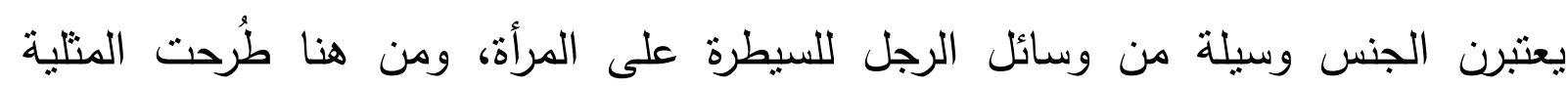

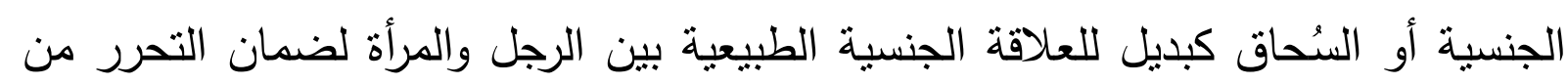

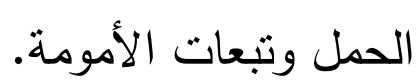
انتقدت بعض النسويات، النسوية الراديكالية ورأين أن أفكارها بها نزعة جوهرية، حيث تبسط

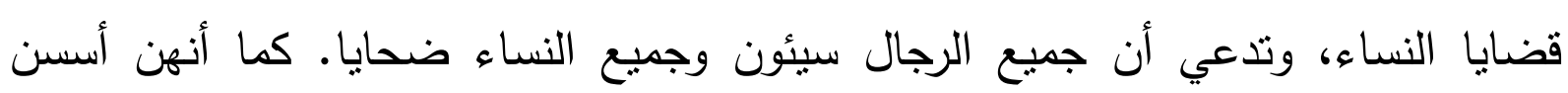

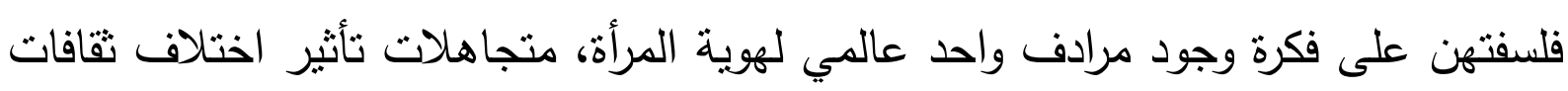
النساء وطبقاتهن الاجتماعية وقدراتهن الجسدية والعقلية وعرقهن وميولهن الجنسية في تثكيل

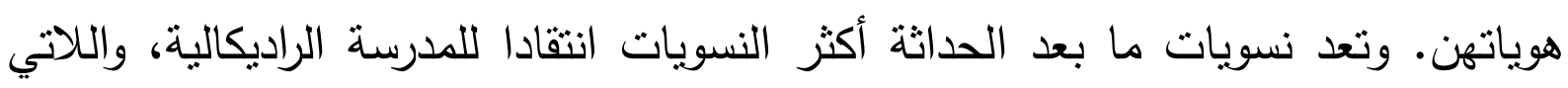

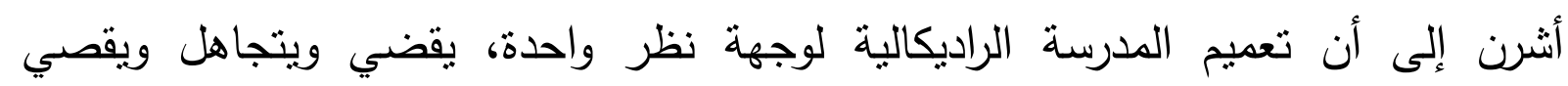
مجموعات كاملة من النساء. (ويكي الجندر ، نسوية راديكالية).

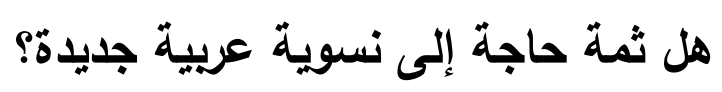

إن التيارات النسوية متعددة الأفكار، نسعى للتغيير الاجتماعي والثقافي، وتغيير بناء العلاقات بين الجنسين، وصولا إلى المساواة المطلقة كهدف استراتيجي، وتتسم أفكارها بالتطرف والثذوذ، وتتبنى العداء والصراع بين الجنسين، وتهدف إلى تقديم قراءات جديدة للاين واللغة والتاريخ والثقافة. 
إن الثيء الذى يبدو هنا أننا أمام كيانين مختلفين، لكلٍ منهما عالمه وحياته ومصيره: عالم

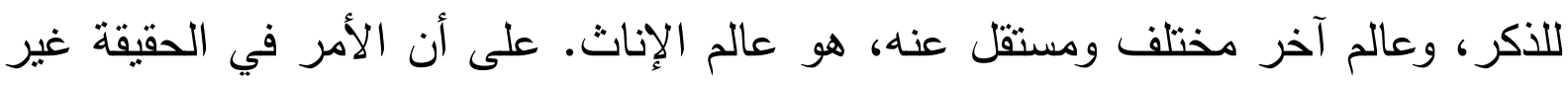
ذلك. نحن بإزاء وجهين لثنيء واحد، تماما كوجهي العملة الواحدة، فرغم اختلافهما، فلا انفصال بينهما لأن الرجل والمرأة هما وجها الوجود الإنساني.

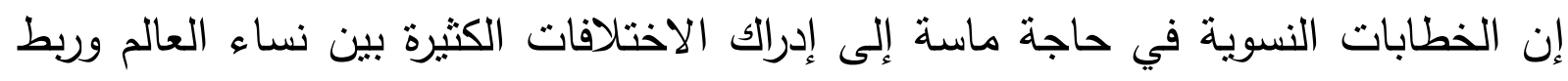

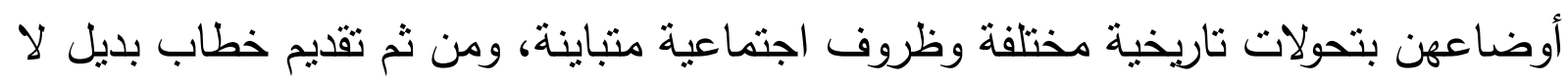

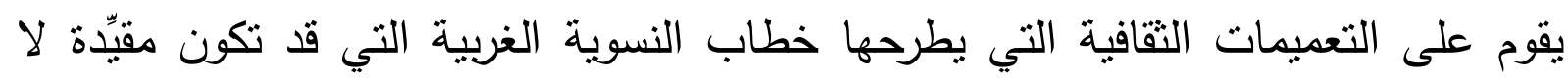

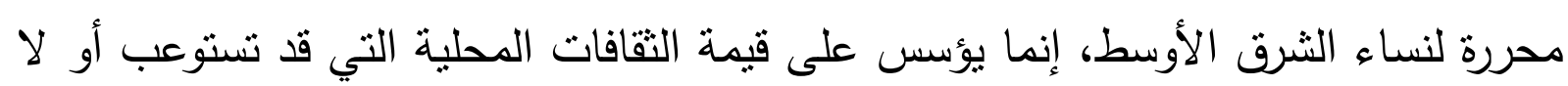

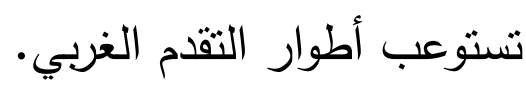

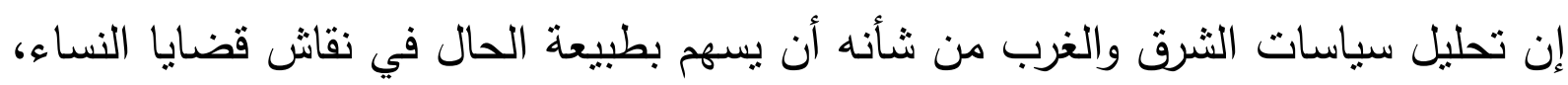

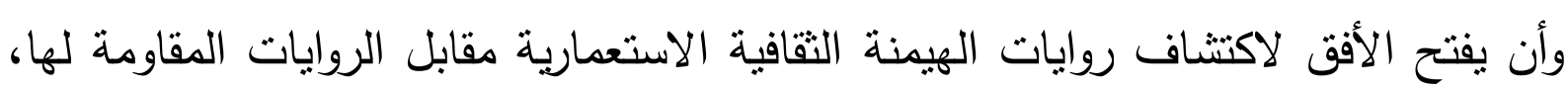

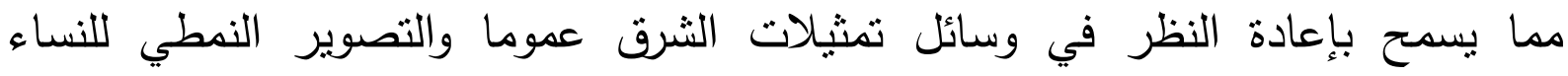
العربيات والثرق أوسطيات خصوصا، بشرط ألا يظل الخطاب النسوي بهذه الصورة مجرد حقل معرفي في سياق تحليل الخطاب الكولونيالي، إنما يتجاوزه إلى التحليل الاجتماعي/الجندري الذي يدرس الخصوصبة الثقافية للمرأة في الثرق الأوسط، ويستكثف

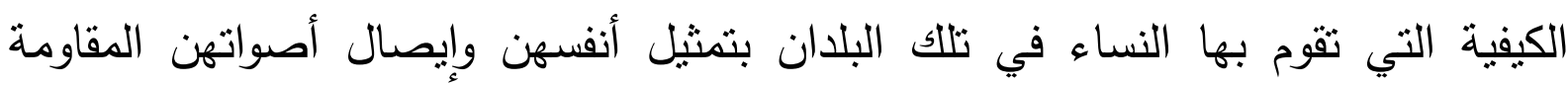

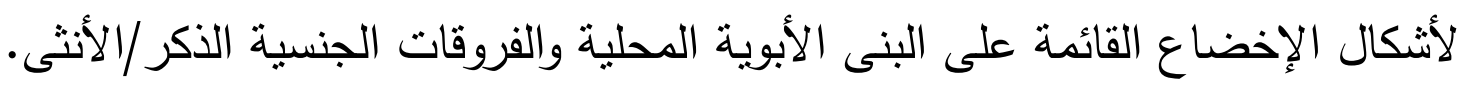

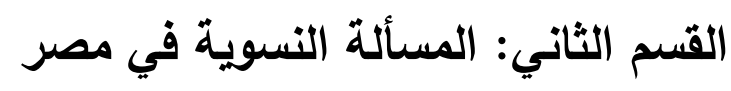

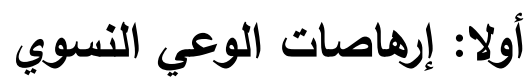

ترجع مشاركة النساء في المجال العام المصري إلى عدة قرون مضت، ولا تمثل ثورة 1919

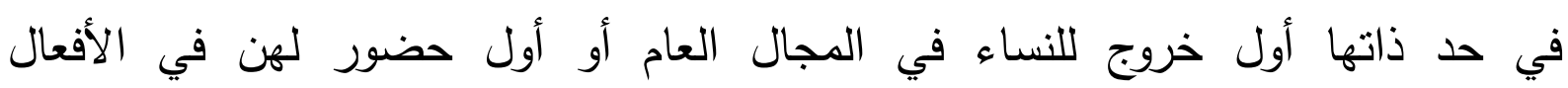

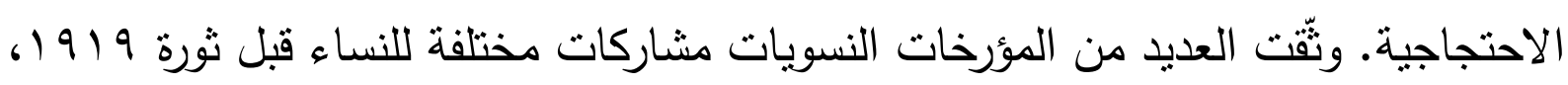

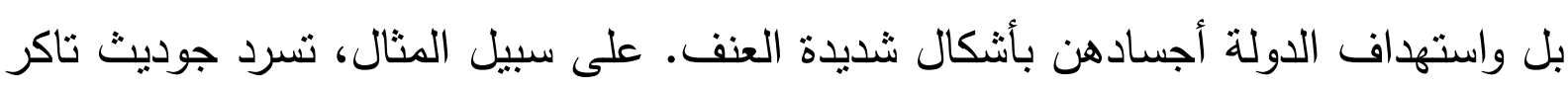
في كتابها (نساء مصر في القرن التاسع عشر) عن وجود أدلة تاريخية عن مشاركة النساء

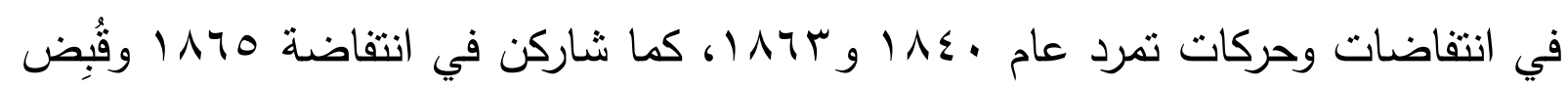

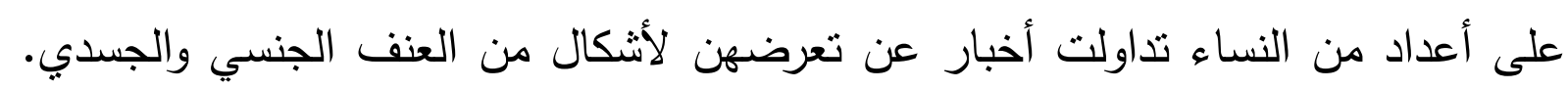

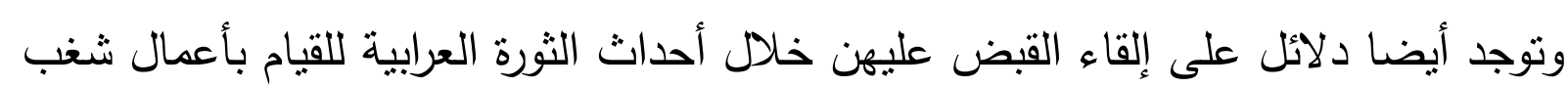




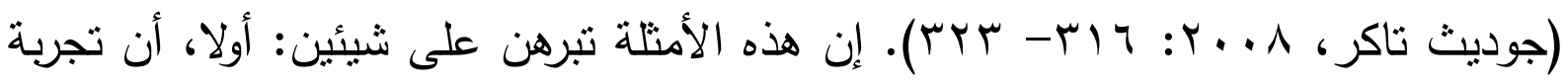
مشاركة النساء في ثورة 9 او 19 لم تأتِ من فراغ بل سبقتها عدة تجارب مرتبطة بحضور هذا الجسد في المجال العام وانتهاكه. ثانيا، أن أحداث من لوراع بـ 1919 شكّلت لحظة شديدة الخصوصية لدى هؤلاء النساء ووعيهن بأجسادهن. وعلى الرغم من عدم تعبير تلاك المظاهرات المبكرة عن مطالب نسوية، إلا أنه تجدر الإشارة إلى كونها تكثف عن عن مرحلة تطور الوعي النسوي على مستوى الشكل إن لم يكن على مستوى المضمون. فقد قامت النساء بتنظيم أنفسهن وخرجن إلى المجال العام في زمن لم تكن تتمتع فيه النساء بحق التعليم، فيما يمكن اعتباره فعلا سياسيا ذا ملمح نسوي. فالبعد النسوي لا يستتد هنا إلى الثعارات التي حملتها النساء، وإنما في تمردهن على الثقافة السائدة التي كانت تقبّد نساء الطبقتين الوسطى والعليا بالمجال الخاص ممثنلا في بيوتهن. في إيجاز ، ربما يكون الأمر الفارق الذي شكّله حراك ثورة 919 (19 بطابعه النسائي الجماعي،

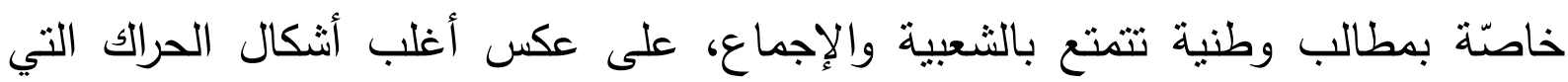

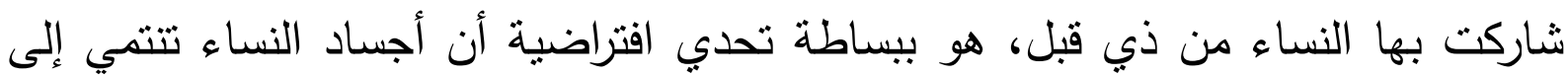

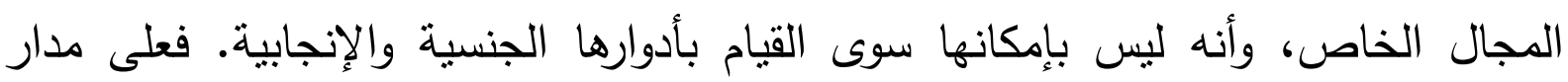
التاريخ المعاصر، اعتمدت الأبوية المصرية، من خلال تسخير الآليات المجتمعية والثقافية والسياسية بل والطبية، على ترسيخ تصورات مرتبطة بأجساد النساء وبمدى قدرة تلك الأجساد على التمرد في مواجهة الحدود التي تم ترسيمها لها سلفا. وكانت هذه المشاركة وما نلاها من تتظيم جماعي تحديا واضحا منظّما ومسيّسا لتلك الحدود. وقد تصرفت النساء اللاتي شكلن فيما بعد بداية الحراك النسوي على أساس الاستحقاق الذي أعطته لهن مشاركتهن في أحداث 1919 اللترسيخ لاستمرارية وجود هذه الأجساد في المجال العام حتى بعد انتهاء

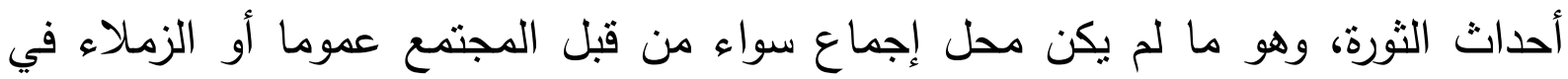
العمل الوطني، على عكس احتفائهر بمشاركتهن في التظاهرات والدور الوطني الذي قمن به. فكما يظهر من مذكرات هدى شعراوي، لم يتقبل أعضاء الوفد بشكل سلس وجود لجنة الوفد المركزية للسيدات، فتوضح شعراوي في خطاب أرسلته إلى سعد زغلول طالبة دعمه احتجاج

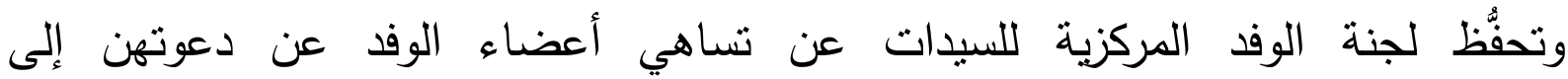
الاجتماعات، وضجرهم من إبداء نساء اللجنة لآرائهن، بل وتصريحهم أنه لا يجوز للنساء التدخل في الأمور السياسية. ولكن ما يبدو واضحا في إثنكالية مشاركة النساء السياسية، 
أنها، كما أوردتها المصادر الناريخية، اتخذت في بداياتها سمات العمل الوطني. ولكن تجدر

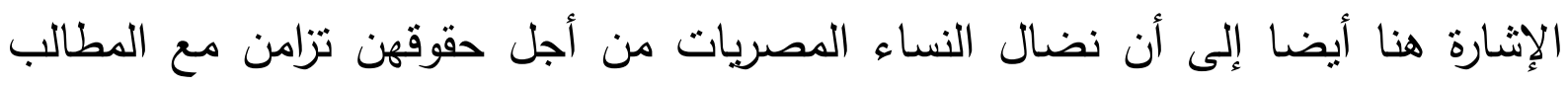

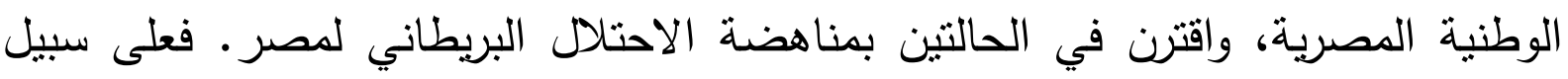
المنال، كانت مطالب النساء بحق التعليم تلقى الرفض والمقاومة من القوى المصرية الرجعية الترنية

$$
\text { والسلطات البريطانية معا. }
$$

أما ثانيا، فريما تكون اللحظة الأخرى المعبرة عن بايات هذه الحركة النسوية في أذهان الكثيرين، هي لحظة خلع هلى شعراوي وسيزا نبراوي لحجاب الوجه أو النقاب أثناء

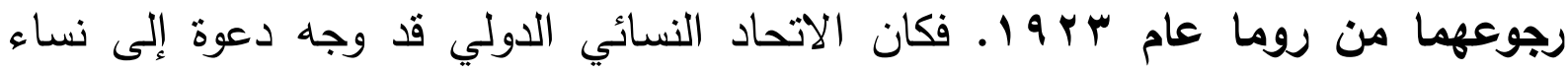
مصر في مارس بr 19 لحضور مؤتمره في روما، وحضرت خلاله هدى شعراوي ونبوية موسى وسيزا نبراوي ممثلات عن الاتحاد النسائي المصري، الذي ألهمت تلأك الدعوة تشكيله

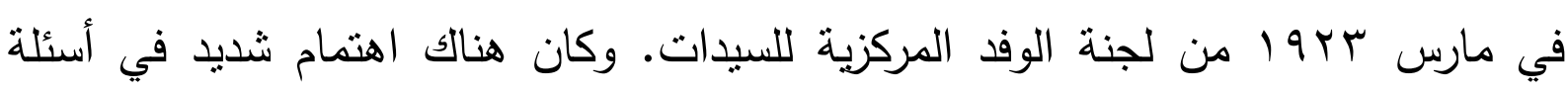

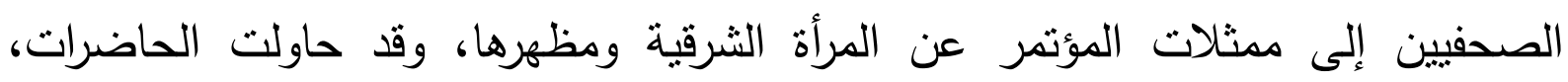

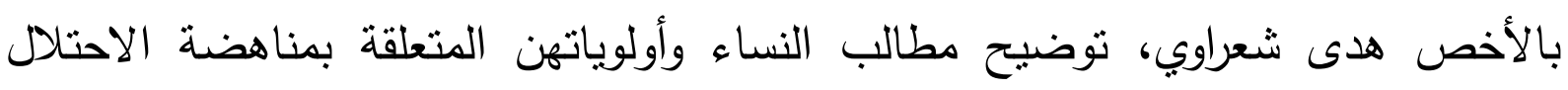

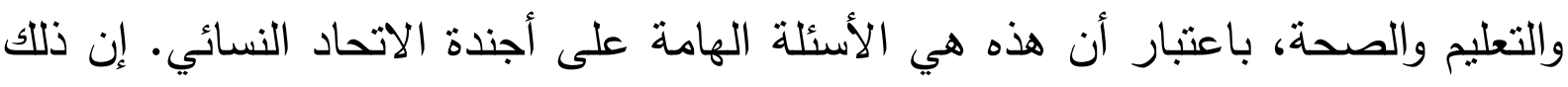

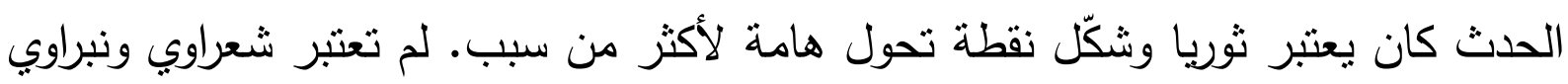

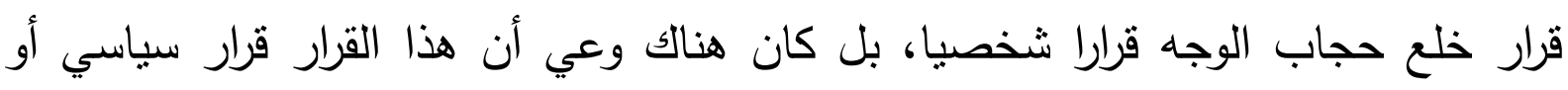

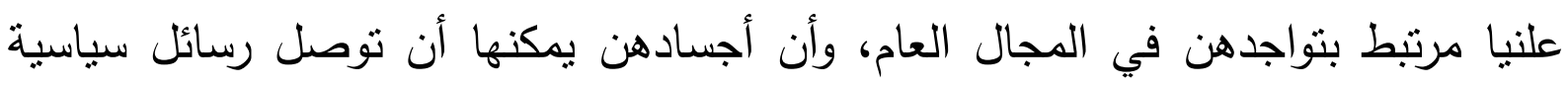
شديدة الوضوح حول النساء وحقوقهن. بالتالي شكلت تلك اللحظة إعلان ما مرتبط بتحرر

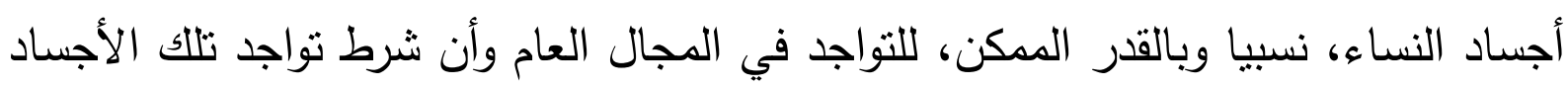

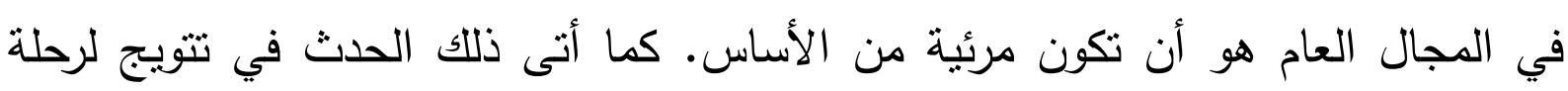
مرنبطة بحقوق النساء، مما يزيد من رمزيته وأهيته في سياقه الناريخي. ولم تكن هذه التهات

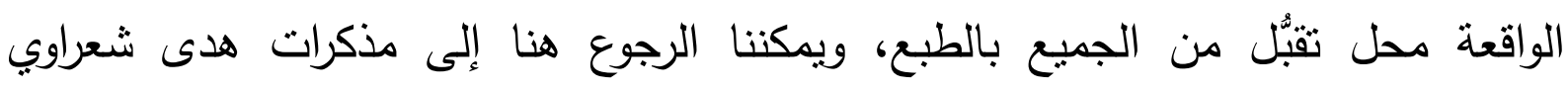

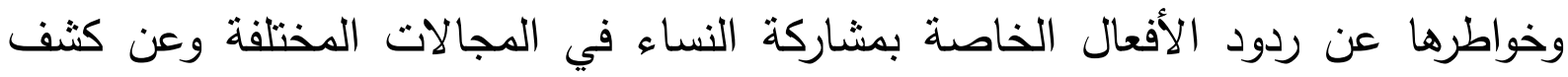
الوجه. وقد قالت في ذلك: الالقد أخطأ الكثيرون فهم المبدأ الأساسي للاتحاد النسائي بشأن

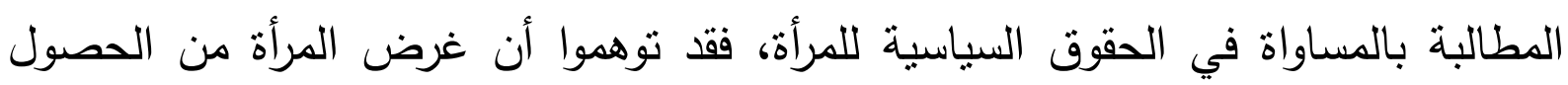

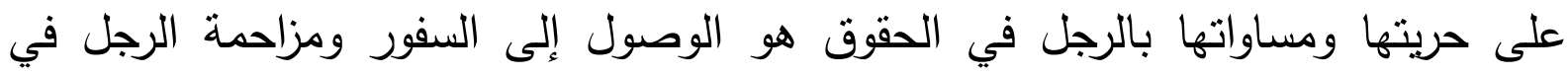
مبادئ السياسة والعمل، مما أدى إلى تذمر بعض الرجال، والحقيقة أن مطالبة المرأة بحقها 
السياسي ليس معناه التنخل في الأمور السياسية والحزبية المحضة، بل للحصول على حقها

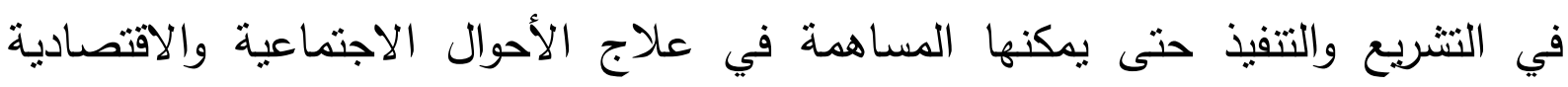

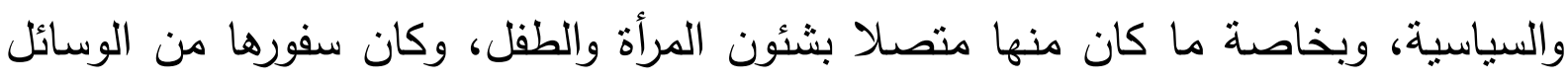

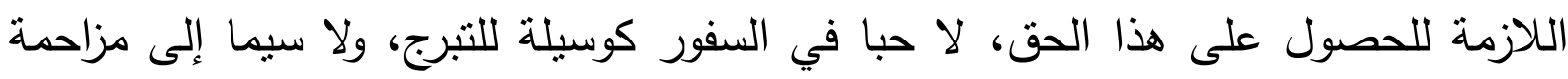

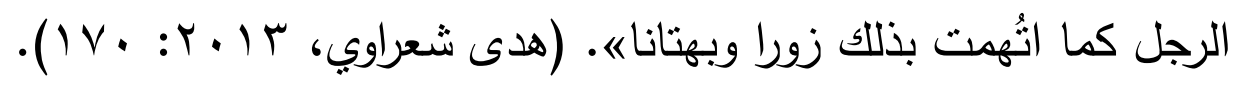

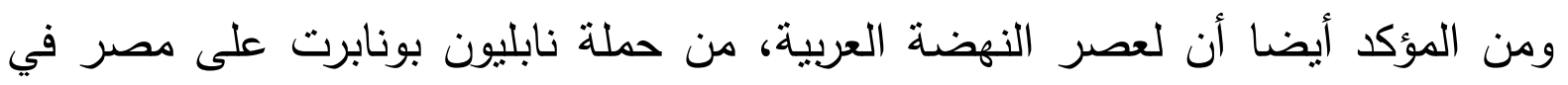

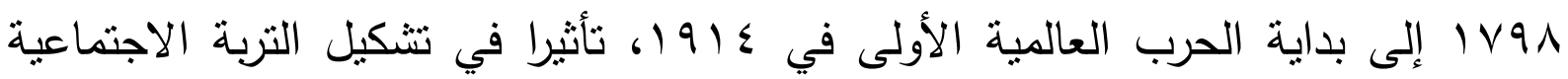
والنقافيّة الخصبة التي ساعدت على أول ظهور لبوادر حركة نسوية تحرية مصرية في

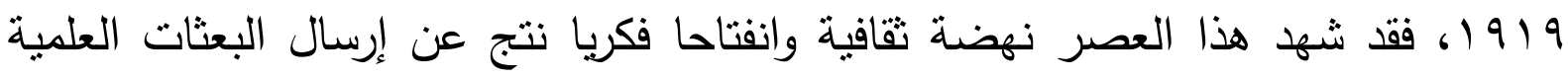
إلى أوروبا عموما، وفرنسا خصوصا، فتأثر مفكرو عصر النهضة العربية بفكر فلاسفة

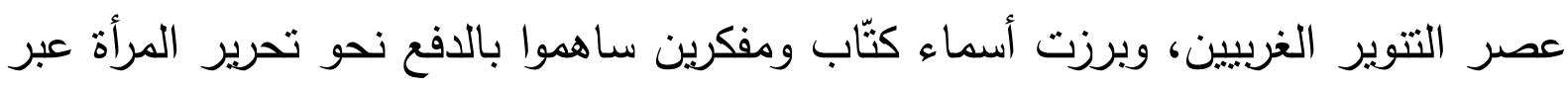

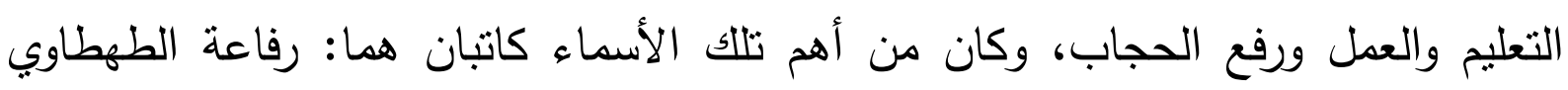

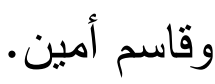

ثانيا: نثأة الحركة النسوية في مصر وتطوُرها لعلها الحركة الأكثر جدلا والأثند تأثثرا على مستوى العالم العربي، فعلى أرضها البدايات

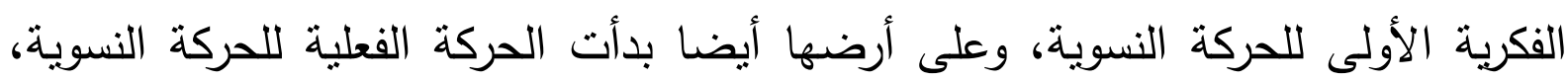

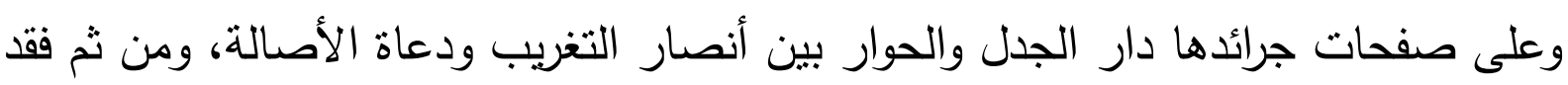

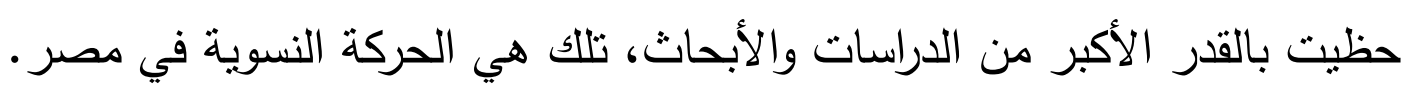
قدمت المرأة الدصرية طوال تاريخها الكثبر من أجل الوطن، وسجل التاريخ نضال نساء الأهاء

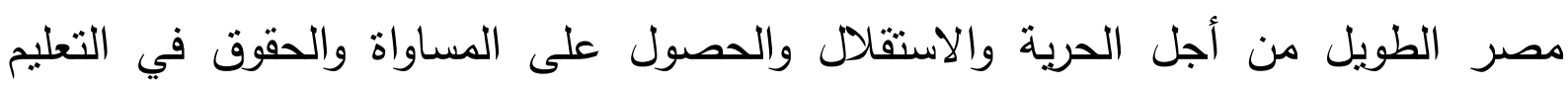
والعمل، وتمثل الفترة من 1919 - 19 ـ ب حقبة هامة في سجل نضال المرأة، فهي سنوات

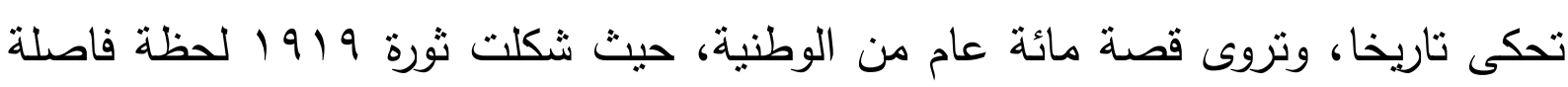

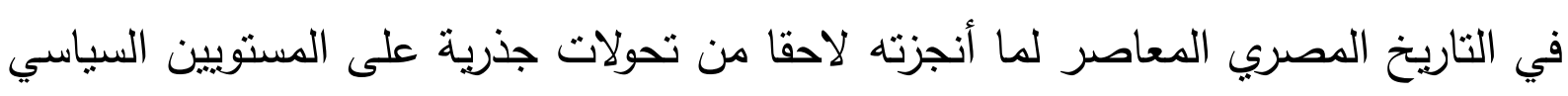

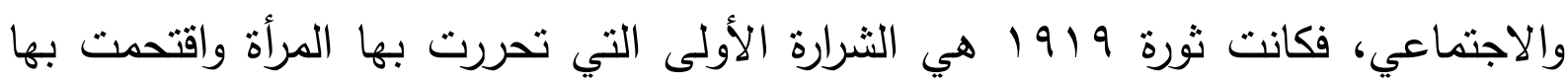

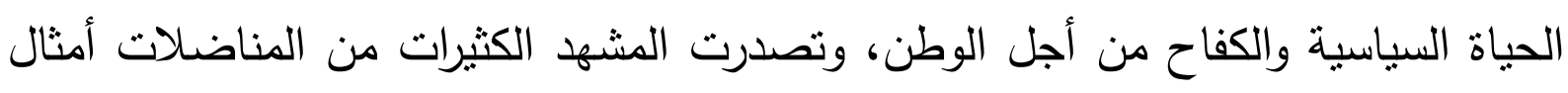

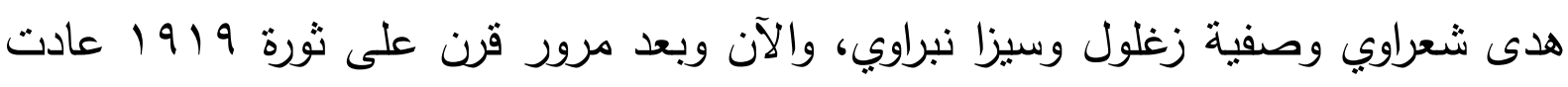

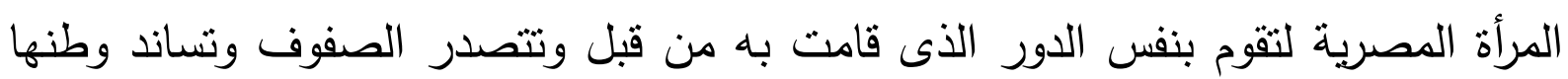


لتقتح صفحة جديدة من التاريخ المصري، مما يؤكد على استمرارية الدور التاريخي للمرأة ومدى مساندته للقضايا الوطنية منذ القدم وحتى الآن. إن للحركة النسوية المصرية تاريخا عريقا، ويمكن تتبعها حسب سياقها التاريخي والمطالب التان

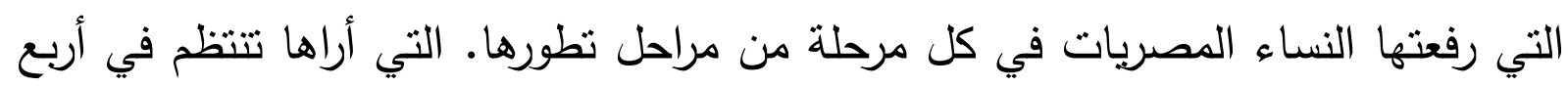
موجات أتتاولها بالتفصيل في الأجزاء الثالية من هذه الورقة. - الموجة الأولى: نهايات القرن الثاسع عشر وبدايات القرن العشرين. - الموجة الثانية: من خمسينيات وحتى سبعينيات القرن العشرين.

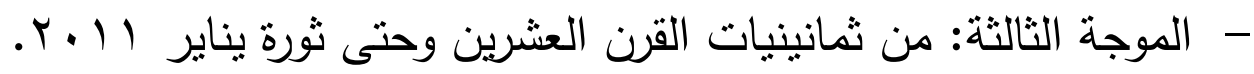

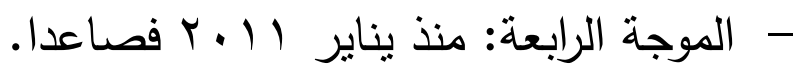
أهم شخصيات وأحداث الموجة الأولى:

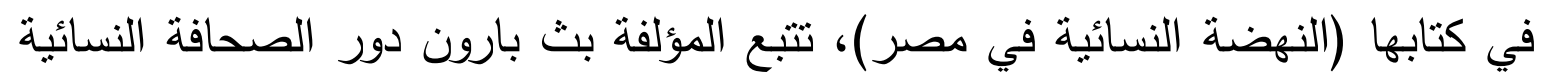

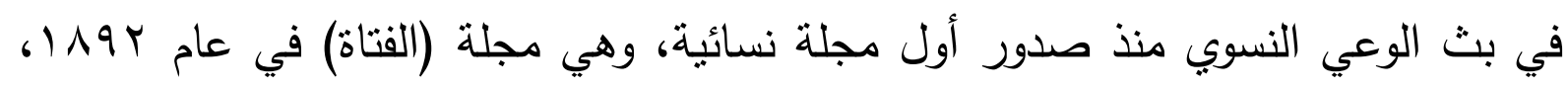

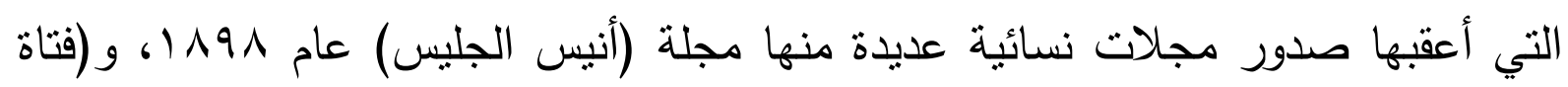

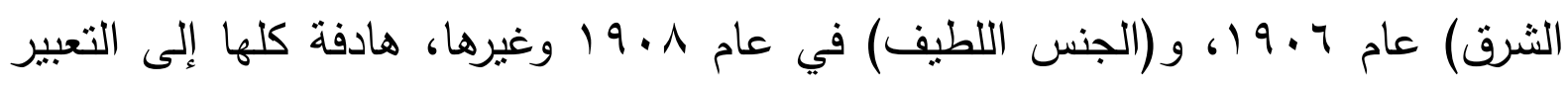
عن آراء النساء والمطالبة بحقوقهن. وتتشير بث بارون إلى أن صعود حركة التحرر الوطني

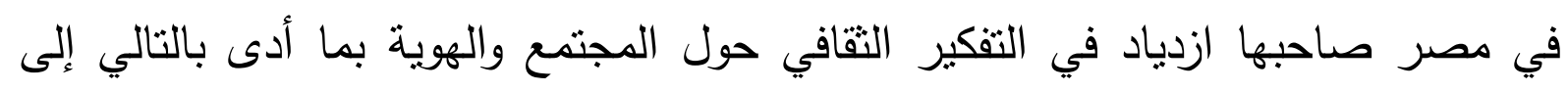

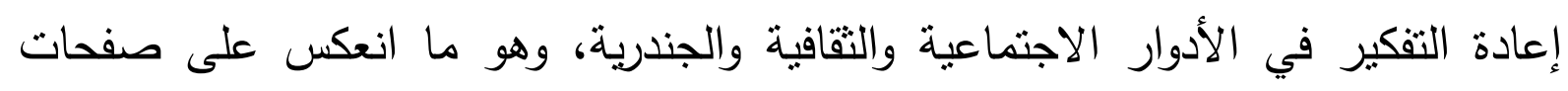

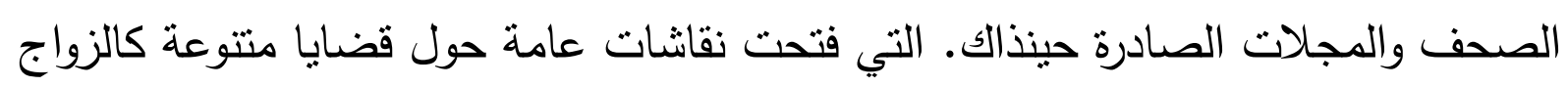

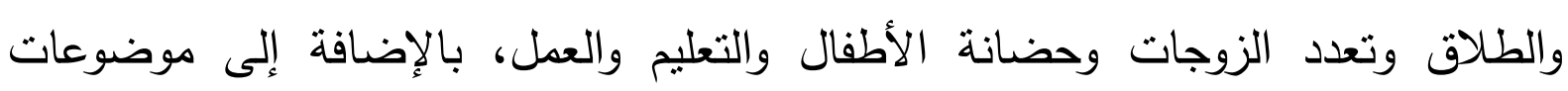
كالحجاب والسفور والحياة المنزلية (بث بارون،

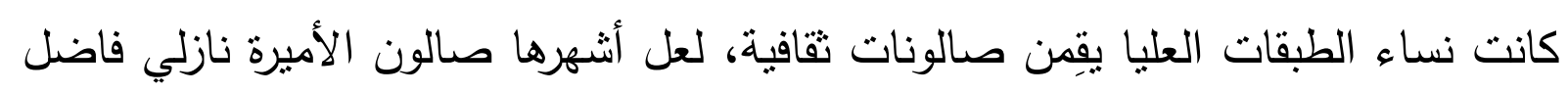

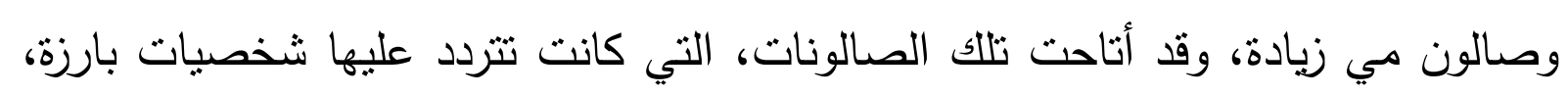

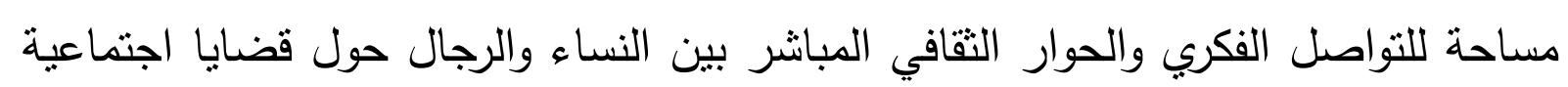
وسياسية وتقافية وجندرية.

إعلان ملك حفني ناصف، المطالب العشرة للنساء في خطبة ألتنها في نادي حزب الأمة

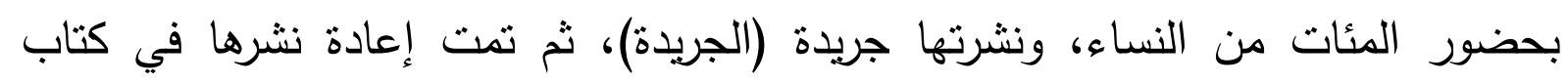

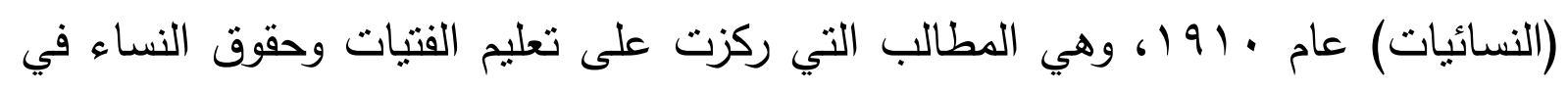


إطار الزواج. (منى إمام، 9 (ب).). وقد واصلت النساء الدفع بمطالبهن التي تبلورت لاحقا في جهودهن الجماعية الرامية إلى النص على حقوق النساء في دستور بrوأها، فاستجابت القوى السياسية لمطالبهن التعليمية وحرمتهن من حقوقهن السياسية، إذ خلت المادة الثالثة

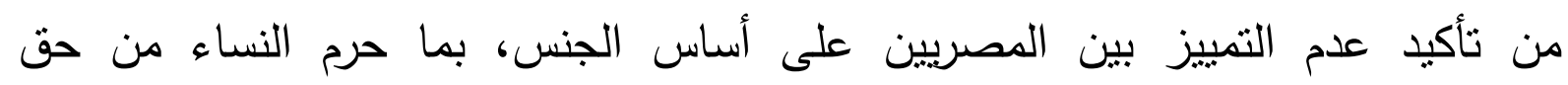
الانتخاب، بينما اقتصر النص على حقوق النساء في دستور بrابل19 على المادة 19 التي

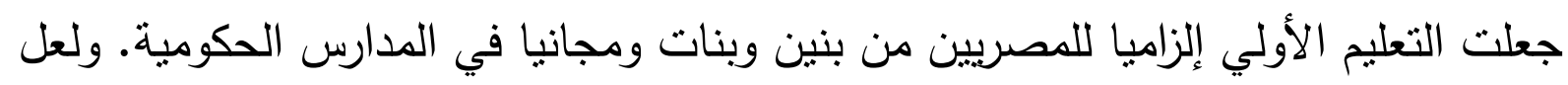

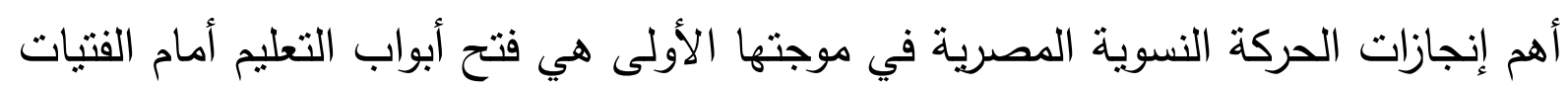

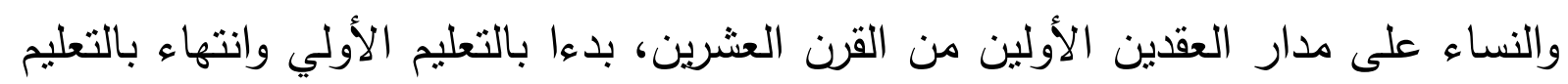

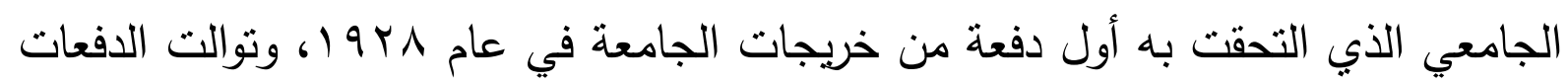

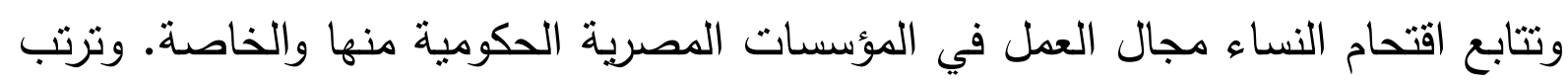

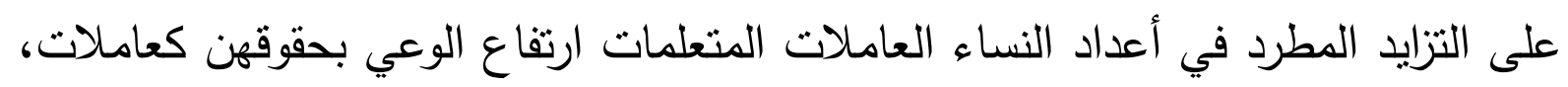

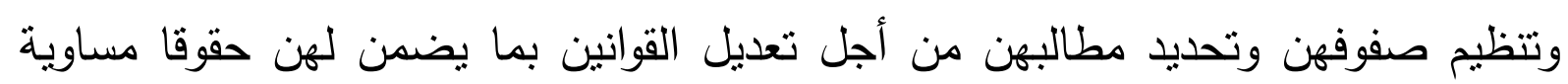

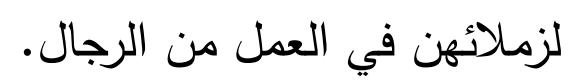

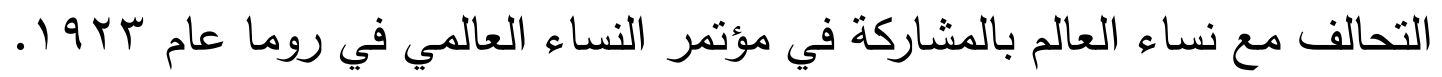

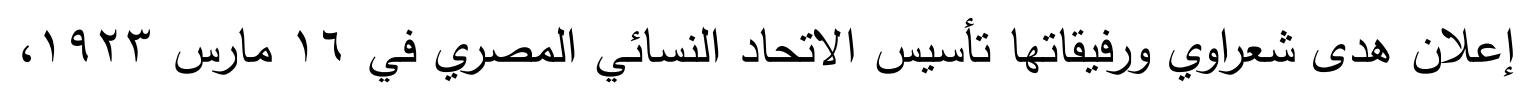
وإصدار وثيقة ببرنامج الاتحاد تتضمن بنودا سياسية تتعلق بقضايا وطنية عامة متلك: الاستقلال والامتنازات الأجنبية والقوانين وبناء الدولة الحديثة، وبنود اجتماعية متلك: النزكيز

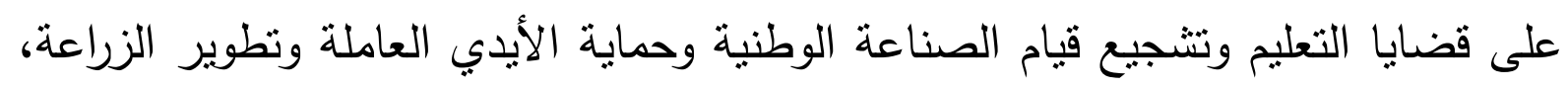

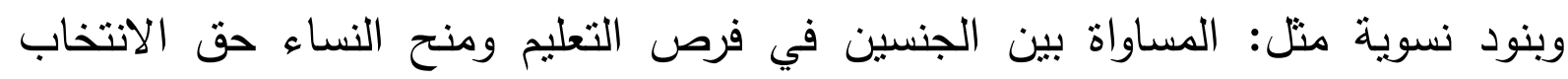

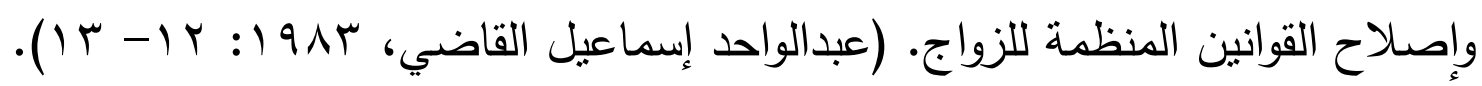

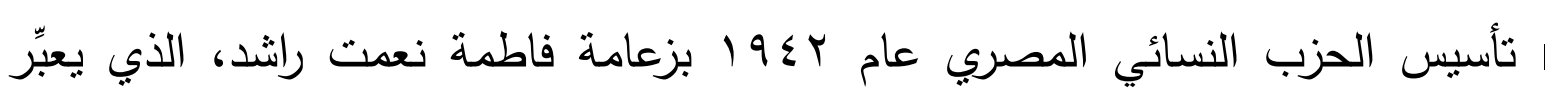
برنامجه التأسيسي عن مطالب تثتنمل على المساواة بين الجنسين وحصول النساء على التى

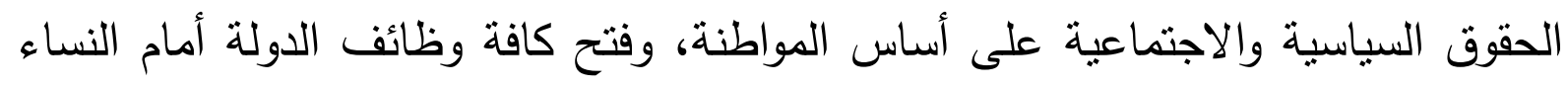
وضمان حقوق النساء في العمل وحقوقهن النقابية، إلى جانب المطالب الخاصة بتعديل القوانين الدتعلقة بالزواج وتعدُد الزوجات والطلاق والنفة وحضانة الأطفال (هالة كمال، () (1): $\{.17$ 
تأسيس إنجي أفلاطون رابطة فتيات الجامعة والمعاهد المصرية عام 9 اله، وارتكزت مطالبها على المساواة بين الجنسين في العمل والأجر إلى جانب حصول النساء على كل

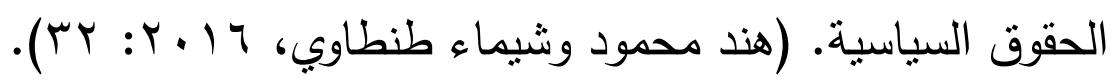
أصدرت درية شفيق مجلتها (بنت النيل) في عام 9 أن أنكون مجلة نسائية موجهة

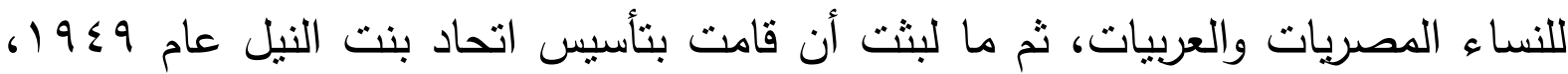
وتضمن برنامجه هدفين اثثين هما: السعي إلى رفع مستوى الأسرة المصرية ثقافيا واجتماعيا

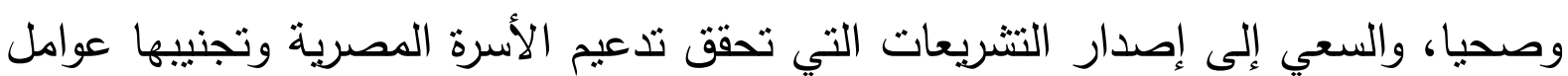

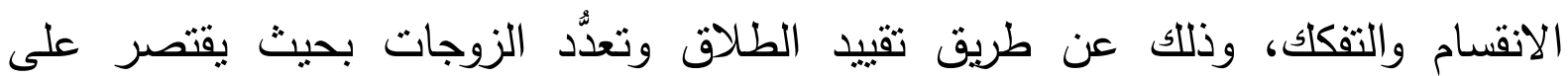
الضروريات التي تجيزهما. ويصون الأسرة من نتائج استعمال هذه الرخصة وذلك لسبغ الحماية على الأمومة والطفولة معا. وسيلتها في تحقيق هذه الأهداف تتحصر في السعي لتقرير حق المرأة في الانتخاب والنيابة عن الأمة، لتتمكن من الدفاع عن حقوق المرأة المصرية والمساهمة في إصدار التشريع الذي يكفل هذه الحقوق واستقرارها وتعميمها. (أمل

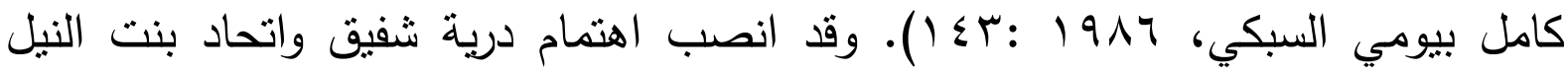
الرئيسي على قضية المشاركة السياسية للنساء اللاتي اعتبرنها المدخل الأساسي لتعديل القوانين في صالح النساء. فدعا اتحاد بنت النيل إلى مؤتمر نسائي في 9 أنبراير 1901 تم فيه رفع المطالب الثلاثة التالية: تعديل قانون الانتخاب بما يساوي بين النساء والرجال في الحقوق السياسية، وتتريع القوانين بما يحمي الأسرة بتقييد حق الطلاق وتعدُّد الزوجات،

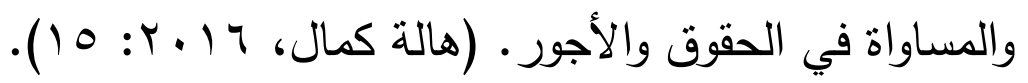

تأسيس اللجنة النسائية للمقاومة الثعبية في ـ ا نوفمبر 1901 أهي في إطار مشاركة النساء في دعم حركة المقاومة الثعبية في منطقة القناة. أهم شخصيات وأحداث الموجة الثانية: تعدُّ هذه الحقبة نقطة تحول أساسية في مسار الحركة النسوية ومطالبها، حيث إنه لم تعد الحركة النسوية وتتظيماتها التي تأسست في الفترة السابقة ودافعت عن القضية الوطنية والقومية، كما ناضلت من أجل حقوق المرأة، مرغوبا فيها من قبل الحكومة الجديدة، وبالتالي فإن الوقت الذي تعرضت فيه كل التيارات الفكرية والسياسية الليبرالية والإسلامية واليسارية إلى الاعتقال والقمع، قد شهد أيضا توقفا في أصوات الحركة النسوية التي تعرضت تتظيماتها الأهلية إلى التجميد والحل. 
إلا أن سنة 1901 كانت نقطة تحول هامة، حيث أغلقت حكومة الضباط الأحرار مكاتب

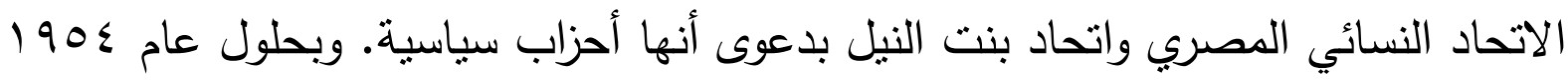
اتخذت الحكومة الجديدة إجراءات حاسمة لصالح تمركز السلطة ومصادرة المبادرات الأهلية،

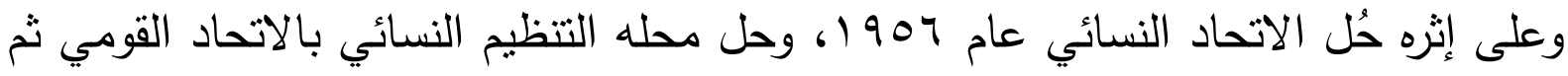
التنظيم النسائي بالاتحاد الاشتراكي، وهي التنظيمات التي تتكلت بقرار من السلطة بديلا

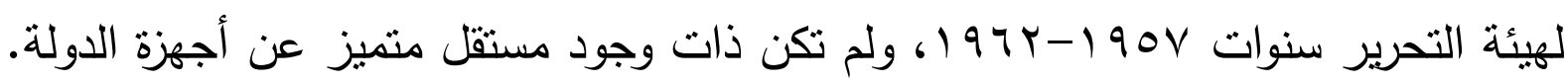

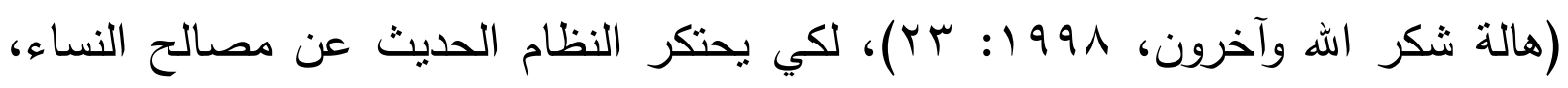
متخذا مسارا معبرا عن نسوية الدولة، أي تحكم الدولة في نداول قضايا النساء.

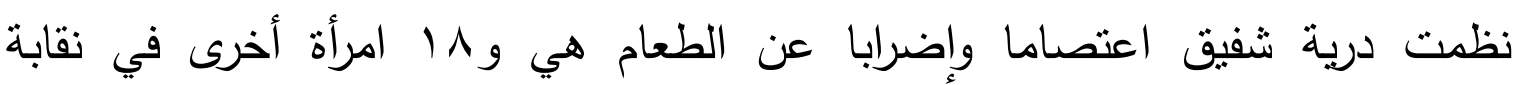
الصحفيين بالقاهرة في Y I مارس 1901، معلنة نفاد صبر الحركة النسوية من تأخر الاستجابة لمطالب استمرت المطالبة بها نحو ثلاثين عاما، كما تم تتظيم اعتصام مشابه في الإنكندرية. وقد كان هذا العمل الاحتجاجي الجماعي بمثابة الفعل الجماعي الأخير للحركة

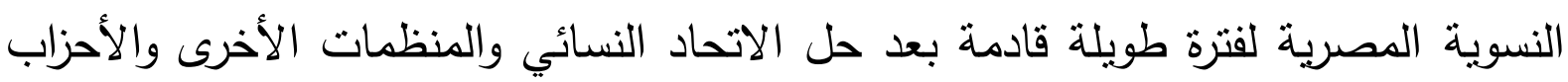
عام 1907، وبعد سنتين من ذللك، أي في عام 1907 نم منح النساء النساء حق الاقتراع. $190 \mathrm{~V}$ 19hater, Akram and Nelson, Cynthia, 1988: 472) أضربت درية شفيق مرة أخرى عن الطعام معربة فيه عن احتجاجها إزاء النظام الجديد الذي

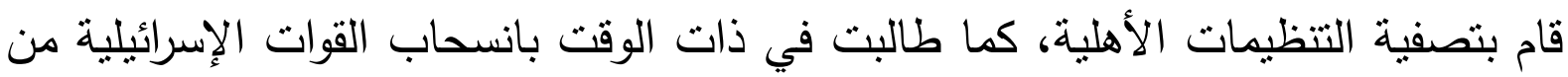

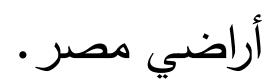
هإعلان دستور 1907 (المادة /T) بما يكفل للنساء حق الترشح والانتخاب، وتعديل قوانين العمل والتعليم بما يحقق المساواة بين الجنسين، مع بقاء قوانين الأحوال الثخصية

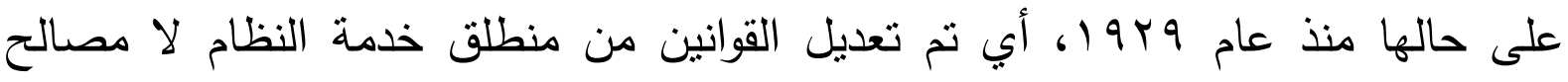

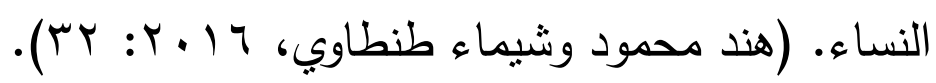
لم يقترب النظام الناصري من قوانين الأحوال الثخصية الني تركتها الدولة في يد الثياه المؤسسة الدينية، وحين توجهت بعض الثخصيات النسائية بقيادة عزيزة حسين، على سبيل المثال، إلى عبد الناصر في عام 197 تنالبه ببعض التعديلات في قوانين الأحوال الثخصية (متل قوانين الطاعة والطلاق)، اقتزح عليهن التوجه إلى المؤسسة الدينية باعتبار 
أنها التي لها الكلمة الأخيرة في هذا المجال. وبهذا وضعت الدولة، وليس لآخر مرة، المؤسسات الدينية وسيطا بين النساء وحقوقهن. (هالة شكر الله وآخرون، 991 ( : ه ب). لم يكن النظام معاديا لولوج النساء إلى المحيط العام أو إعطائهن حق المشاركة السياسية

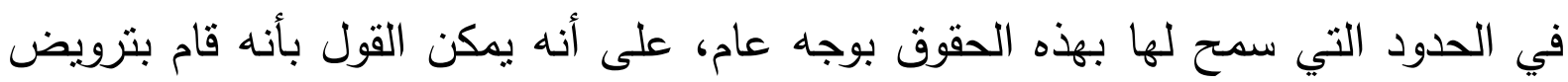
المشاركة النسائية بحيث تتسجم مع البرنامج السياسي والاجتماعي والاقتصادي الذي تبناه، وتكوين قيادة نسائية جديدة أكثر قبولا وتأقلما مع الروية الاجنماعية والاقتصادية للنظام الجديد (Talhami, Ghada Hashem, 1996:25). فكانت راوية عطية أول نائبة تدخل البرلمان المصري عن دائرة القاهرة عام 90 19، وتلا ذلك تعبين أول وزيرة للشئون الاجتماعية في مصر وهي حكمت أبو زيد عام ب797 أ وإن كانت بشكل عام تمثل نسبة ضئيلة لا تتتاسب سواء مع حجم النساء في مصر بوصفهن نصف القوة البشرية، ولا مع

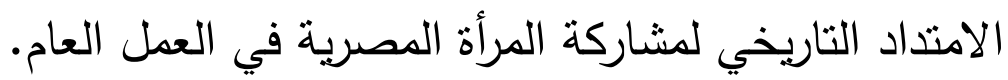
ومع إعلان الاتحاد الاشتراكي في ع يولية باج (1، حرصت الدولة علي إنشراك المرأة في العديد من هيئاته لاسيما في اللجان السكانية والجماهيرية، إلى جانب تشكيل لجان نسائية بمحافظة القاهرة التي أقيم فيها لجان للنشاط النسائي، وحصلت 9 .با سيدات في مايو 19VI على عضوية الوحدات الأساسية للاتحاد الاتشتراكي، وتقرر تكوين التتظيم النسائي للاتحاد الاشتراكي في V سبتمبر و9 19 ا، الأمر الذي خلق النواة الأساسية لمشاركة المرأة في المنابر التثاثة التي قرر السادات إنشاءها عام 9 19 ا، التي تحولت إلى أحزاب سياسية

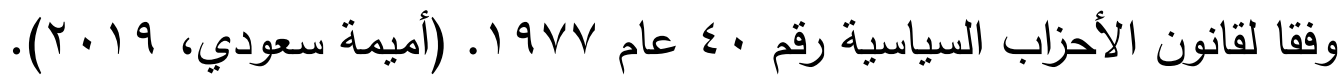
تحملت المرأة المصرية ويلات فقد الزوج أو الابن أو الأخ بعد نكسة لو 97 (ا، فأقبلت

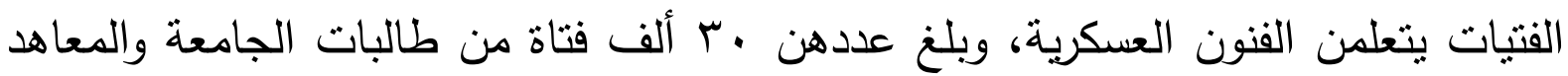
العليا والمدارس الثانوية. وكان إعدادهن ليس من أجل الوقوف في الصفوف الأولى في الحرب، وإنما تأهيلا للقيام بأعمال التمريض والإسعاف، وإعداد الطعام والإمدادات والذخائر

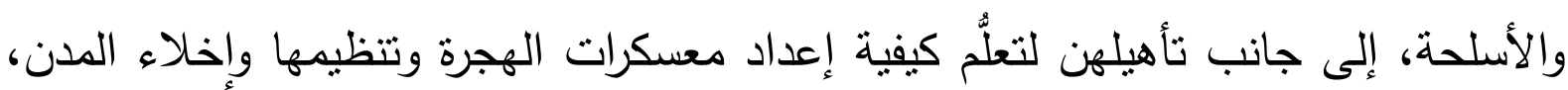

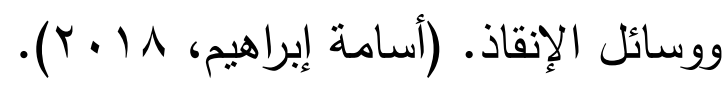
صدر دستور سنة 19V1 الذي أكد المساواة التامة بين الرجل والمرأة، حيث نصت المادة • ـ منه على الآتي: 》أن المواطنون لدى القانون سواء، وهم متساوون في الحقوق والواجبات 
العامة، لا تمييز بينهم في ذلك بسبب الجنس أو الأصل أو اللغة أو الدين أو العقيدةه.

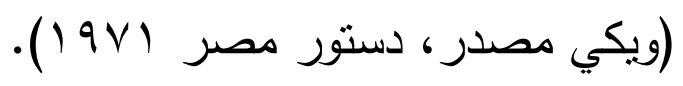

تُشر كتاب نوال السعداوي (المرأة والجنس) عام (9Vץ ال، وصار رمزا لإعادة إحباء الحركة النسوية المصرية. طالب الكتاب بمعيار موحد لدفهوم الثرف لكلٍ من النساء والرجال، وهجر الممارسات الاجتماعية التي نستغل الدين لتبرير اضطهاد المرأة. وقد سبّب

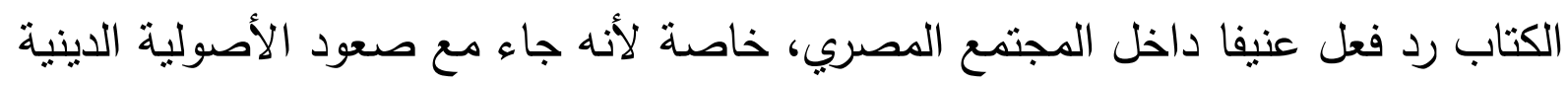
في البلاد، (ويكيبيديا الموسوعة الحرة، النسوية في مصر ).

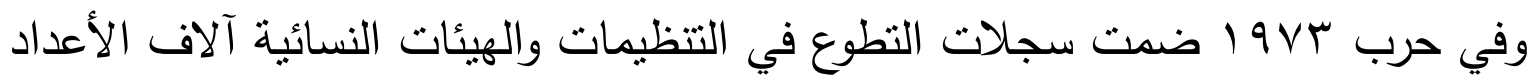
من الأسماء اللاتي أسهمن بالفعل في التطوع والمساعدة في حرب أكتوبر بثكل أو بآخر ،

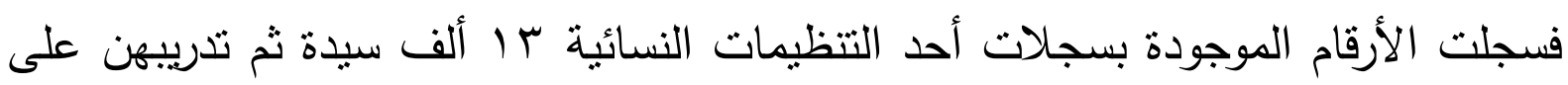
أعمال الإسعاف والتمريض للمساعدة في الستتنفيات. كما سجلت حوالي تسعة آلاف سيدة

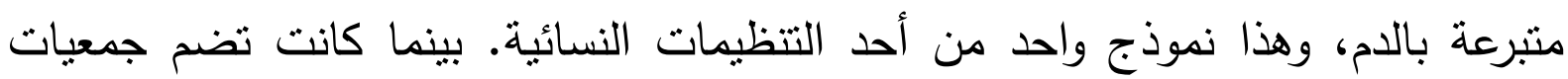

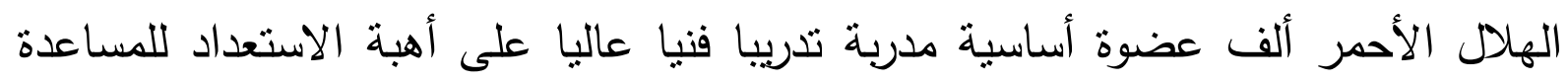
والمشاركة. (ويكيبيديا الموسوعة الحرة، المرأة في مصر ).

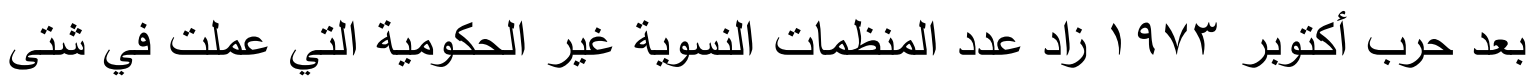

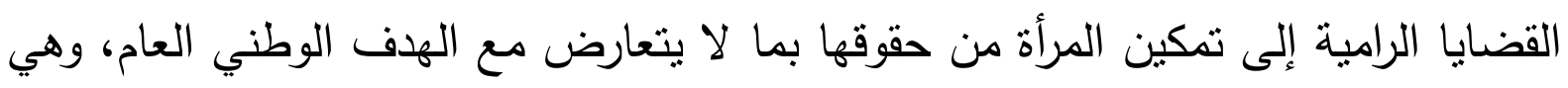

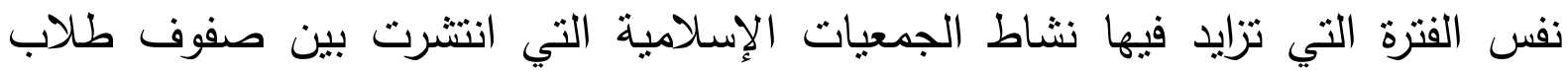
الجامعات المصرية، وهي أيضا تلاك الفترة التي أضيرت فيها المرأة أدبيا ونم الاستهانة لفانة

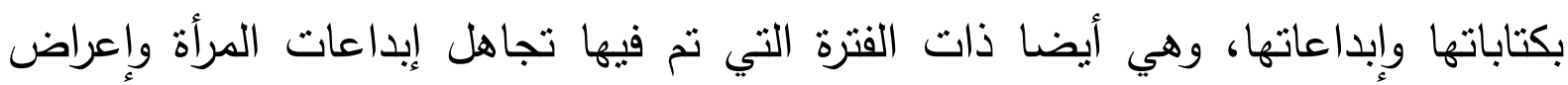

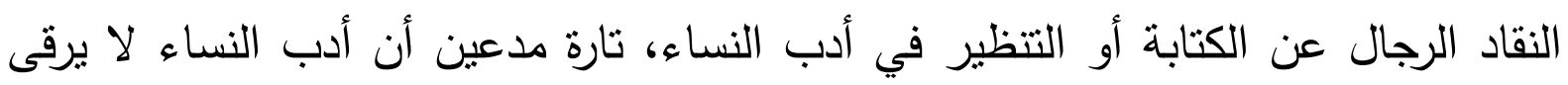
إلى مستوى الأدب، وتارة مدعين الفصل بين ما هو نسائي وما هو ذكوري، وإثارة التساؤل:

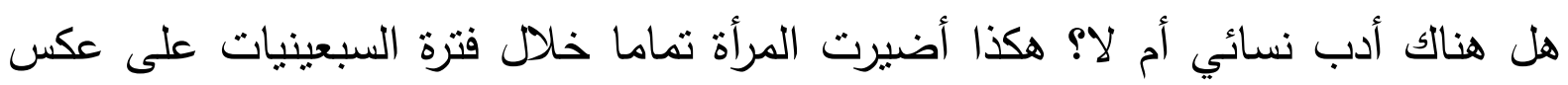

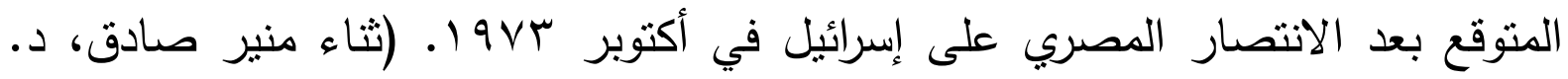
. (ن)

في نفس الفترة ومع إرهاصات الردة عن المكاسب الاجتماعية والسياسية الني حققتها المرأة إبان ثورة يوليو ، ارتفعت أصوات الحركة الإسلامية تخاطب النساء بما يجوز ولا يجوز

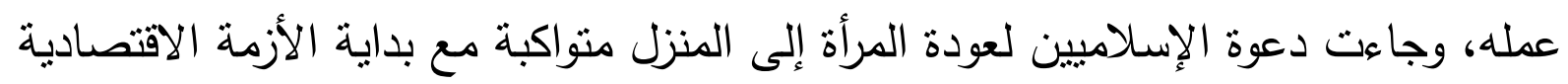


وصعوبات ظروف العمل ومؤشرات انتشار البطالة، فكان خطابهح يتضمن تلاقيا واضحا بين الأجندة النسائية الإسلامية وبين الاستجابة للظروف الاقتصادية وتزاحم النساء للرجال في سوق العمل المحدود. وهو ما دعا قيادات الأربعينات النسائية إلى التعبير عن قلقهن من الن التهن بوادر هذه الردة، وبدأ إحساس ينتاب مجموعات متتاثرة من النساء بأنهن خرجن من رومانسية النضالات إلى وضع أكثر تجردا من أي حقوق سواء كان ذلك على المستوى بلى بله

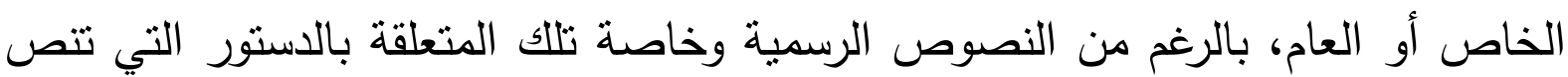

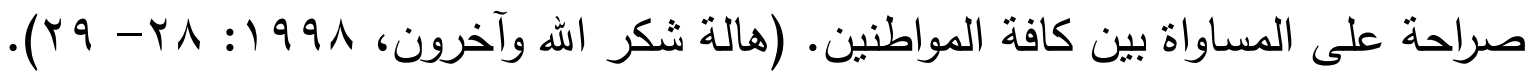
ولم تنلم المرأة المصرية من الاعتقالات التي شنها نظام السادات عقب انتفاضة الخبز عام 9VV IV، حيث خرجت المرأة مع الرجال ضد سياسات غلاء الأسعار، ونالت ما ناله الرجال من اعتقالات جماعية. شكلت البنية التشريعية والقانونية في هذه المرحلة أطرا جوهرية في مسيرة العمل السياسي

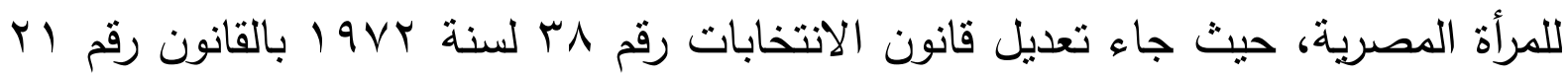
لسنة 19V9 بتخصيص ثلاثثن مقعدا للنساء كحد أدني وبواقع مقعد على الأقل لكل محافظة، ولم يسمح هذا القانون للرجال بالتتافس على هذه المقاعد، في الوقت الذي سمح

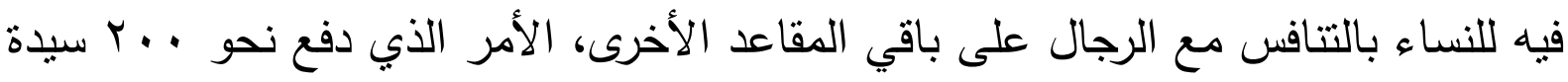
للترشح في انتخابات 9 19 و، وقد فازت ثلاثون منهن بالمقاعد المخصصة للنساء وبثلاث مقاعد أخرى من المقاعد غير المخصصة لهن، بالإضافة إلى ذلك عيّن رئيس الجمهورية

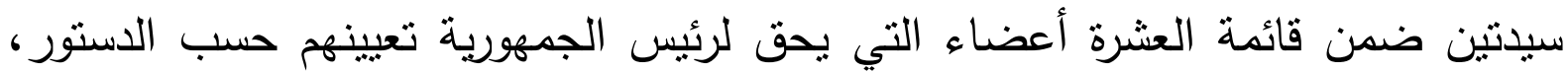
وبهذا أصبح إجمالي النائبات خمسة وثلاثثين بنسبة ^^\% من إجمالي الأعضاء. (أميمة

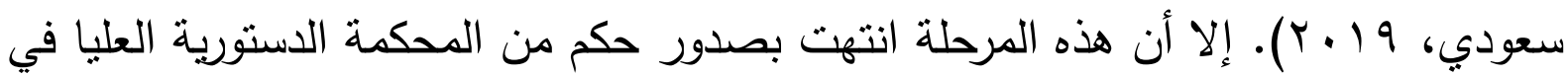
عام 9 19 بعدم دستورية القانون رقم |Y لسنة 9V9 1، لما ينطوي عليه من تمبيز على أساس الجنس. وقد انتهي هذا الوضع بالعودة لتطبيق نظام الانتخاب الفردي، مما نرتب عليه تراجع نسبة تمثيل المرأة في المجالس المتعاقبة. تم قصر العمل النسوي على الأعمال الخيرية تحت سيطرة وزارة الثنئون الاجتماعية. أهم شخصيات وأحداث الموجة الثالثة: صدّقت مصر على اتفاقية السيداو (القضاء على كافة أنثكال التمييز ضد المرأة) بتاريخ

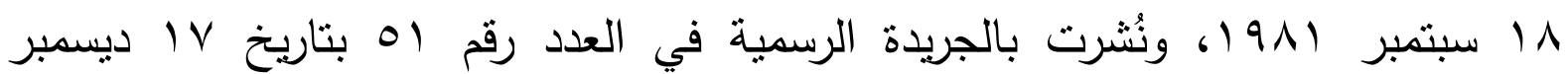


191 ا ـ وهي معاهدة دولية بمثابة وثيقة لضمان حقوق النساء، وقع اعتمادها في ديسمبر

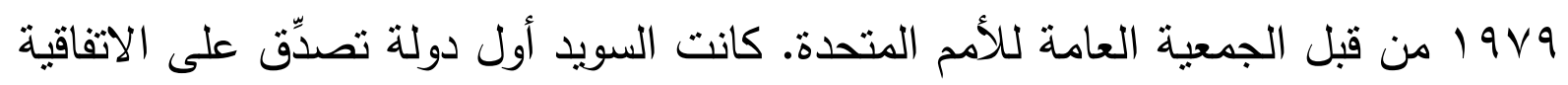

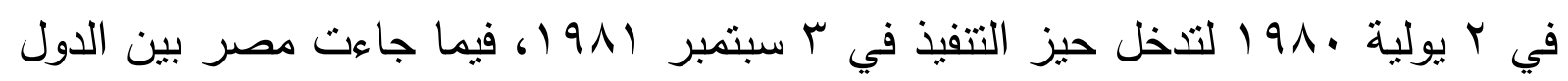
الأوائل المصدِّة على الاتفاقية، وتندرج ضمن الاتفاقيات الدولية تلك المتعلقة بحقوق الإنسان بصفة عامة، أو بحقوق بعض الفئات، ومنها المرأة، على وجه الخصوصن الأن وبناء

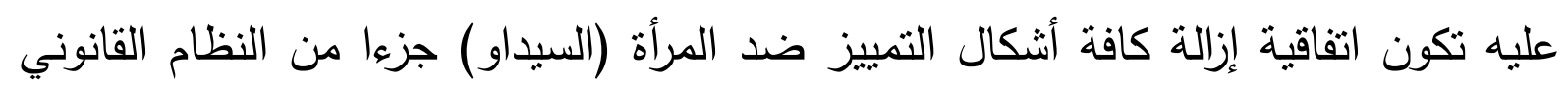
في الدولة، لها على الأقل قوة النصوص القانونية الصادرة عن السلطة النشريعية (البرلمان) في مصر (المجلس القومي للمرأة، ب ا • Y). تكوين منظمات نسوية مستقلة تنتبى جوانب منتوعة من قضايا وحقوق النساء، مستقيدة

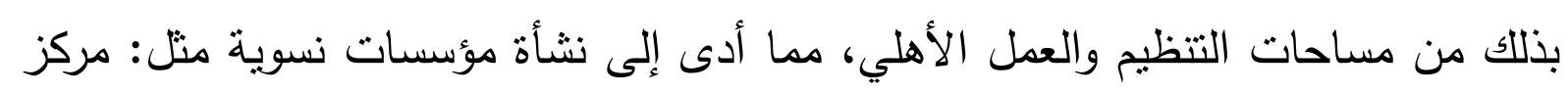
دراسات المرأة الجديدة، ورابطة المرأة العربية، ومركز قضايا المرأة المصرية، ومؤسسة المرأة

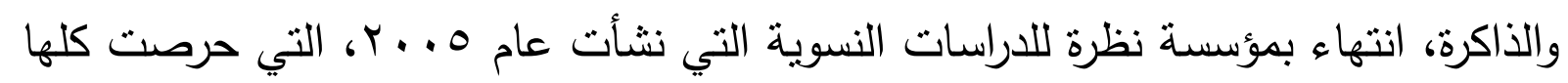
على استمرار عملها رغم القيود المتتالية المفروضة على منظمات المجتمع المدني والقوانين المنظمة لعملها واستهداف مؤسساتها. تصنّف بعض الكتابات هذه التشكيلة على أنها تتتمي إلى الثرائح العليا من الطبقة

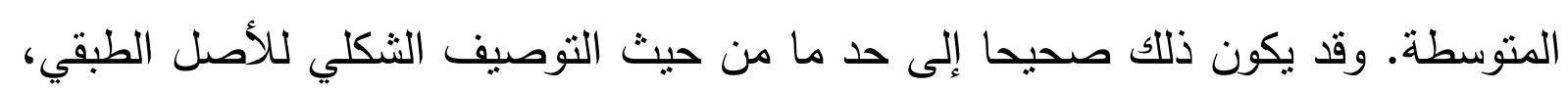
إلا أن النساء اللاتي اندرجن في هذه المجموعات قد انطلقن من مواقع فكرية واجتماعية مختلفة عن تلك التي حرّكت التجمعات النسائية في مراحل سابقة. فقد انطلقت مؤسسات

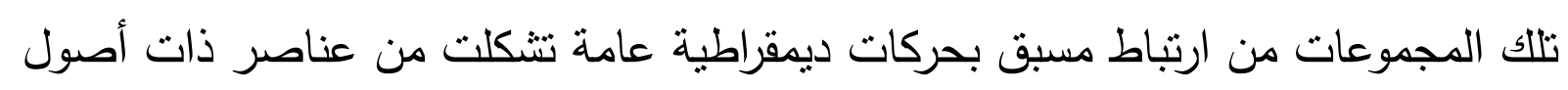

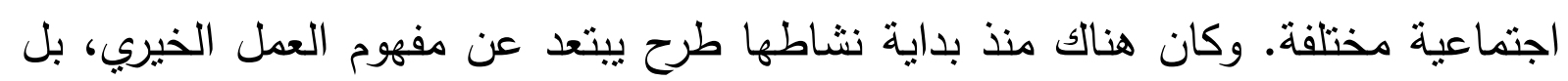
من رفض هذا النمط من العمل. كما طرحت القضية من منظور نسوي لله بعد اجتماعي

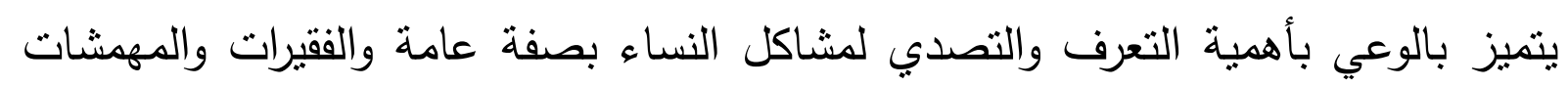

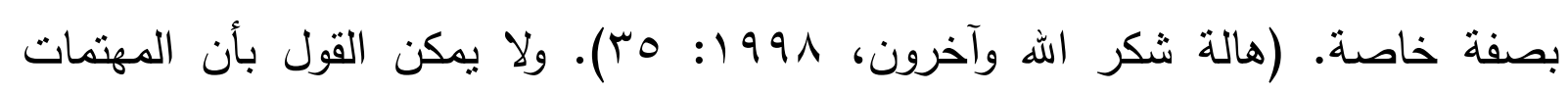
بقضايا المرأة كان قد نجحن فعلا في الوصول إلى الجماهير العريضة من النساء، سواء من والهن

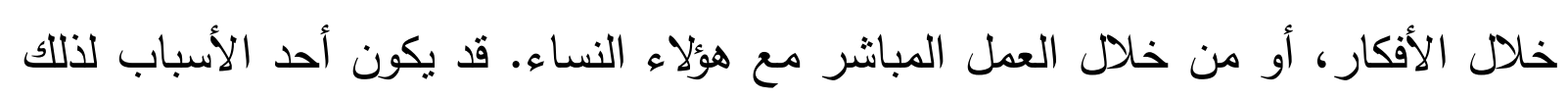

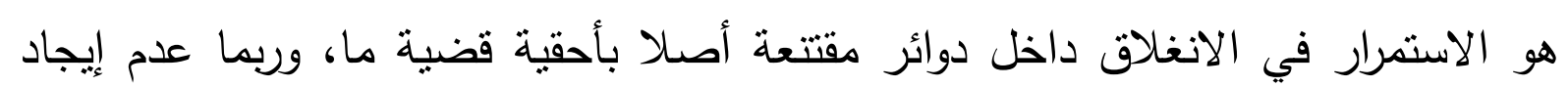
اللغة التي تثار من خلالها هذه القضية. ولكن ما من شك في أن هناك أسبابا أخرى وراء r纟 
هذه العزلة، ومن أهمها عدم تشجيع الدوائر الرسمية لوجود خطاب نسوي قد يؤدي إلى الاثتباك مع المد الأصولي المعادي لتحرير المرأة. وبالتالي وجدت الكثير لهنه من النساء المطالبات بالمساواة بين الجنسين صعوبة كبيرة في إيجاد القنوات المناسبة للوصول إلى وجى القاعدة العريضة من النساء المصريات الفقيرات وخاصة في الريف. قدم المؤتمر الدولي الثالث للسكان والنتمية، الذي نظمته الأمم المتحدة وعُقد في القاهرة عام \&9 9 1، دفعة للحراك النسوي في مصر ، إذ إنه وضع قضايا النساء على قمة الأولويات الوطنية حينما أصدر وثيقته التوجيهية لصندوق الأمم المتحدة للسكان يقول فيها: اإن تعزيز

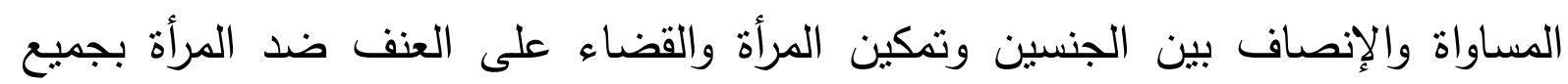
أنتكاله وكفالة قدرة المرأة على السيطرة على خصوبتها، أمور تمنل حجر الزاوية في البرامج

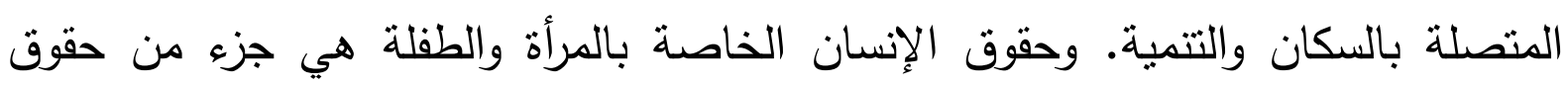

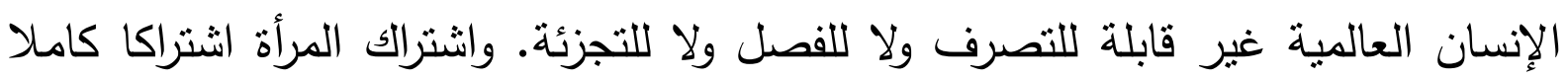
وعلى قدم المساواة في الحياة المدنية والثقافية والاقتصادية والسياسية والاجتماعية على

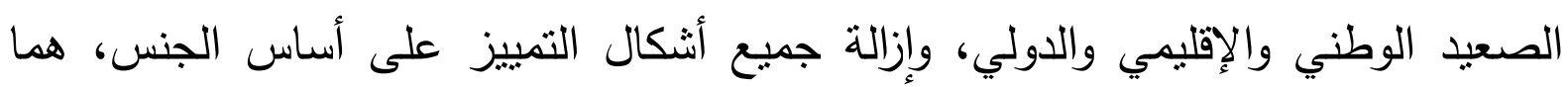

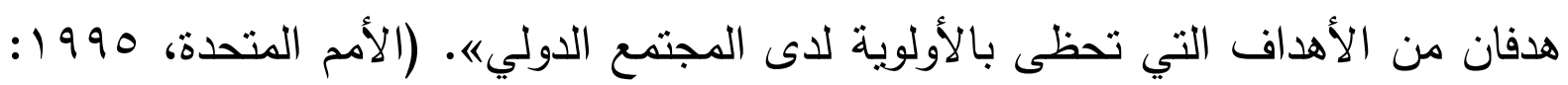
• (- 1 (1). إن الربط بين السكان وحقوق الإنسان والنمو الاقتصادي المطرد والتتمية المستدامة ومعالجة هذه القضايا بطريقة شمولية ومتماسكة كان أحد أهم إنجازات مؤتمر لهر الإنيان

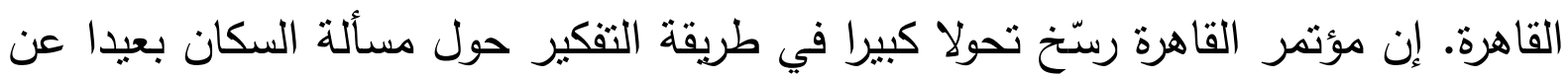

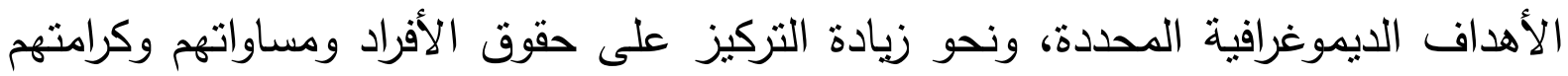
ورفاهيتهم خلال مرورهم بدورة الحياة. وقد ظهر ذلك جليا في إدراج مشروعات تتموية ووضع خطط قومية للدولة المصرية مراعية لمنظور النوع الاجتماعي تم التعبير عنه في

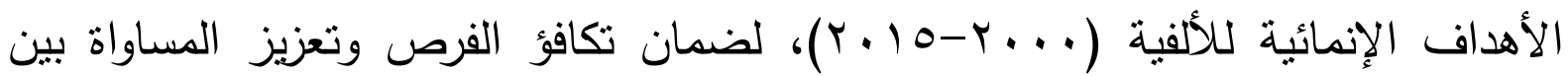
الجنسين وتمكين المرأة. أما التقرير الرسمي للحكومة المصرية المقدم إلى المؤتمر الدولي الرابع للمرأة (بكين 1990)، فإنه رغم الميل الواضح إلى التخفيف من حدة الأوضاع التي تعيشها المرأة المصرية وإبراز بعض الجوانب الإيجابية، اضطر إلى الاعتراف ببعض الأمور الجوهرية

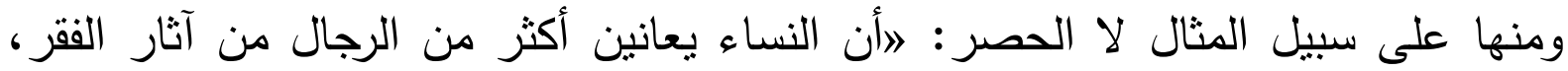

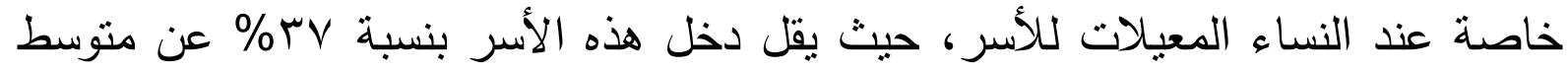


دخل الأسر التي يعولها رجل، وأن هناك تفضيلات لتتغيل الذكور عند أرباب العمل، وأن نسبة أمية المرأة الحضرية قد بلغت 0ء

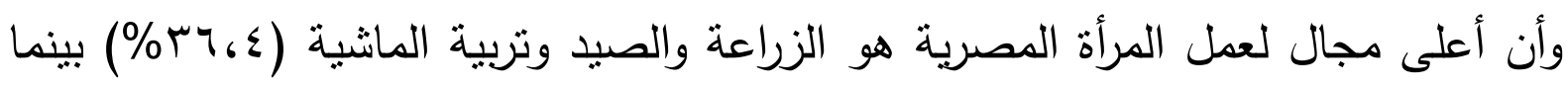

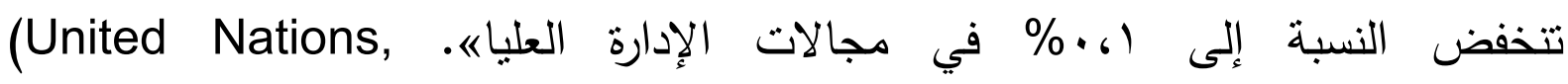

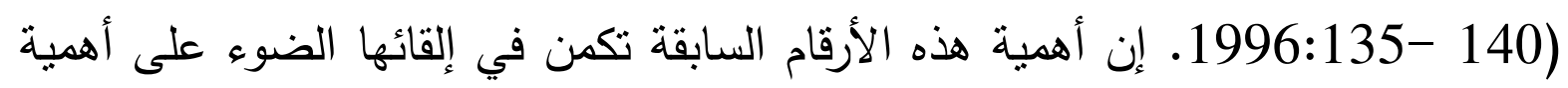

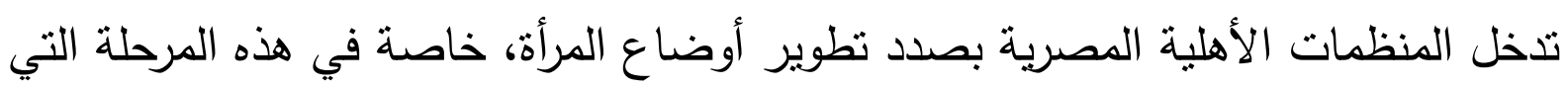

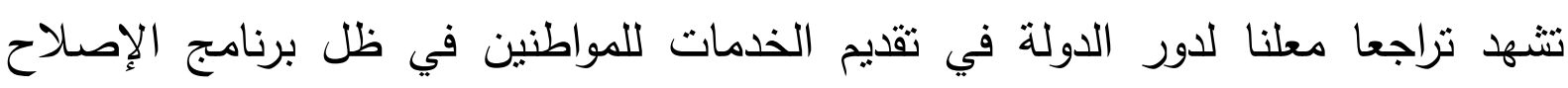

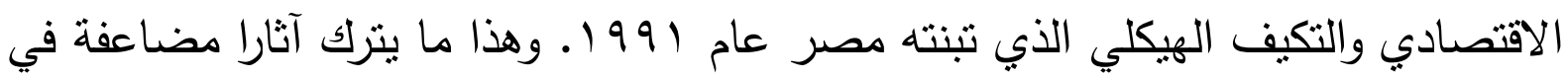
حالة النساء، نظرا للعوامل الثقافية والتاريخية الني لا تعبر أهمية متكافئة بالنسبة للجنسين.

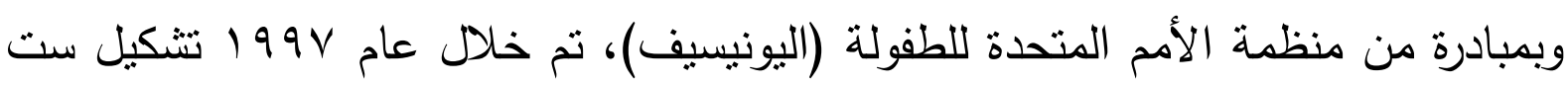

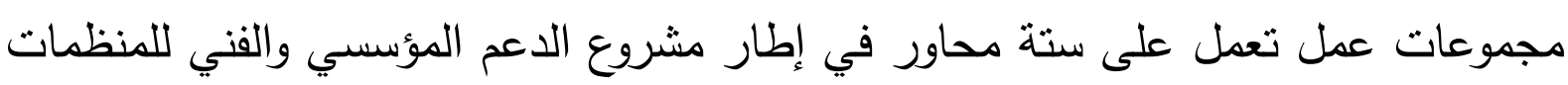
غير الحكومية لتتفيذ وثيقة بكين. والمحاور الست هي: الصحة الإنجابية، التمييز ضد

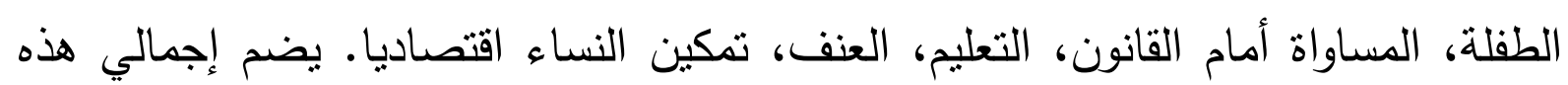

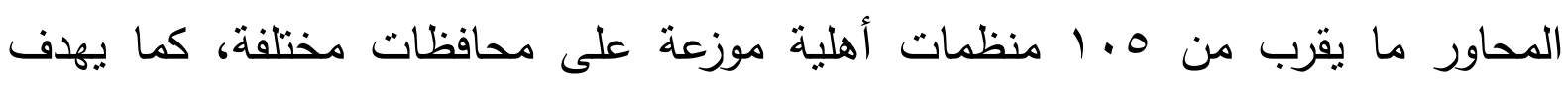
المشروع إلى خلق 1 شبكات من المنظمات التي تعمل على المحاور الدذكورة. هذا وتتميز

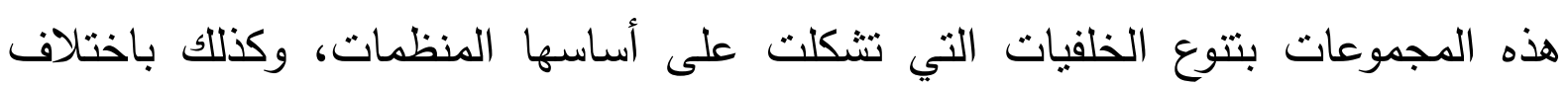

$$
\text { الرؤى والاقترابات. (سيدة محمود، د. تش). }
$$

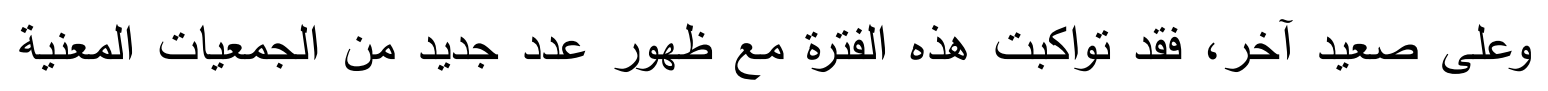

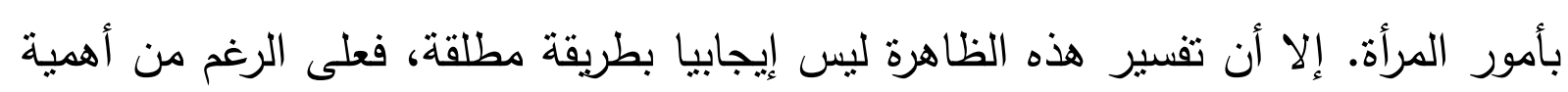

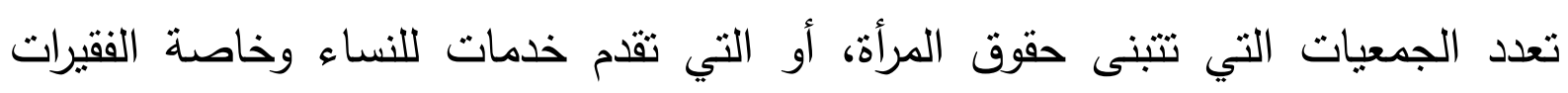

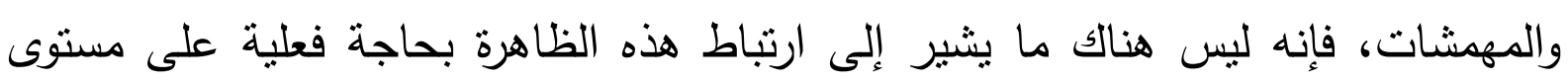

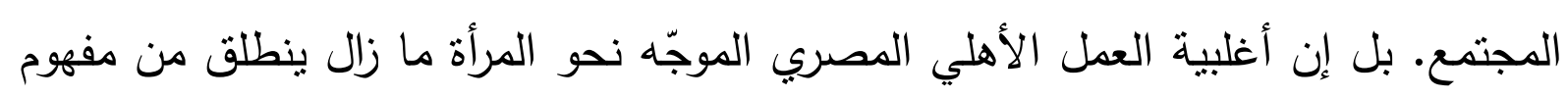

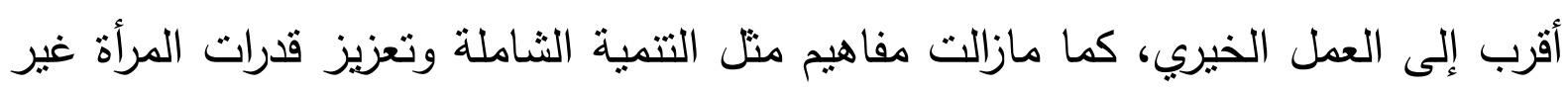

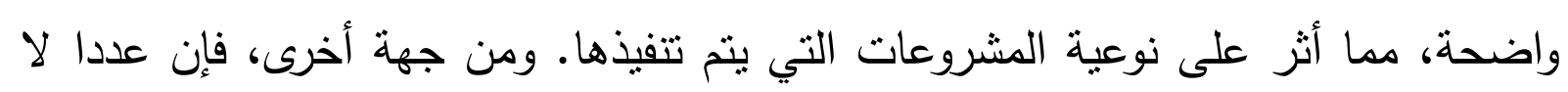

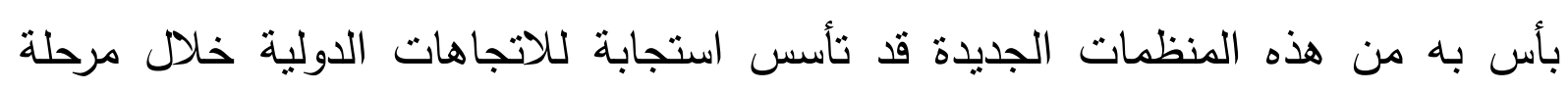

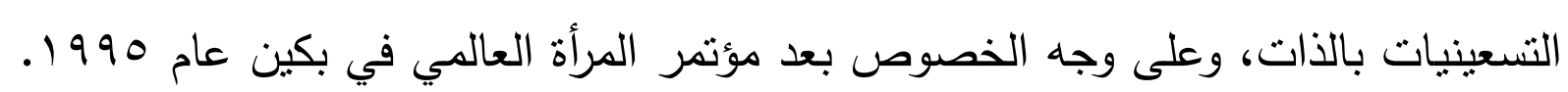

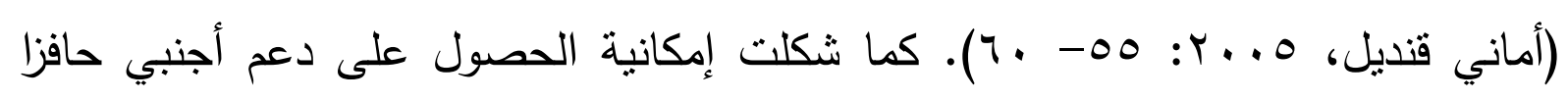


قويا لتكوين بعض هذه الجمعيات. وبالرغم من تزايد مصادر النمويل الأجنبي للجمعيات

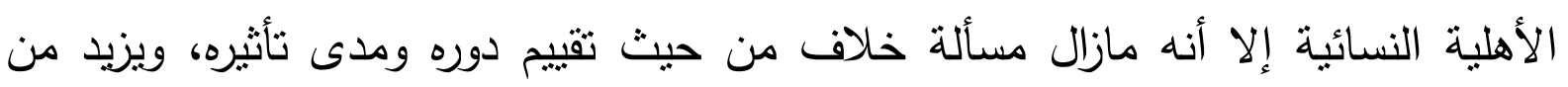

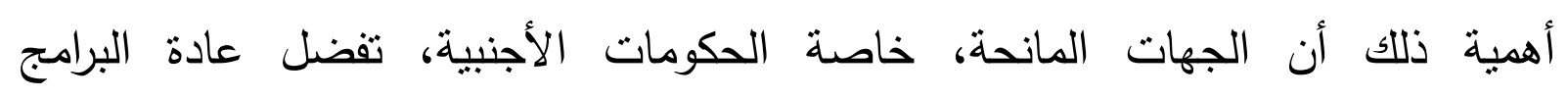

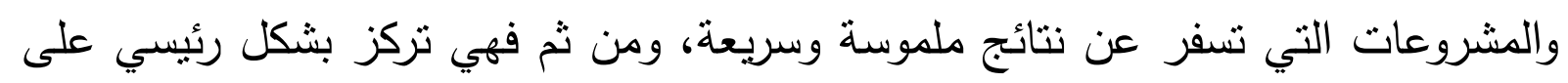

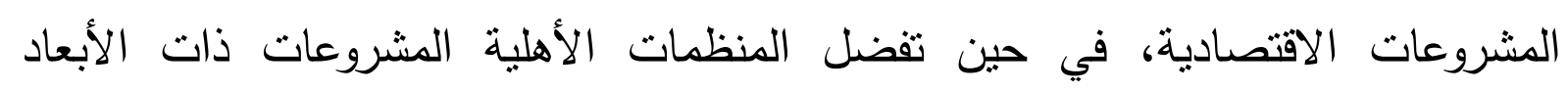

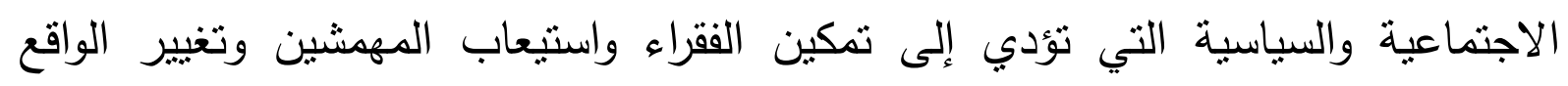

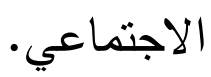
ـ تكوين لجان المرأة في الأحزاب السياسية، وعلى الرغم من اهتمامها بالنساء إلا أن عملها

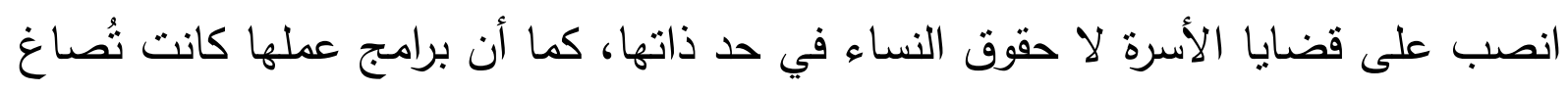

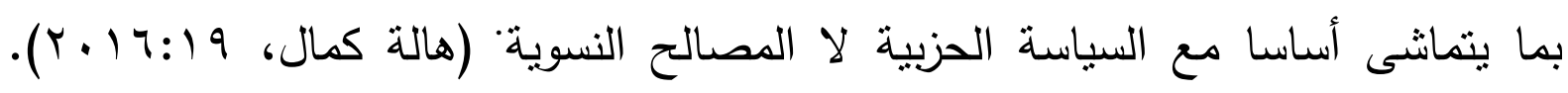

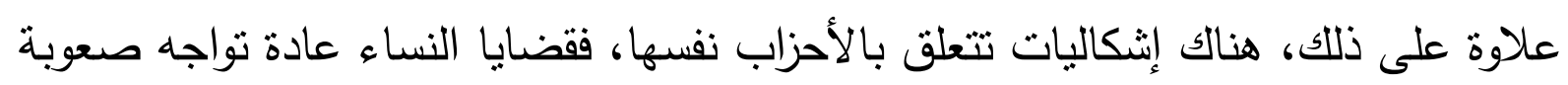

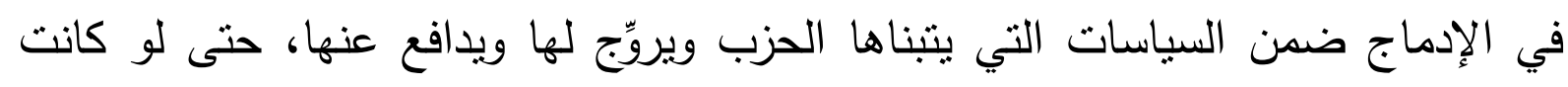

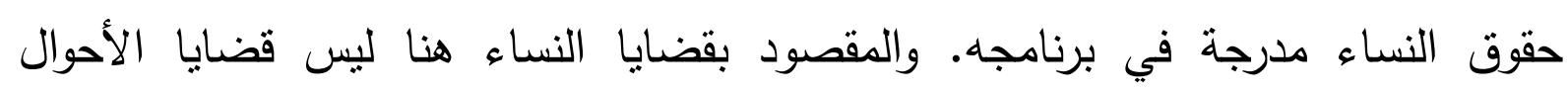

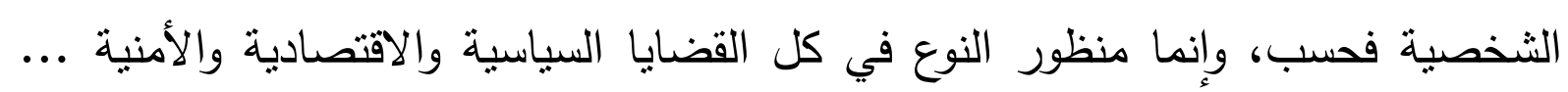

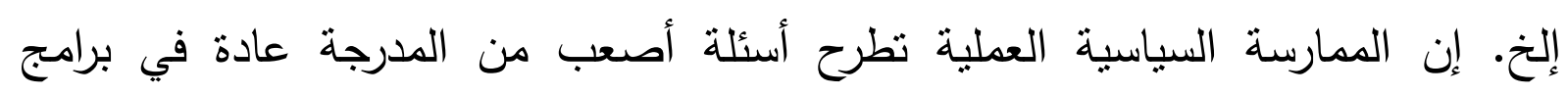

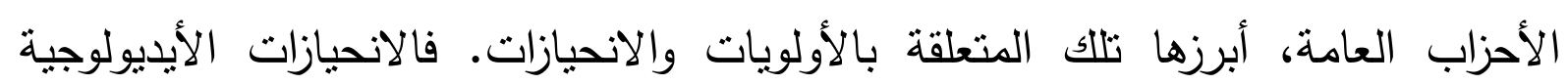

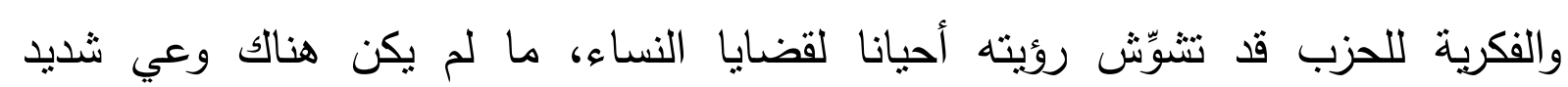

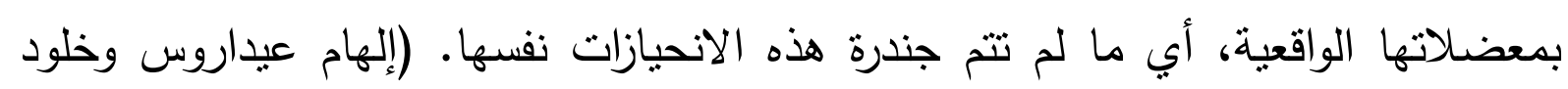

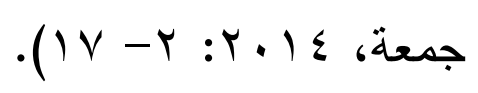

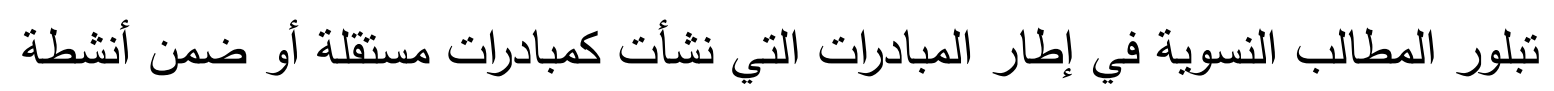

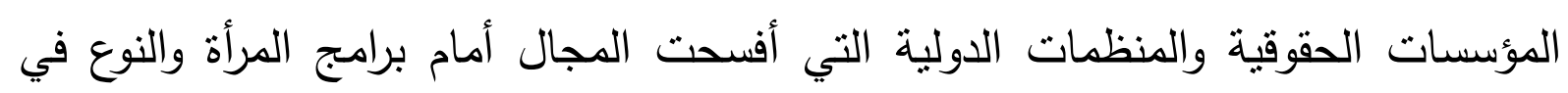

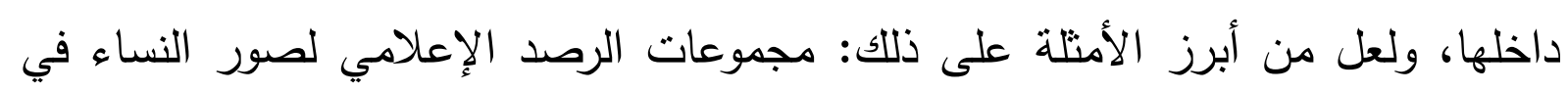

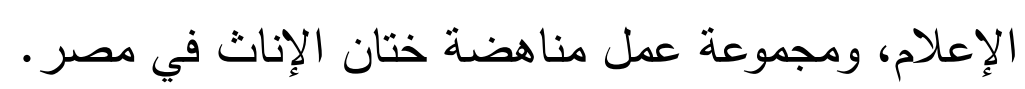

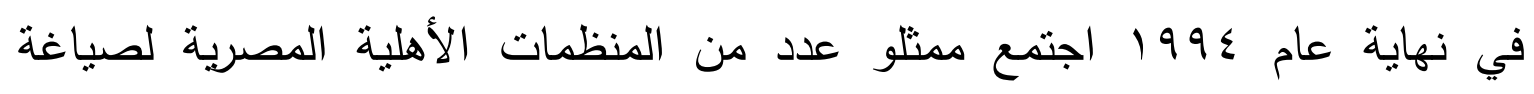

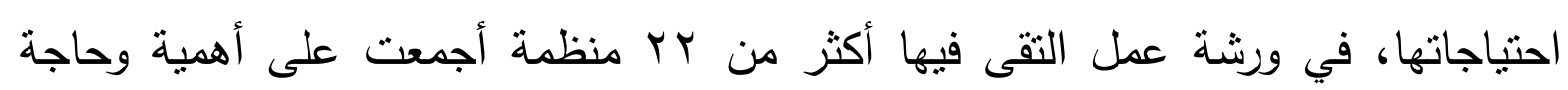

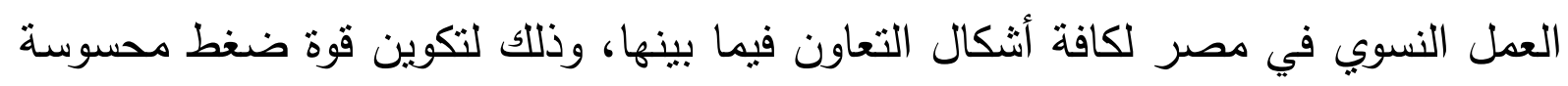
الأثر في قضايا المرأة عن طريق تقوية ودعم الكفاءات وتتمية قدرات المشاركين 
والمستهدفين لتطوير أدواتهم في تتمية المجتمع، متخذين من الالتزام بالاتفاقية الدولية لإلغاء كافة أثكال التمييز ضد المرأة أساسا فكريا لعملهم المشترك وكحد أدنى للمبادئ التي تجمع بانه بين المنظمات المشاركة في الملتقى. وفي نوفمبر عام 997 19، بدأ العمل بملتقى الهيئات لتتمية المرأة كمنظمة أهلية مشهرة وكثركة مدنية غير هادفة للربح بمشاركة إحدى عشرة منظمة أهلية شكلت مجلس الأمناء، تعمل في ضوء الاتفاقية الدولية لإلغاء جميع أنثكال

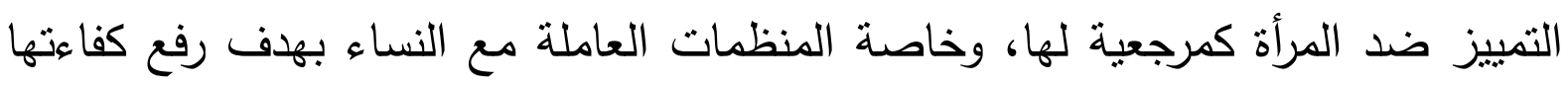

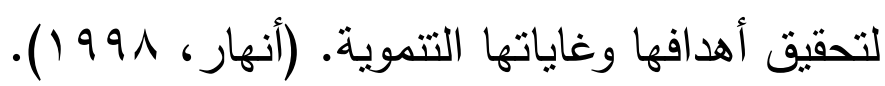
وقد أدت نسوية المجتمع المدني إلى تهديد سلطة الدولة في التعبير عن النساء، مما

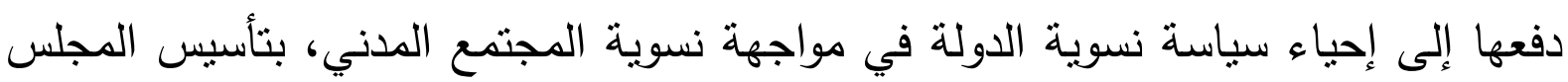

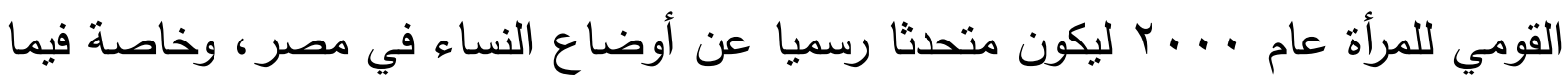
يتعلق بالتواصل مع المنظمات الدولية والحصول على دعمها بدعوى تتفيذ بنود الاتفاقات

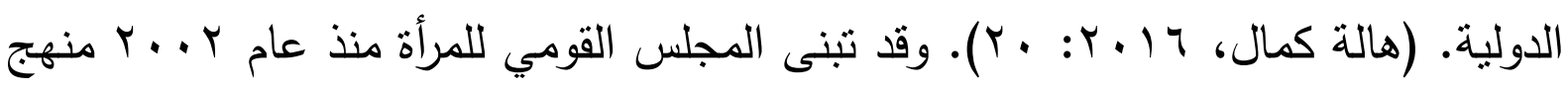
إدماج النوع الاجتماعي في الخطط القومية للدولة التي تضمنت احتياجات المرأة المصرية على المستوي المركزي (خطط الوزارات)، واللادركزي (خطط المحافظات) متضدنة عدة التهات قطاعات مثل: (التعليم - الصحة - البيئة - مكافحة الفقر والتمكين الاقتصادي - الرعاية

$$
\text { الاجتماعية - تكنولوجيا المعلومات - السياحة- التوعية والتدريب). }
$$

وفي عام . . . ب تم تحديث البنية الإجرائية لمنازعات الأحوال الثخصية وتخفيض تكلفة التقاضي وتيسير إجراءاته، بالإضافة إلى إقرار حق الخلع والطلاق من الزواج العرفي. تم

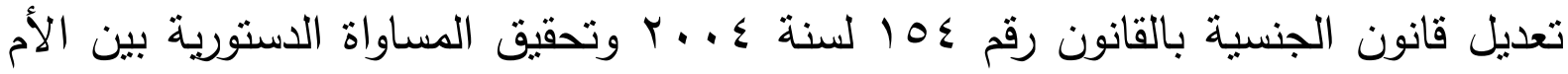
المصرية والأب المصري في منح الجنسية المصرية لأبناء المصرية المتزوجة من أجنبي. (ويكيبيديا الموسوعة الحرة، المرأة في مصر ). نشر المعرفة بمناهج البحث النسوي، وتتجيع الإبداع والنشر النسوي. المطالبة بحق النساء في حصة محددة لنظام الكوتا في التمثيل النيابي. (هند محمود وشيماء طنطاوي، 17 • Y: r r). وقد أدت استجابة النظام للحملات الداعية إلى تطبيق

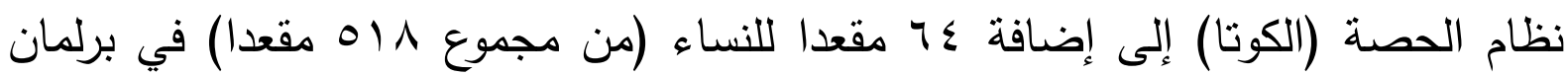
• ( . . . ولكن بدلا من أن نأني معبرة عن نساء المجتمع المصري، احتلت أغلبها نساء من دوائر الحكم وعضوات الحزب الوطني الحاكم والمجلس القومي التابع لرئاسة الجمهورية. فقد 
أدى تلاعب الدولة بنظام التمثيل البرلماني للنساء في انتخابات عام • ـ . البرلمانية إلى تتكيك الحركة النسوية في جدوى نظام حصة النساء في التمثيل السياسي. وسعى الناشطون إلى إلغاء نظام الكوتا النسائية الخاص بالأنظمة السابقة، آملين في استبدالها ببديل أفضل لتعزيز المشاركة السياسية للمرأة بدلا من ذلك. قامت ثورة يناير 11 بـ ضمن حركات الربيع العربي ضد الأنظمة المستبدة في الدول العربية، وشاركت الفتيات في الوقفات الاحتجاجية التي مهدت لهذه الثورة ولعبن دورا أساسيا على مواقع التواصل الاجتماعي (فيسبوك وتويتر)، المحفّز للثورة ومحركها الأساسي. وانطلقت أولى مظاهرات منددة بانتهاكات وزارة الداخلية وتعذيب المواطنين داخل أقسام الثرطة وفساد حكم مبارك وحاثيته يوم هب يناير • وأدهشت المرأة المصرية العالم بدورها

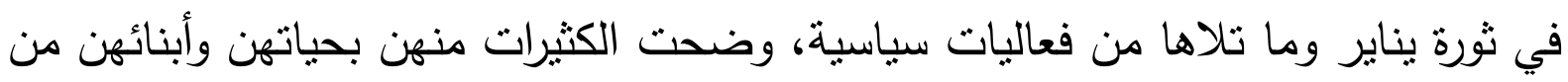
أجل تحقيق تطلعات المصريين في الحرية والكرامة والعدالة الاجتماعية. أهم شخصيات وأحداث الموجة الرابعة: إن العصر الرقمي، وما نتج عنه من ظهور العديد من المواقع والثبكات الإككترونية وصفحات التواصل الاجتماعي، وفّر منصة عظيمة التأثثر للقيادات النسوية لتحقيق مزيد من التقاعل مع القضايا المجتمعية، وأتاح لهن قدرة أكبر على ترك بصماتهن على حاضر ومستقبل بلدانهن، ووفّر لهن المساحة المناسبة للتعبير عن آرائهن ونظرتهن إلى القضايا المحلية والدولية بحرية ومسئولية.

تتكيل مجموعات مستقلة مناهضة للتحرش تتظدّم نفسها بحيث تنواجد في أماكن التجمعات خلال الاحتجاجات والاحتفالات. وهي مجموعات تضم نساء ورجالا مدربين على التعامل مع الاعتداءات الجنسية من خلال آليات الاشتباك والأمان، مع توفير الدعم الطبي والنفسي والقانوني اللازم. وقد تطورت حركة مناهضة التحرش الجنسي خلال السنوات الماضية، وتكونت داخل بعض المؤسسات النسوية والحقوقية برامج لمواجهة العنف الجنسي، كما اكتسبت قدرا من المصداقية بما جعل جامعة القاهرة على سبيل المثال تستعين بخبراتها في تكوين وحدة لمناهضة التحرش والعنف داخل الجامعة. وقد قامت ناشطات نسويات مصريات منل: أمل المهندس، ومزن حسن وهند زكي، وداليا عبدالحميد بتسليط الضوء على تلكك القضية وتحليلها والكتابة عنها وطرح سبل مواجهتها. (هند ذكي وداليا عبدالحميد،

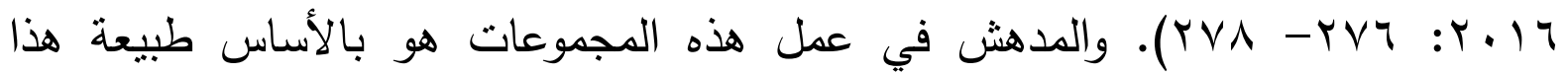


العمل، فنحن نشه لأول مرة حراكا حول قضايا تتتمي لصلب المسألة النسوية تطرحها مجموعات نتكلت بشكل تطوعي تماما وتمارس عملا جماهيريا شديد الأهمية والصعوبة، ولم يكن على أجندة القوى الثورية نفسها حتى وقت حوادث الاغتصاب الجماعية في التحرير وحتى بعدها. وعلى الرغم من عدم طرحها خطابا نسويا واضحا في بعض الأحيان، فإن نضالها على الأرض شكّل في حد ذاته ذروة جديدة تماما في العمل النسوي الراديكالي تمنل في عزم وتصميم شابات وشباب بالغي البسالة قرروا استخدام أجسادهم كدروع بشرية لإنقاذ

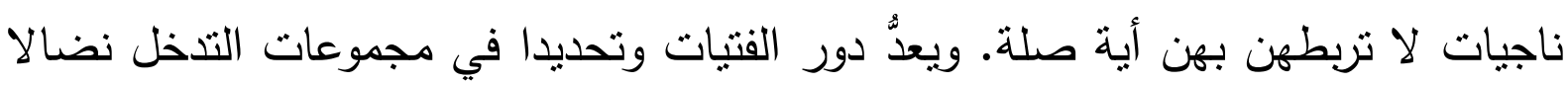
نسويا راديكاليا وأصيلا مستوحى من حالة نضالية طرحتها الثترة، وإن تجاوزتها لتطرح أسئلة عميقة تتعلق بالجسد وحرمته، وحق وجود النساء في المجال العام.

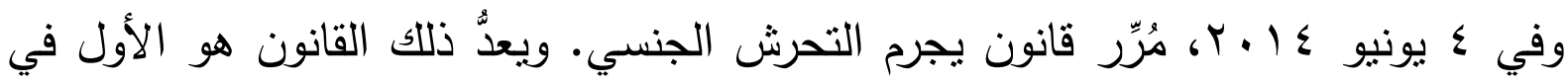

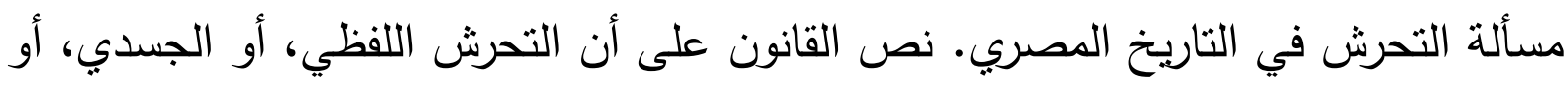
السلوكي، أو الهاتفي، أو عن طريق الإنترنت، يمكن أن يؤدي لعقوبة الحبس فيما بين 7

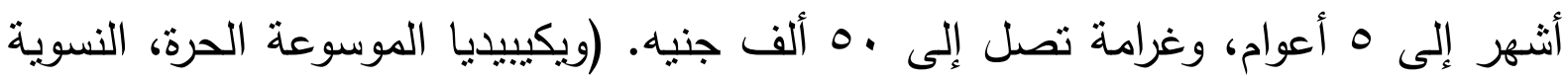
في مصر). أما المجال الآخر الذي شهر عملا نسويا منظما فقد تمثل في عملية كتابة الدستور الجديد، حيث قامت مجموعة من المنظمات والمؤسسات النسوية بتثكيل تحالف فيما بينها

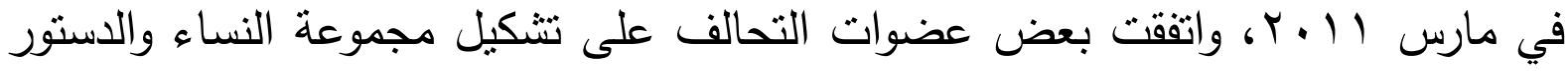
في مايو 11/Y تتضمن ممثلات عن بعض المنظمات النسوية والمؤسسات الحقوقية المصرية جنبا إلى جنب مع ناشطات وباحثات نسويات. هذا وقد تم عمل المجموعة على ثلاث مراحل، وتوجهت بمطالبها إلى الجهات القائمة على صياغة دستور مصر ، بما في

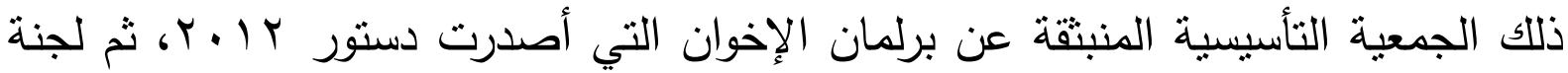

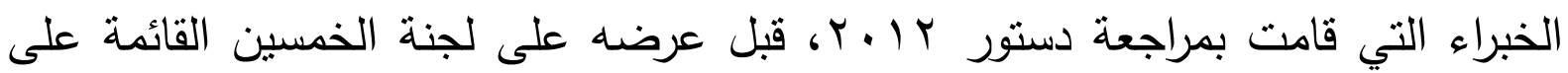

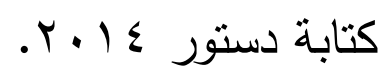

وقد تضمنت مراحل عمل مجموعة النساء والدستور ما يلي: أولا، دراسة التاريخ الدستوري المصري وحقوق النساء فيه، وتتبع المواد الخاصة بالنساء والأسرة وقضايا الجندر في عدد من دساتير العالم. ثانيا، تحديد مطالب النساء وحقوقهن الواجب إدراجها في الدستور الجديد، مع صياغتها صياغة قانونية. ثالثا، التواصل مع القوى السياسية واللجان المشاركة في كتابة $\varepsilon$ 
الدستور لطرح مطالب النساء والقيام بحملة لإدراجها ضمن مواد الدستور الجديد. (هالة

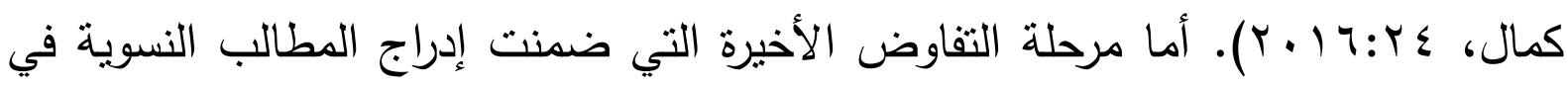

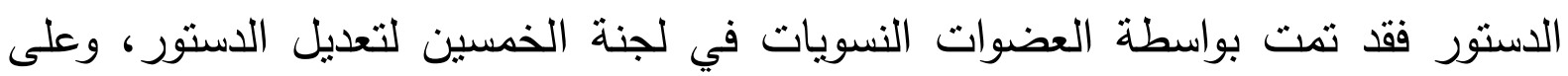
رأسهن هدى الصدة، التي نركز النقاش فيها حول المادة 11 من الدستور المعروفة بكونها

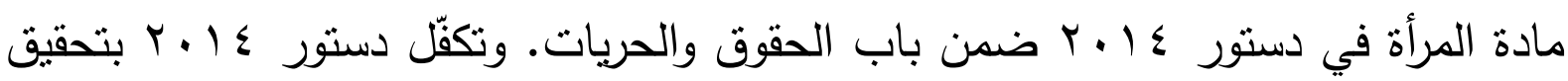
المساواة بين المرأة والرجل في جميع الحقوق المدنية والسياسية والاقتصادية والاجتماعية والتقافية طبقا للمادة 1/ من الدستور التي تتص على الآتي: لاتعمل الدولة على اتخاذ التدابير الكفيلة بضمان تمثيل المرأة تمثيلا مناسبا في المجالس النيابية، على النحو الذي يحدده القانون، كما تكفل للمرأة حقها في تولى الوظائف العامة ووظائف الإدارة العليا في الدولة والتعيين في الجهات الهيئات القضائية، دون تمييز ضدها. وتلتزم الدولة بحماية المرأة ضد كل أثنكال العنف، وتكفل تمكين المرأة من التوفيق بين واجبات الأسرة ومتطلبات

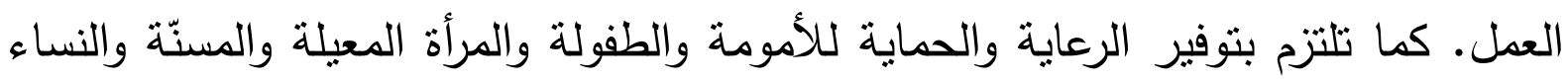
الأثد احتياجاه. (دستور مصر). إن الحقوق التي أقرها الدستور المصري الجديد للمرأة غير

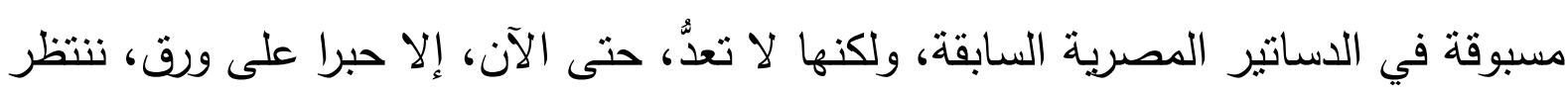
تطبيقه من خلال تشريعات تصدر قريبا وتدابير من الدولة تكفل هذه الحقوق. استطاعت المرأة أن تحرز مكانا في النقابات المهنية حيث حصلت المحامية سامية سعيد على مقعد نقيب المحامين بمحكمة منيا القمح بالثرقية, حيث تفوقت على منافسيها الثلاثة من الرجال, كما حققت المرأة في عام 11 بـ إنجازات علمية متميزة منها على سبيل المثال حصول الباحثة زينب أبو النجا على لقب نساء في الكيمياء، حيث ورد اسمها ضمن القائمة التي أعدتها اليونيسكو في إطار مبادرتها لجعل عام || بـ هو عام الكيمياء، وذللك بالتزامن

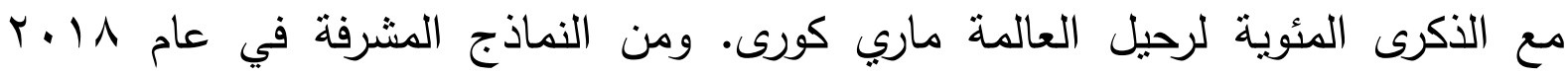
حصلت مايا مرسي رئيسة المجلس القومي للمرأة على جائزة امرأة العقد في التمكين والحياة العامة بالهند، وتم تكريم السفيرة منى عمر من اتحاد قيادات المرأة العربية. وفى هذا السياق يمكن الإشارة أيضا إلى الأحزاب النسائية التي تكونت بعد الثثرة, منها ما يهدف بالأساس لاعم قضايا المرأة, ومنها ما يمارس العمل السياسي بشكل عام، ولكن التهن ييدو فيه التمثيل النسائي واضحا ومؤثرا، حيث تأنى المرأة على قمة الهرم التنظيمي لهذه

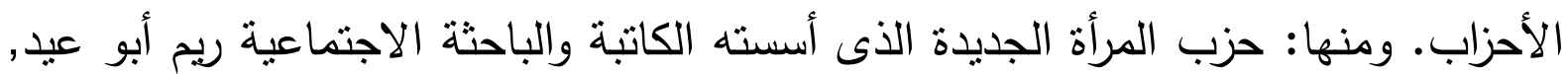


وحزب المساواة والتتمية برئاسة الفنانة تبسير فهمى, وحزب الحرية والانتماء برئاسة المحامية

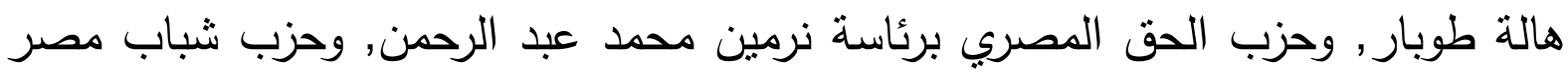
الجمهوري برئاسة مشيرة أبو غالى عضو مجلس محلى حلوان, وحزب الحق برئاسة مريم

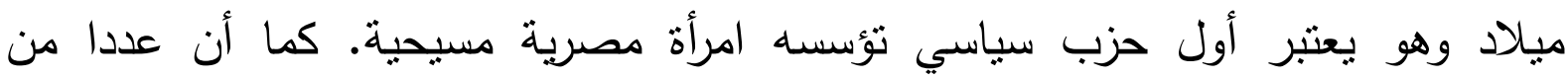
الأحزاب الأخرى غير النسائية حرص على وجود شخصيات نسائية في المناصب القيادية العليا، ولعل أبرزها: انتخاب هالة شكر الله رئيسة لحزب الدستور ، واختيار هدى الصدة نائبة لرئيس الحزب المصري الديمقراطي، وكريمة الحفناوي كأمينة عامة للحزب الاشتراكي المصري، بالإضافة إلى العديد من الرموز النسائية والنسوية النشطة في لجان الأحزاب الجديدة.

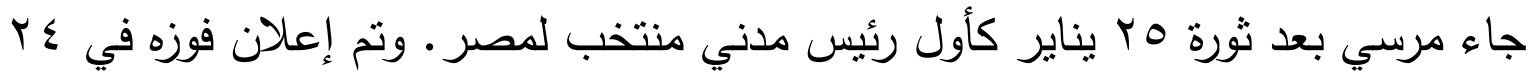

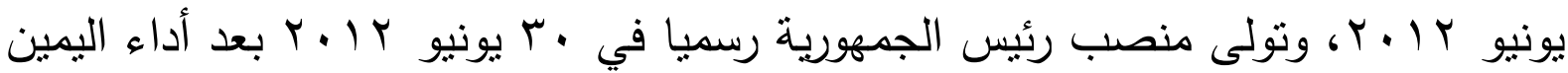
الجمهورية. وفي البداية فقد ضَعُفَ تمثيل المرأة في الفريق الرئاسي، الذي اقتصر على ثناث سيدات فقط، وهن باكينام الشرقاوي، والكاتبة الصحفية سكينة فؤاد وأميمة كامل القيادية بحزب الحرية والعدالة قبل أن تستقيل سكينة فؤاد، ويتقلص العدد لاثتتين فقط، وأتبع ذلك

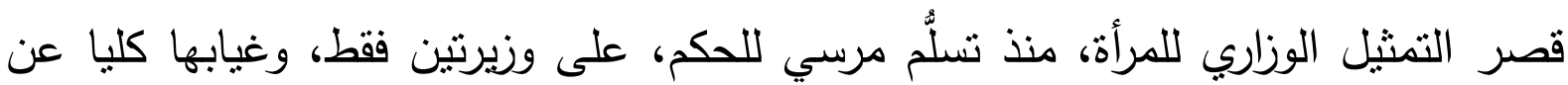
شغل منصب محافظ، وإقصاؤها من عضوية المحكمة الدستورية العليا بعد استبعاد المستشارة تهاني الجبالي التي كانت أول امرأة مصرية تنولى مهنة القضاء في الحقبة المعاصرة، ومازالت المرأة المصرية التي احتلت المنصب القضائي الأعلى في تاريخ مصر . مشهد يسوده التهميش والإقصاء والقهر والتمييز والظلا، جميعها سمات رسمت معاناة المرأة المصرية خلال تلك الفترة، حيث تعرضت مكتسبات المرأة المصرية إلى ردة بعد أن كانت

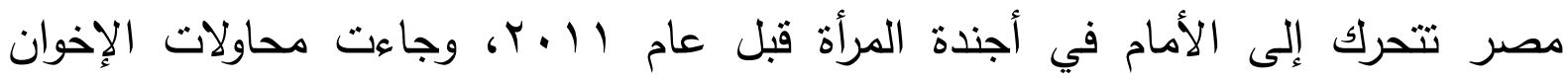
المستمرة للانقضاض على حقوق المرأة. وقد ظهرت النوايا الأولى لإقصاء وتهميش المرأة منذ بداية حكم الجماعة، فمنذ بداية تشكيل الجمعيتين التأسيسيتين لوضع دستور البلاد، تم تمثيل V سيدات فقط بتلك الجمعيتين وتتتمين لتيار الإسلام السياسي من إجمالي .. عضو، كما كن عضوات بالبرلمان المنحل بالمخالفة لحكم قضائي واجب الاحترام من محكمة القضاء الإداري بعدم جواز عضوية أعضاء البرلمان في التشكيل الخاص بالجمعية التأسيسية للاستور، تناها خروج مشروع قانون الانتخاب خاليا من رغبة حقبقية في مشاركة 
المرأة في البرلمان، وتعدد إقصائها عن الانتخابات، وبات يطلق على النساء المنتسبات

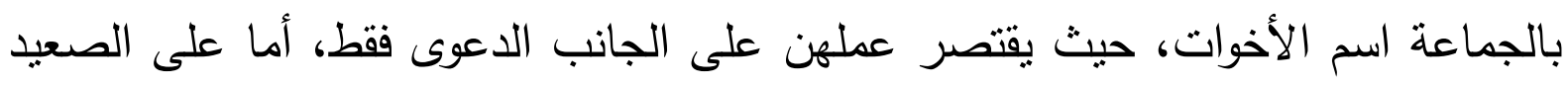

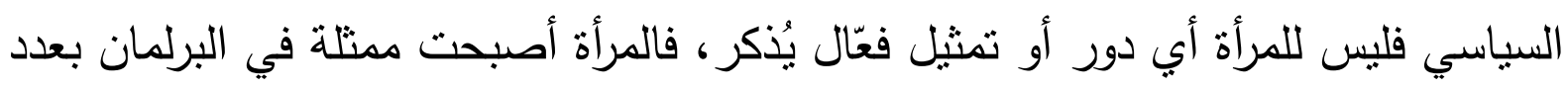

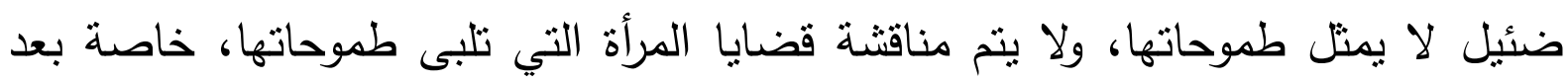

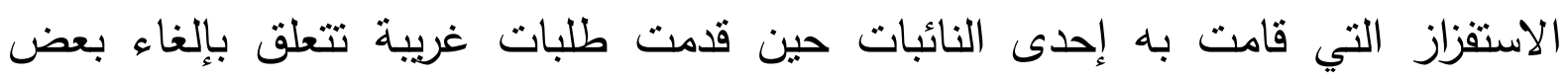
القوانين الخاصة بالتحرش الجنسي، وإلقاء التهم على المرأة كونها هي الجاني والمسئول الأول عن إنارة الرجل واستفزازه. كما سعت بعض التبارات داخل البرلمان لتعديل قوانين

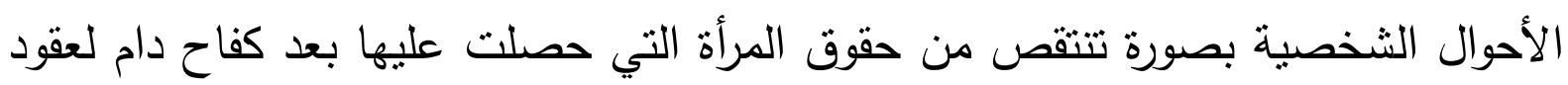

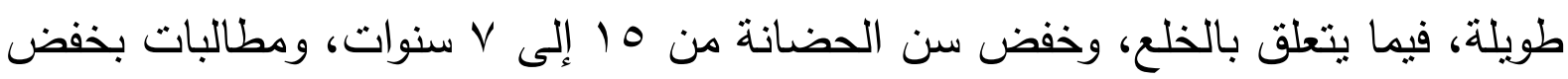
سن الزواج، كما ظهرت دعاوى لإجراء ختان الإناث بالهجان ببعض القرى. وظهرت أيضا

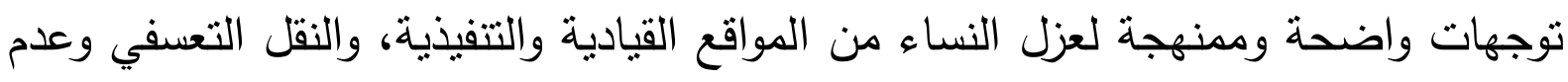

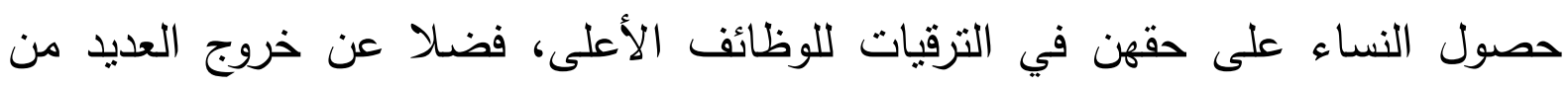
التصريحات من قبل بعض التيارات والأحزاب ذات النوجه الديني لنقييد دور المرأة داخل المنزل فقط، وهذا مثّل انتكاسا شديدا لحقوق المرأة، وخرقا للاساتير والقوانين الوطنية

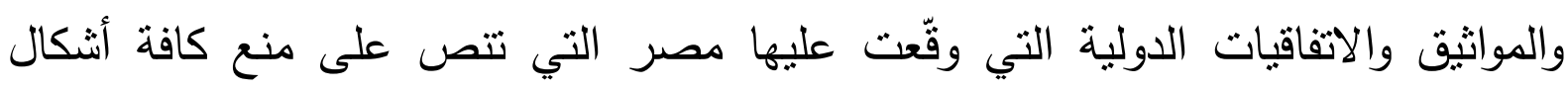

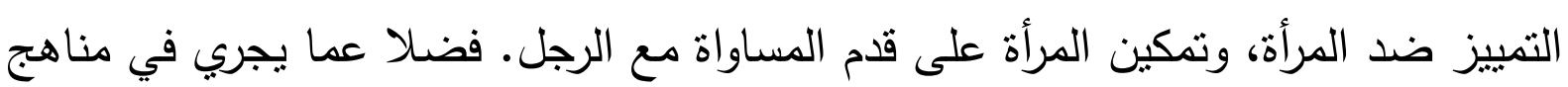
التعليم من تغييرات عديدة، حيث تمت إزالة صور الرائدات النسويات اللاتي لا برتدين حجابا لتابيا من كافة المناهج المقررة على طلاب المدارس، في تزوير واضح وعنصري للناهج التاريخ واللغة العربية، فضلا عن إلغاء فصل كامل من مناهج التاريخ حول إسهام المرأة المصرية في ناريخ الحركة الوطنية.

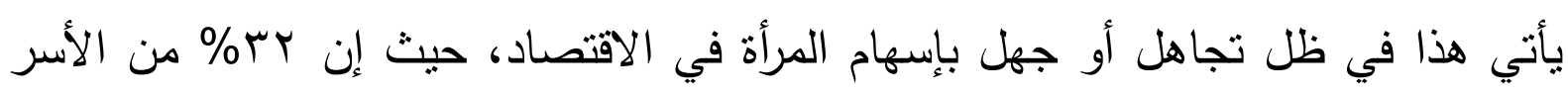

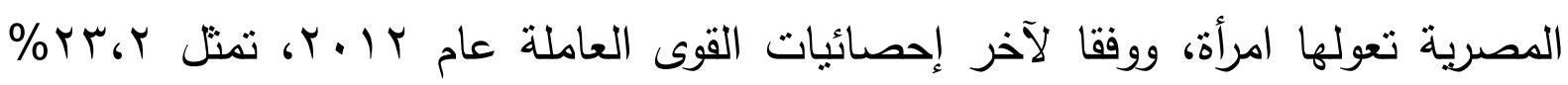
من قوة العمل في القطاع الرسمي و •v \% في القطاع غير الرسمي. (ويكيبيديا الموسوعة الحرة، المرأة في مصر ). وبسبب نلك الأحداث جميعا ونتيجة لهذا التهميش والإقصاء المتعد، انتفضت المرأة المصرية عدة مرات وخرجت في مظاهرات في جميع المبادين المختلفة للمطالبة بإسقاط نظام ظالم، ولم تمنعها حملات التحرش الممنهجة ضد المنظاهرات من التعبير عن غضبها، 
حتى جاء يوم • ب يونيو r| ب الذى شهد خروج ملايين المصريين في ميدان التحرير وميادين مصر المختلفة بالمحافظات، تتصدرهم جموع نساء مصر من جديد، معلنة رفضها

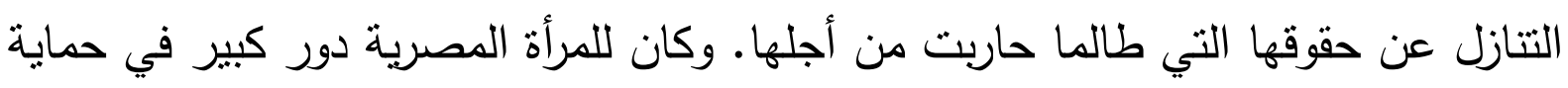

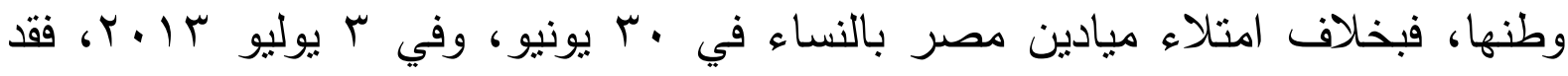

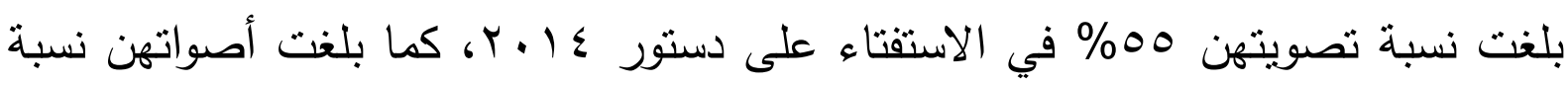

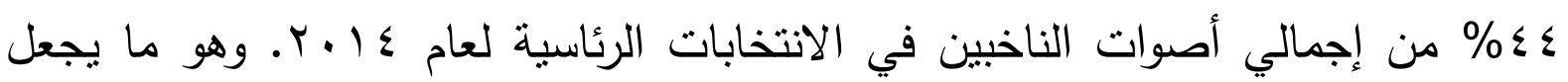
المرأة كتلة حرجة في التصوبت في الانتخابات. وجاء أول دليل عملي على احترام القيادة السياسية الجديدة للمرأة وتقديرها من خلال فلانل اعتذار الرئيس السيسي للسيدة التي تعرضت لتحرش جنسي بميدان التحرير أثناء الاحتقالات بمناسبة تتصيبه رئيسا للجمهورية في عام ع ( ب.، حيث قام الرئيس الجديد للبلاد بزيارتها بالمستشفى وتقديم باقة من الزهور لها مع الوعد بأن الدولة لن تقبل منل هذه الحوادث في المستقبل، وسوف تتخذ إجراءات صارمة. تحقق للمرأة المصرية مكتسبات عديدة وهامة على صعيد تمكينها من الوصول إلى مواقع صنع القرار، ويذكر أنه نم تعيين أول امرأة محافظا وأول امرأة مسنتارا للأهن القومي لرئيس

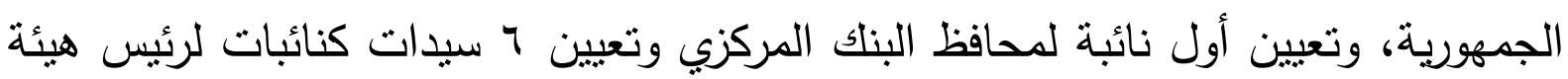
قضايا الدولة، وأول سيدة قاضية تتولى رئاسة محكمة في مصر، وتعيين ه نائهات

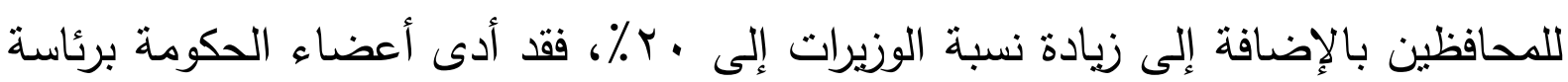

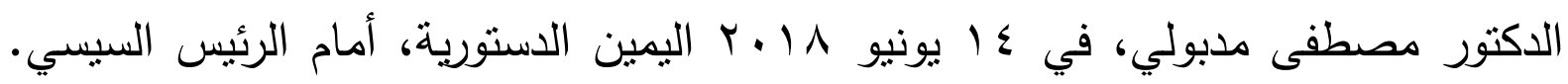
وتضمنت ^ وزيرات مما يعكس التوجه لإتاحة الفرصة للسيدات لتولى مناصب قيادية.

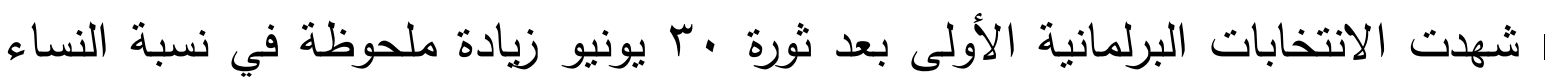

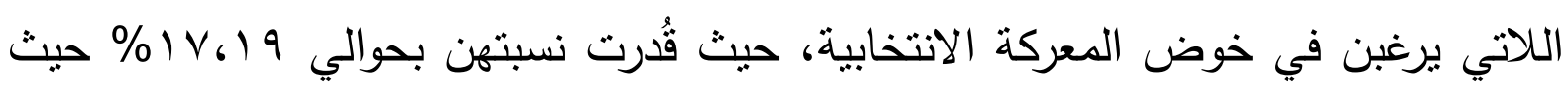

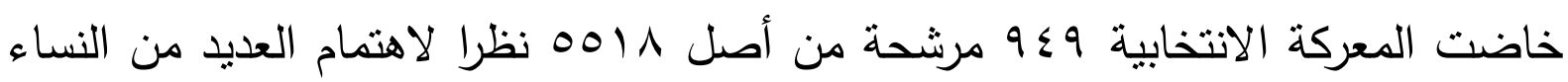

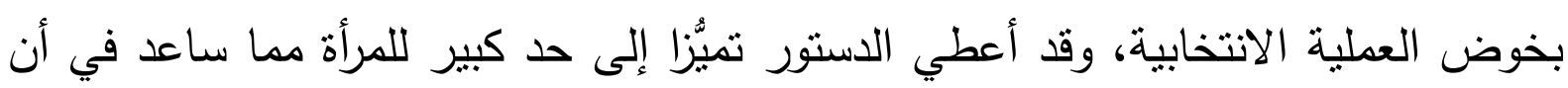

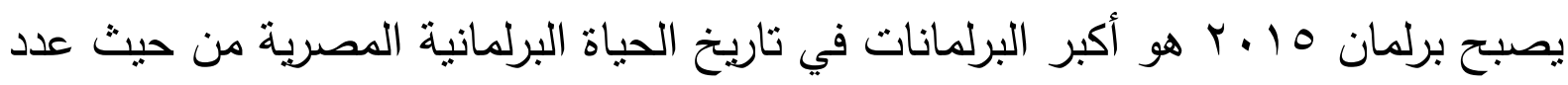

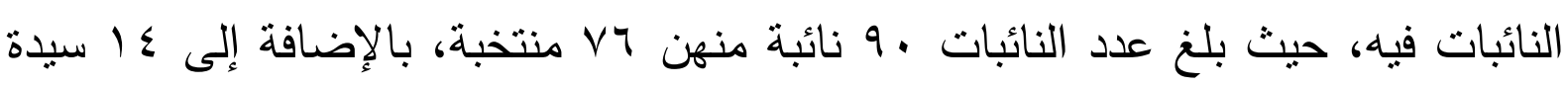

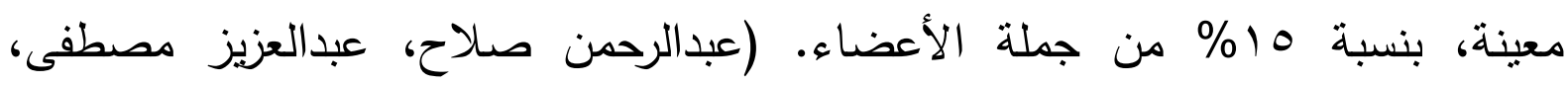

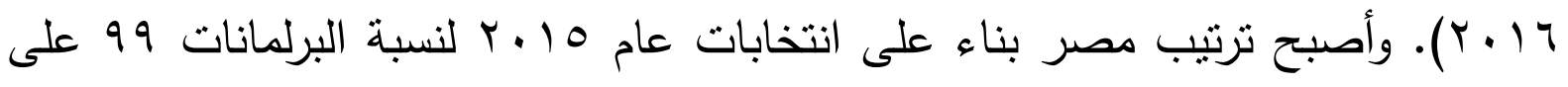




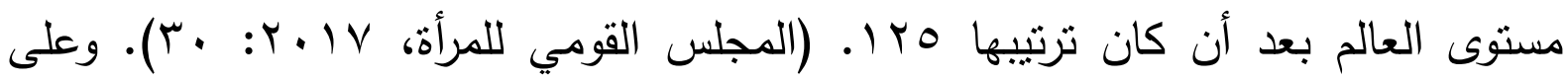
مستوى المحليات خصصت المادة •11 من الدستور للنساء ربع عدد المقاعد في المجلس المنتخب لكل وحدة محلية في مختلف مستويات الحكم المحلي، من المحافظة إلى المركز ثم المدينة وحتى مستوى القرية. (دستور مصر ).

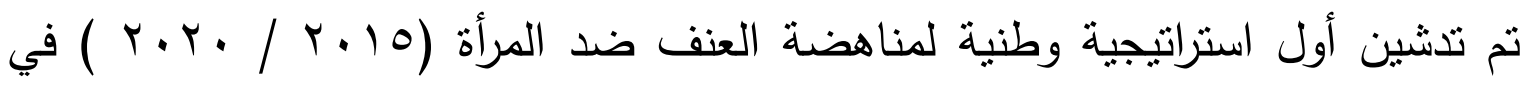

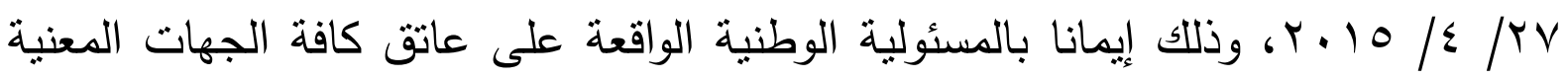

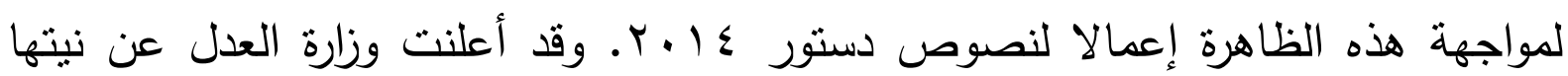

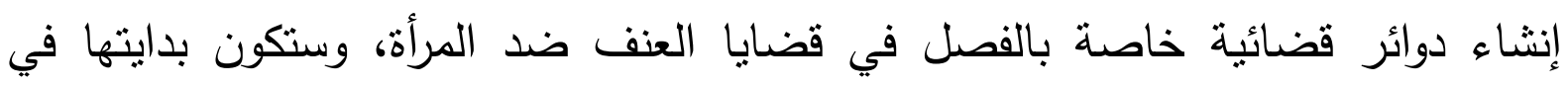
المحاكم الابندائية، ومهنتها الأساسية الفصل في كل القضايا التي لها علاقة بقضايا

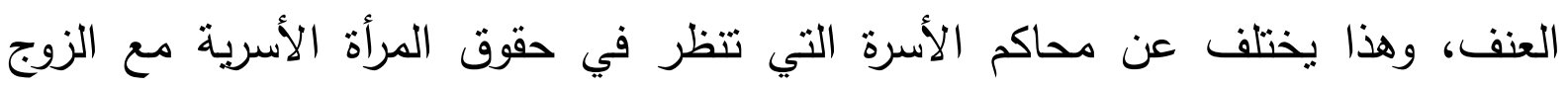

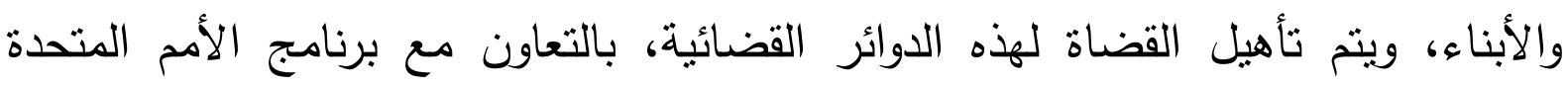
الإنمائي، والمجلس القومي للمرأة، ووزارة العدل. أنت الخطة الوطنية لمناهضة ختان الإناث (الاستراتيجية القومية لهناهضة ختان الإناث

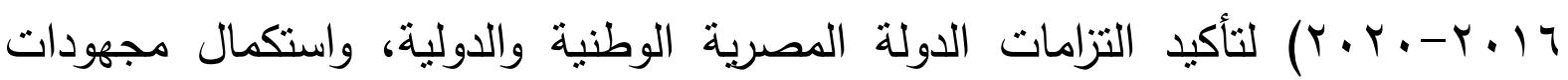

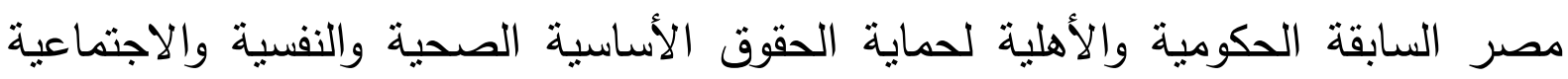
للطفل والمرأة والأسرة المصرية.

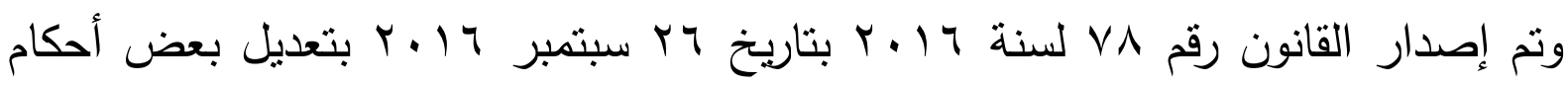
قانون العقوبات الخاصة بختان الإناث، حيث تم تعديل نص المادة r Y مكرر من قانون

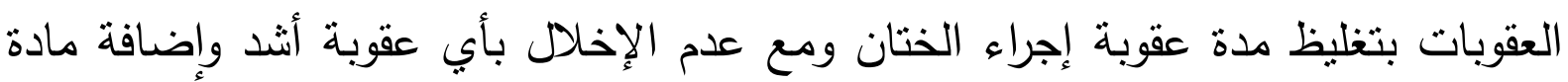

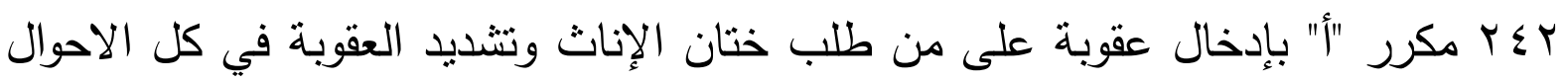

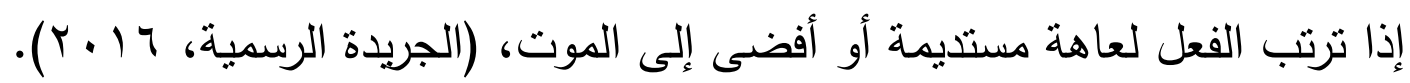

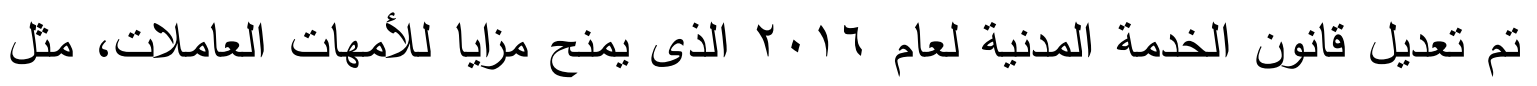

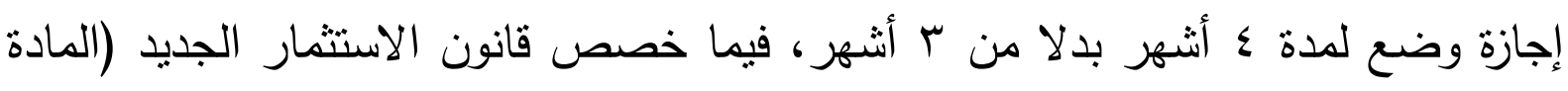

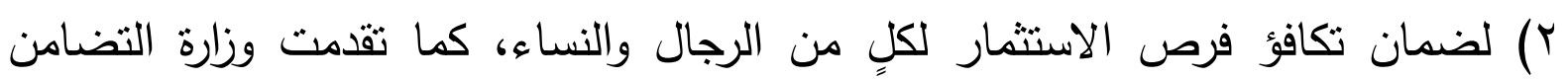
الاجتماعي بقانون لتغليظ عقوبة الامتناع عن النفقة، كذلك حرص المجلس القومي للمرأة

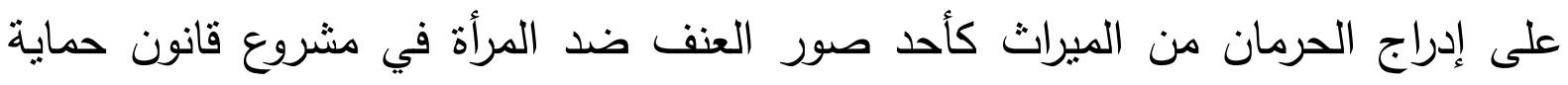
المرأة من العنف المعد من المجلس منذ عام ع ا.ـr، واتصالا بذلك قدم المجلس في يونيو 
10 ب إلى مجلس الوزراء مقترح تجريم منع تسليم أحد الورثة، ذكرا أو أنثى، حقه في

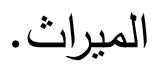

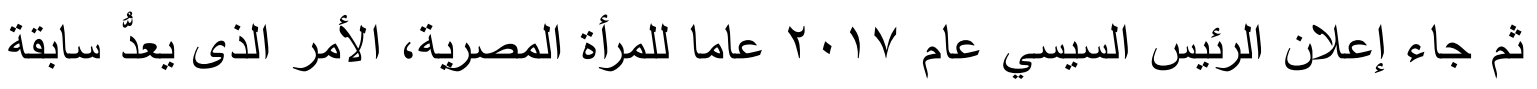

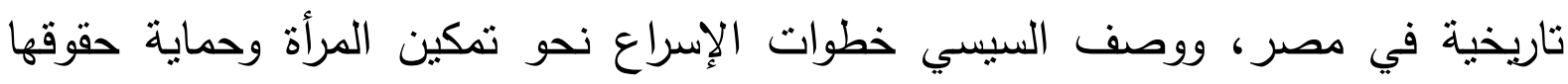

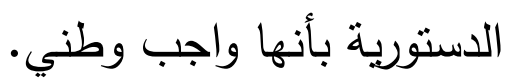
هي أعقاب إعلان الرئيس السيسي عام Y. V. Vام المرأة المصرية، أطلق المجلس

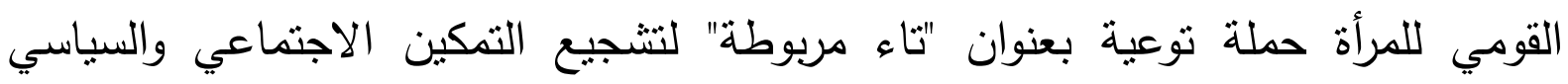

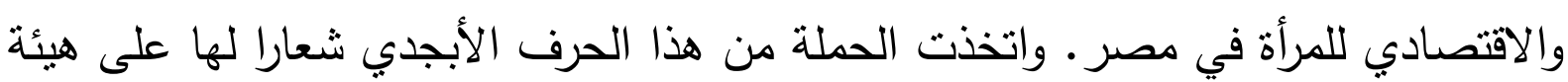

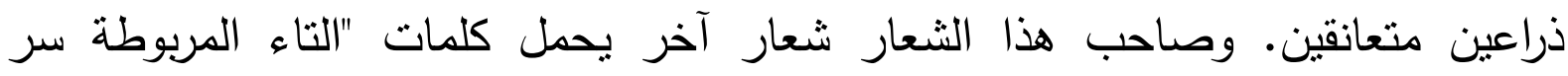

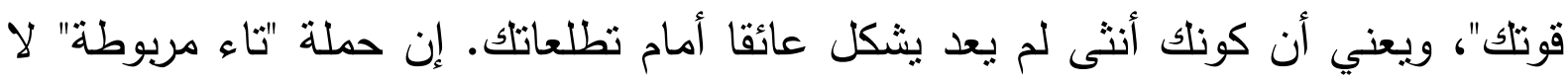

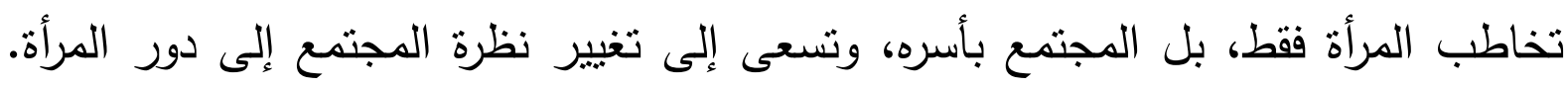

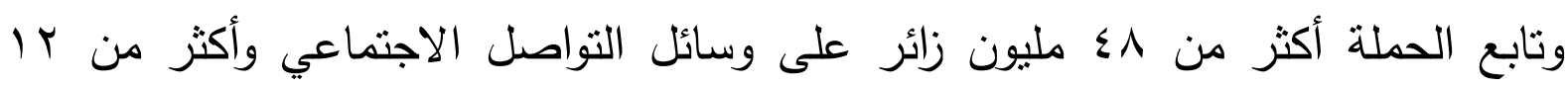
مليونا على شاثنات التليفزيون. وما يؤكد التزام القيادة السياسية بتحقيق تمكين المرأة المصرية، اعتماد الرئيس السيسي

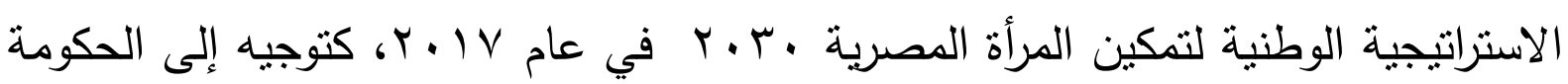

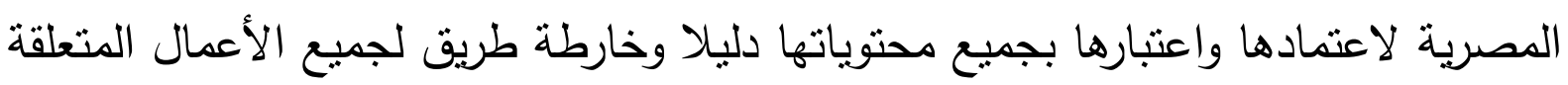

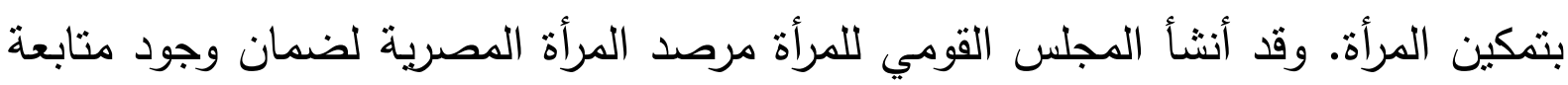
للاستراتيجية الذى يتابع تتفيذها من خلال تطبيق آليات الرصد والتقييم.

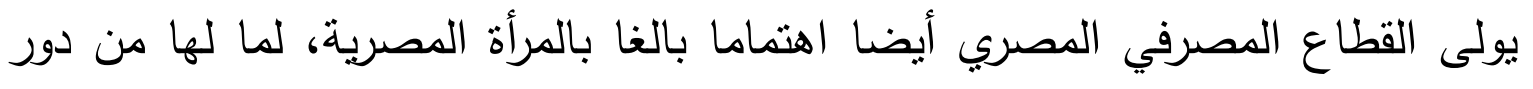
فعَّال كثريك في تتمية المجتمع، حيث تعمل البنوك على تقديم برامج تمويلية وفنية من أجل تحقيق فهم أفضل لاحتياجات الثركات الصغيرة والمتوسطة التي تقودها الرأة، بالإضافة

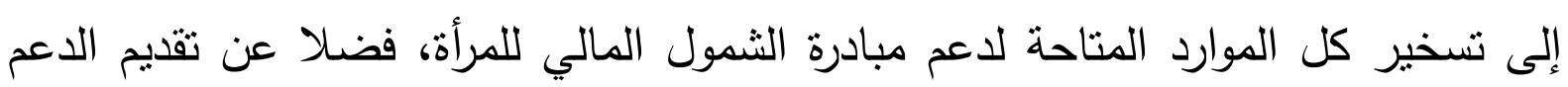

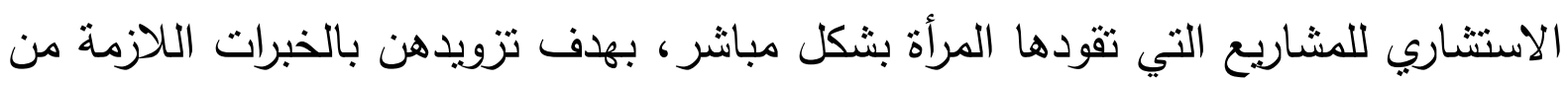
خلال مساعدتهن في إعداد البيانات المالية، وتتظيم دورات تدريبية، وورش عمل. (مصطفى لإنى

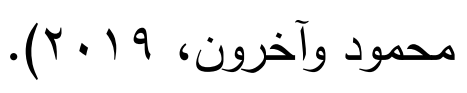

ها كما أطلق الرئيس السيسي مبادرة "مصر بلا غارمين ولا غارمات"، وتم إعداد مشروع

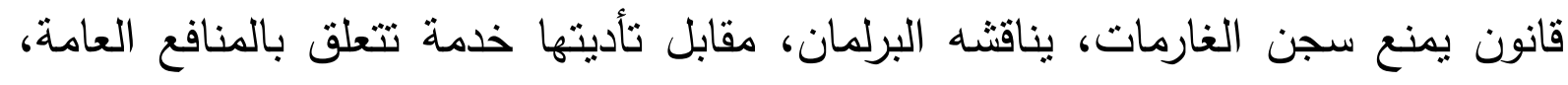


ويتم العمل بالتوازي مع تلك المبادرة وبرنامج "مستورة"، الذى يوفر تمويلا تتراوح قيمته ما

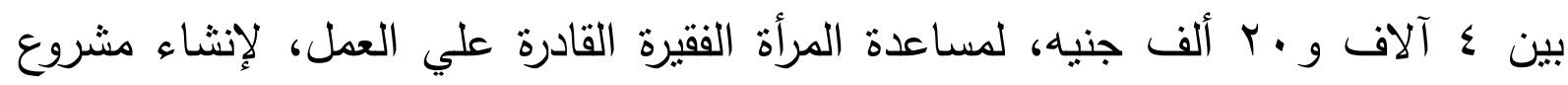

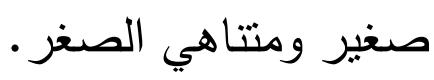
وتم تششين مشروع تكافل وكرامة عام 10 ـ ب، وهو برنامج التحويلات النقديـة المشروطة الذي أطلقته وزارة التضامن الاجتماعي تحت مظلة تطوير شبكات الأمان الاجتماعي.

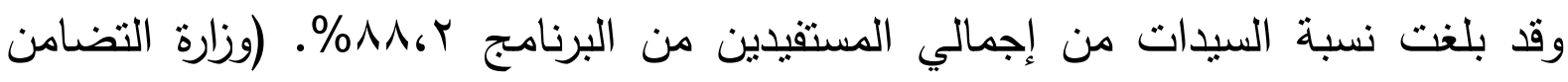
(الاجتماعي).

أقيمت في مطلع 9 ـ ب فعاليات الدورة الثالثة لمهرجان أسوان الدولي لسينما المرأة، ويهدف المهرجان إلى تسليط الضوء على الأعمال السينمائية الهامة المتعلقة بقضايا المرأة.

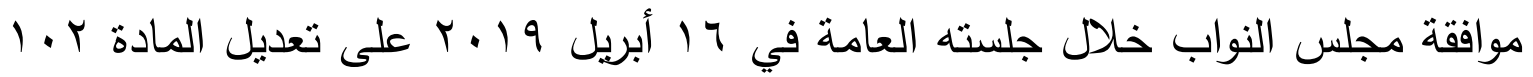
من الدستور ، ويقضى التعديل بتخصيص مب\% من من مقاعد البرلمان للمرأة. مطالب النسويات المصريات على مدار قرن: شهدت الحركة النسوية المصرية تواصلا عبر أجيالها من حيث المطالب المرفوعة وأدوات مدات مُات العمل النسوي، فكل موجة من موجات الحركة النسوية المصرية تحرص على الحفاظ على مكتسبات الأجيال السابقة والبناء عليها بما يجعلنا أمام مطالب نسوية سياسية واجتماعية منطلقة من واقع المجتمع المصري عامة وتاريخ النساء والنسويات خاصة. وقد استتد النضال النسوي في موجاته المختلفة إلى حق المواطنة، الذي يشير إلى العلاقات بين دولة ما والمواطن الفرد، وكذلك العلاقات السياسية بين المواطنين أنفسهم. وهكذا يتضمن مفهوم المواطنة سلسلة من العلاقات السياسية والاجتماعية، وبالتالي حزمة من الحقوق والواجبات المتعلقة بها.

وقد أدى التضامن النسوي والعمل المشترك إلى صياغة برامج نسوية نسعى إلى الحفاظ على حقوق النساء ومكتسباتهن على مستويات عديدة وفي سياقات منتوعة، لتظل الحركة النسوية المصرية حركة سياسية واجتماعية متواصلة عبر الأجيال. فبينما يحتفى العالم بيوم المرأة العالمي، يحتفى تاريخ مصر الحديث في كل يوم برائدات يانعات أنرن سطوره بمداد التمدين والحضارة، فقد اقترنت الحركة النسوية في مصر بالحراك الثقافي والاستتارة ، حتى صارت مكونا أساسيا لكل مشروعات التمدين المصرية منذ القرن التاسع عشر وحتى اليوم. 
ومما لا شك فيه أن المرأة المصرية استطاعت الحصول على الكثير من الحقوق الاجتماعية

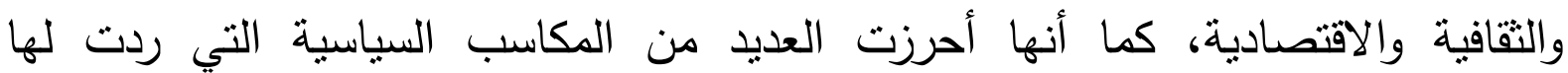
اعتبارها. وقدمت الوثيقة الدستورية في مصر عام ؟ ا ـ ب فرصا حقيقية للقضاء على التمييز ضد النساء وتحفيز مشاركتهن سياسيا، وهو الأمر الذي كان محل نضال لحركات حقوقية ونسوية في مصر على مدار عقود حتى تتحقق تللك المطالبات في الدساتير المصرية المتعاقبة، وهناك العديد من النصوص في دستور ع ( ـ ب تمثل فرصا لابد من النضال من أجل استخلالها.

ثالثا: تحديات وفرص تحقيق المساواة بين الجنسين وتمكين المرأة في مصر يثير مصطلح تمكين المرأة إلى تقوية النساء في المجتمعات المعاصرة، وقد أصبح هذا

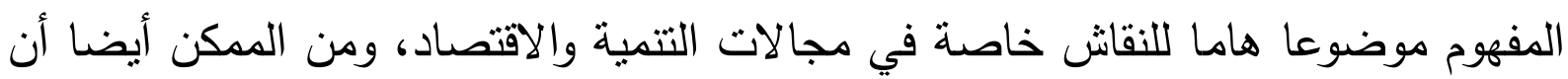

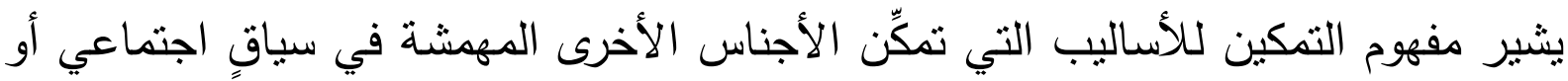

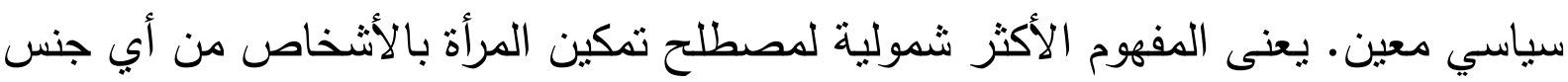
كان (مع التشديد على الفرق بين الجنس البيولوجي والجنس كدور يؤديه الثخص)، وبذلك يشير أيضا إلى الأجناس المهشة الأخرى في سياق سياسي أو اجتماعي معين.

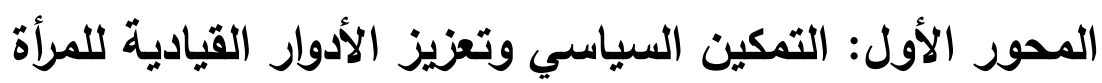
جدول (1) مؤثرات قياس الأثر لمحور التمكين السياسي والقيادة

\begin{tabular}{|c|c|c|}
\hline المرصودة & السنة & مؤثرات قياس الأثر \\
\hline$\% \leq \varepsilon$ & $r \cdot 1 \leq$ & نسبة الإناث من إجمالي المشاركين \\
\hline$\% 10$ & $r .17$ & نسبة تمثيل المرأة في البرلمان \\
\hline$\% \cdot .0$ & $r .10$ & نسبة الإناث في الهيئات القضائية \\
\hline$\% \varepsilon_{6} Y$ & $r .17$ & نسبة الإناث في المناصب العامة \\
\hline$\% \backslash \Lambda_{6}$ & $r .17$ & نسبة الإناث في وظائف الإدارة العليا \\
\hline
\end{tabular}

المصدر : مرصد المرأة المصرية.

على الرغم من المتغيرات الواسعة التي حدثت بالمجتمع المصري خلال السنوات الفائتة والنقلات الثقافية والاجتماعية والثورية، إلا أن الأمر لم يصل بعد إلى عدد من المسائل 
والقضايا المجتمعية، وفي الرأس منها قضية دور المرأة وتمكينها سياسيا والمساواة بينها وبين الرجل في ثقلُّل المناصب القيادية داخل السلطة التتفيذية والقضائية. تشير خبرات المرأة المصرية في مجال المشاركة السياسية إلى أنها تواجَه بالعديد من القيود

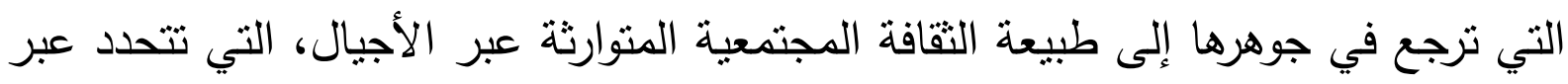

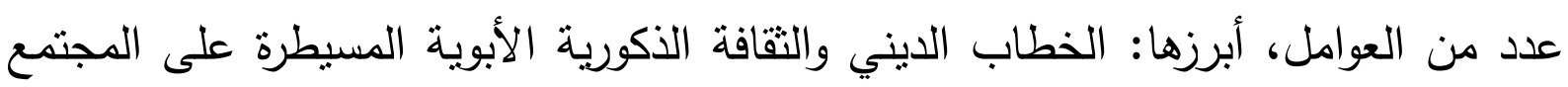
المصري بصفة عامة، ما يتزك أثزه على تصورات المصربين والمصريات بشأن وجود وحرية المرنية حركة المرأة في المجال العام. وتواجه الدولة تحديا كبيرا لتحقيق هذه الأهداف، فتمة فجوة نوعية كبيرة لصالح الرجال بشأن نسب تمثيل النساء في مواقع اتخاذ القرار، حيث يتطلب القضاء على هذه الفجوة وتحقيق المساواة بين الجنسين مراجعة لجملة من القوانين، وإقرار سياسات عامة من منظور النوع الاجتماعي، تتضمن إجراءات محددة من أجل تحقيق تكافؤ الفرص داخل جميع المؤسسات بالدولة، فضلا عن تدخلات جادة من أجل تغيير التقافة الذكورية السائدة في المنتمع التي لني تضع النساء في أطر تقليدية، وتكرِّس للتمييز ضدهن في شغل المناصب القيادية، وتحول دون وصولهن لمواقع اتخاذ القرار • المحور الثاني: التمكين الاقتصادي جدول (Y) مؤشرات قياس الأثر لمحور التمكين الاقتصادي التشئ

\begin{tabular}{|c|c|c|}
\hline المرصودة القيمة & 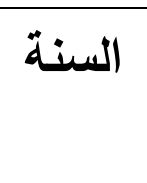 & مؤثرات قياس الأثر \\
\hline \%үт,r & $r .17$ & نسبة المرأة المعيلة تحت خط الفقر \\
\hline$\left.\% \curlyvee \varepsilon_{6}\right)$ & $r \cdot 11$ & نسبة مشاركة المرأة في قوة العمل \\
\hline$\%$ \%rl & $r \cdot I V$ & معدل البطالة بين الإناث \\
\hline$\% \tau_{6} \varepsilon$ & $r \cdot 11$ & نسبة النساء في وظائف إدارية \\
\hline$\% r \Lambda_{6} \varepsilon$ & $r \cdot 11$ & نسبة النساء في وظائف مهنية \\
\hline$\%$ \%A & $r \cdot 11$ & الدخل المكتسب المقدر (فجوة الدخل بين \\
\hline$\% \curlyvee \wedge$ ○ & $r \cdot 11$ & نسبة المشروعات الصغيرة الموجهة للمرأة \\
\hline$\% 01$ & $r \cdot 11$ & نسبة الإقراض متتاهي الصغر الموجه للمرأة \\
\hline
\end{tabular}




\begin{tabular}{|c|c|c|}
\hline$\% q_{6} r$ & $r \cdot 11$ & نسية الاناث اللات لدبئ حساب نيك \\
\hline
\end{tabular}

$$
\text { المصدر: مرصد المرأة المصرية. }
$$

يكثف تقييم الواقع المصري لتتمية ريادة الأعمال النسائية عن أن النساء لايزلن تشكلن موارد غير مستغلة في قطاع الأعمال على أكمل وجه. فعلى الرغم من هيمنة النساء على قطاع

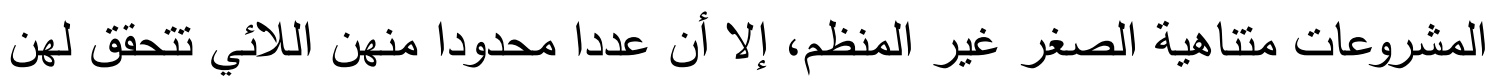
فرص نمو كافية للتحول إلى مشروعات منظمة. الأمر الذي يقتضي خلق المزيد من الوعي

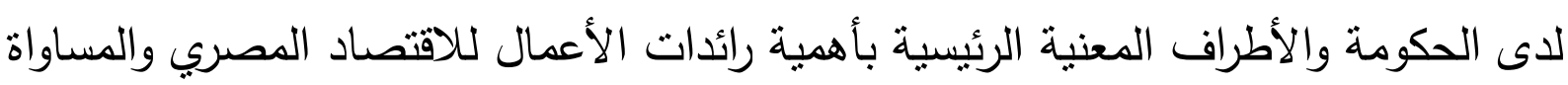
بين الجنسين في السياسات ودعم البرنامج.

وفيما يتعلق بنقاط القوة النسبية للشروط المرجعية الستة لتتمية ريادة الأعمال النسائية، تم تقييم مصر كأكثر قوة فيما يتعلق بالنظام القانوني المراعي لاعتبارات المساواة بين الجنسين،

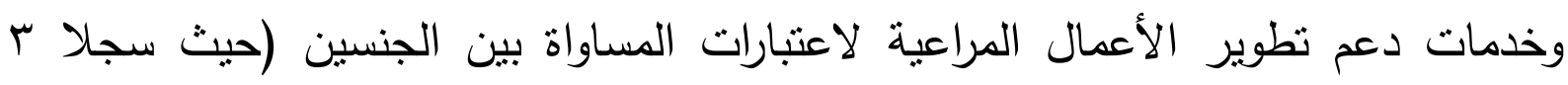

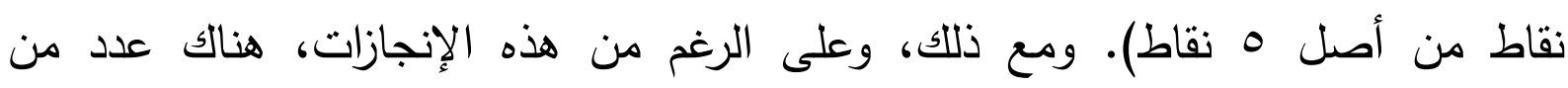

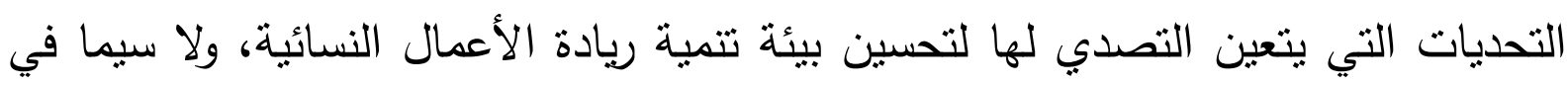

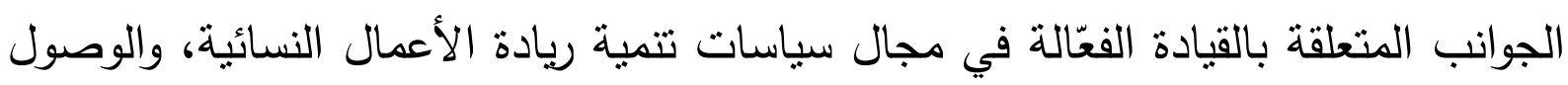
إلى التمويل، والوصول إلى الأسواق والتكنولوجيا، ومشاركة رائدات الأعمال في حوار السياسات.

ولا يمكن للجهود الرامية إلى تعزيز مشاركة النساء في النشاط الاقتصادي أن تؤتي ثمارها دون إزالة التمييز النوعي بين الرجل والمرأة، الذي يمثل أحد المشاكل الهيكلية في سوق العمل المصري، حيث يأتي التمبيز سواء في تقسيم الوظائف بشكل أو بآخر ، أو حتى في

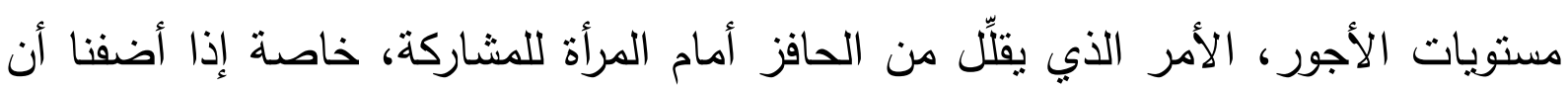

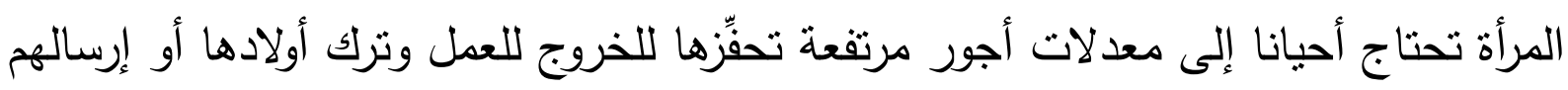

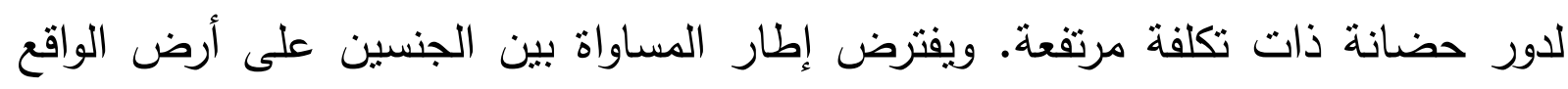

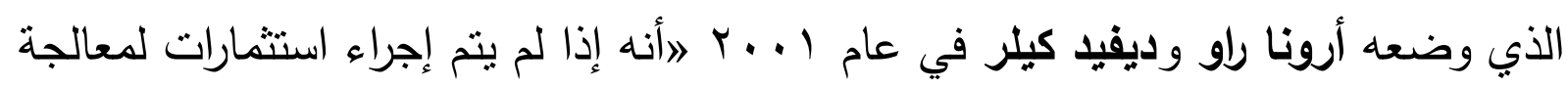
أنماط التحيُّز القائمة على أساس نوع الجنس والهياكل الراسخة للأنظمة والمؤسسات المكلفة بتحويل سياسة المساواة بين الجنسين إلى واقع عملي يعود بالنفع على النساء والفتيات، فان هذه الأعراف الاجتماعية غير الرسمية المترسخة بشدة ستؤدي إلى إفساد أفضل السياسات 0. 


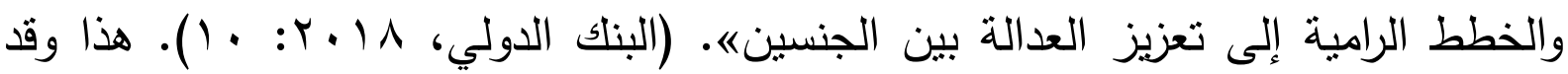

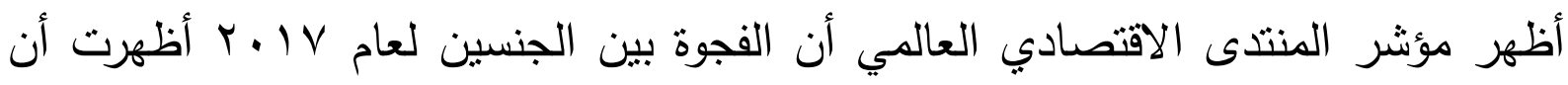

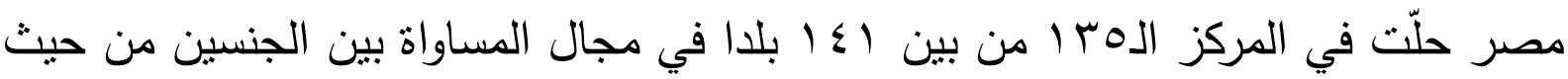
المشاركة والفرص الاقتصادية (World Economic Forum, 2018:24). المحور الثالث: التمكين الاجتماعي جدول (r) مؤشرات قياس الأثر لمحور التمكين الاجتماعي

\begin{tabular}{|c|c|c|}
\hline المرصودة القيمة & 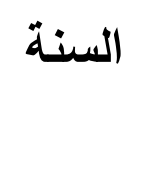 & مؤشرات قياس الأثر \\
\hline$\%$ \% ‘ $\Lambda$ & r.IV & نسبة الأميات بين الإناث +1+ \\
\hline$\% 196 \varepsilon$ & $r .1 \mathrm{~V}$ & 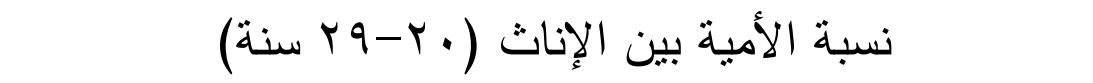 \\
\hline$\% \circ \Lambda_{6} 0$ & $r \cdot 1 \varepsilon$ & نسبة السيدات المتزوجات اللاتي يستخدمن وسائل تتظيم الأسرة \\
\hline 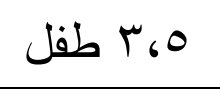 & $r \cdot 1 \leq$ & معدل الإنجاب الكلي (طفل لكل سيدة) \\
\hline$\% \wedge r_{6} \wedge$ & $r \cdot 1 \leq$ & نسبة السيدات اللاتي حصلن على رعاية حمل منتظمة \\
\hline$\% 01,1$ & $r \cdot 1 \leq$ & نسبة الولادة القيصرية \\
\hline$\leqslant 0,9$ & $r \cdot 17$ & نسبة وفيات الأمهات (لكل . . 1 ألف مولود حي) \\
\hline 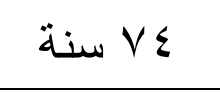 & $r \cdot 1 \wedge$ & توقع الحياة عند الميلاد \\
\hline ك & $r \cdot 17$ & متوسط عدد السنوات التي تعيشها الأنتى بصحة جيدة \\
\hline$\% 1>$ & $r \cdot 10$ & نسبة الإناث المعاقات المعيّنات بالقطاع الحكومي \\
\hline$I V \varepsilon$ & $r \cdot 17$ & عدد دور المسنين \\
\hline$\%$ \% 9.0 & r.IV & 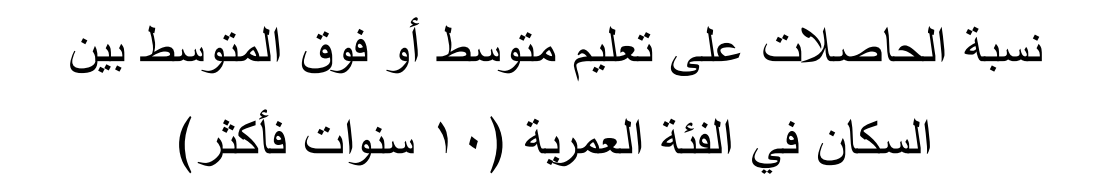 \\
\hline$\% 11,4$ & r.IV & 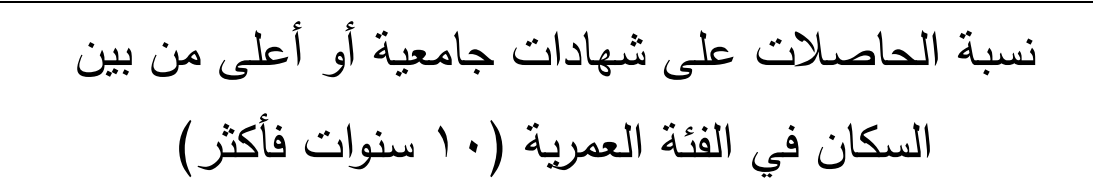 \\
\hline
\end{tabular}
المصدر: مرصد المرأة المصرية

يمثل التمكين الاجتماعي خطوة أساسية وأولية في أبي اتجاه تمكيني للمرأة على الصعُد كافة. فالتمكين الاقتصادي حاله حال التمكين القانوني والسياسي، يصبح غير ذي جدي جدوى في حال 
كانت المرأة مهمشة اجتماعيا وغير مرغوب في مشاركتها الفعّالة في الواجبات والحقوق، أو

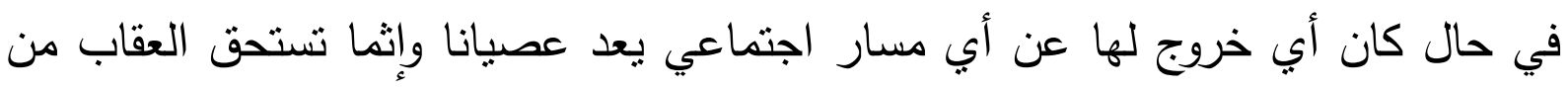
أجله. وحين نتحدث عن العقاب هنا، فنحن نتحدث عن مجتمع سلطوي برمته من ناحية

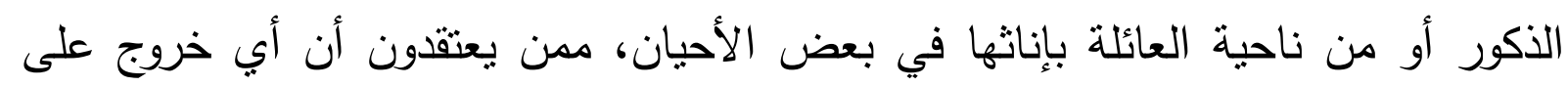

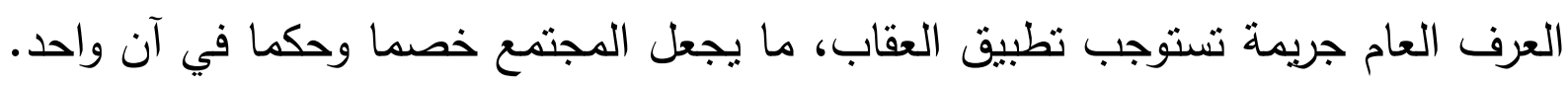

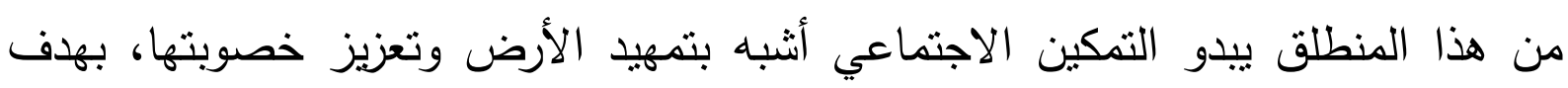

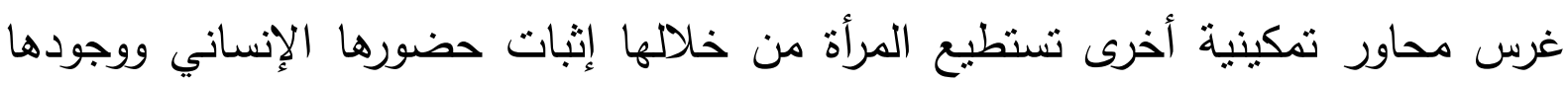
عنصرا فاعلا في بناء المجتمع، إذ إنها والرجل يعدان صنوين متكافئين ومتماتلين في التيان

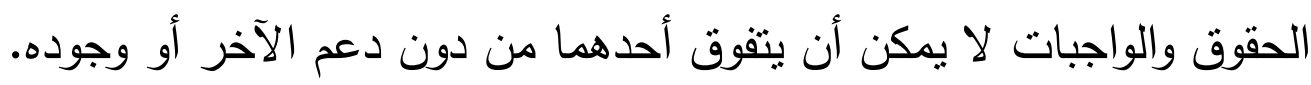

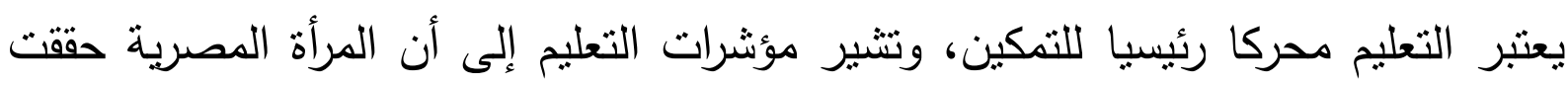

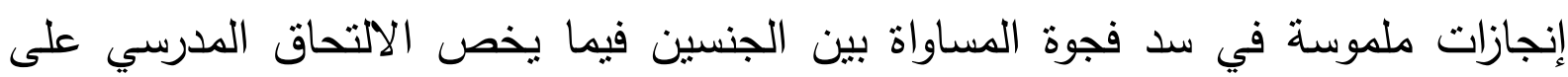

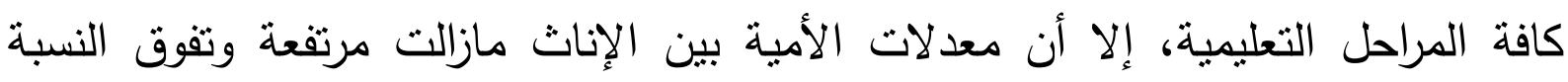

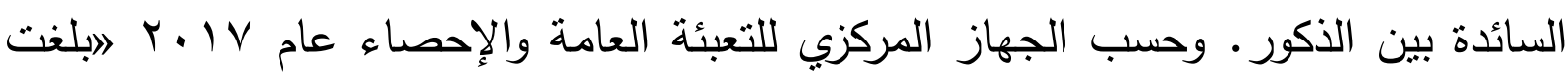

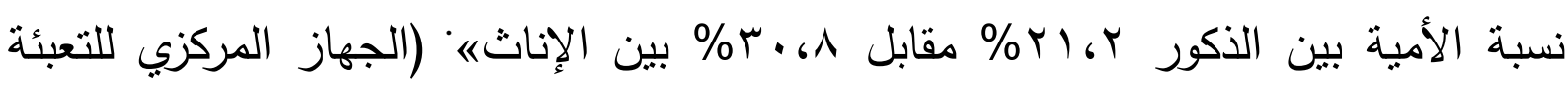

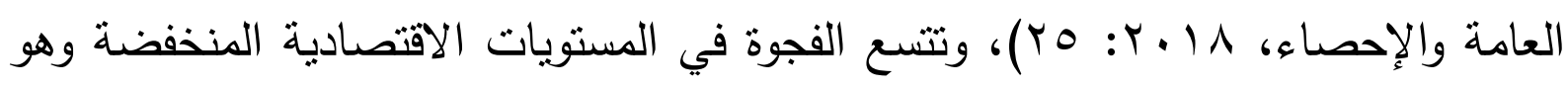

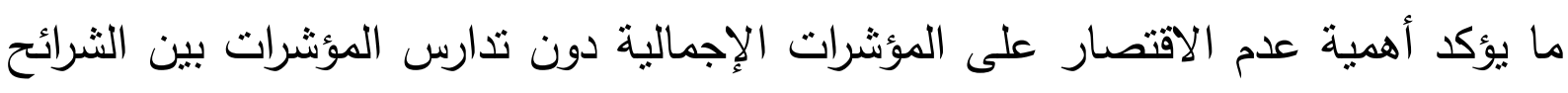

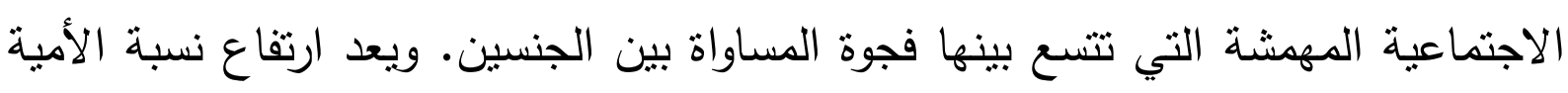

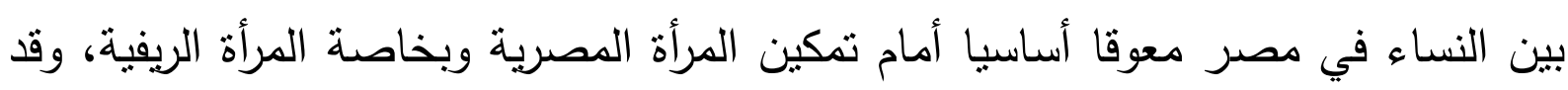

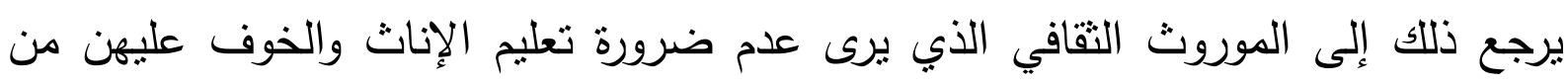

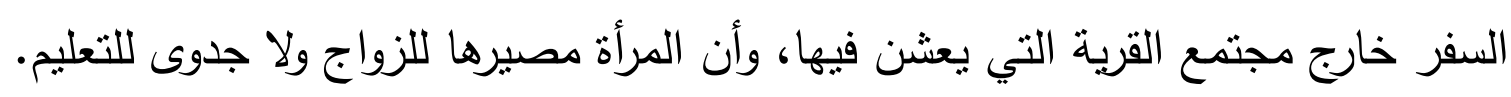

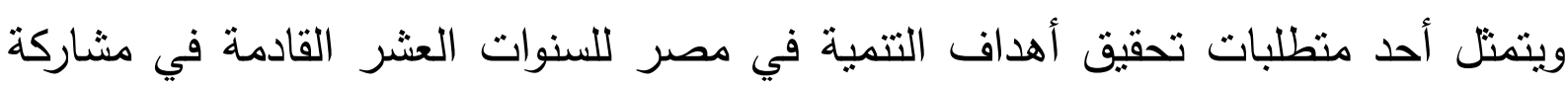

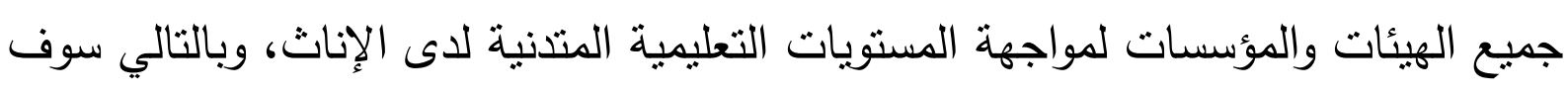

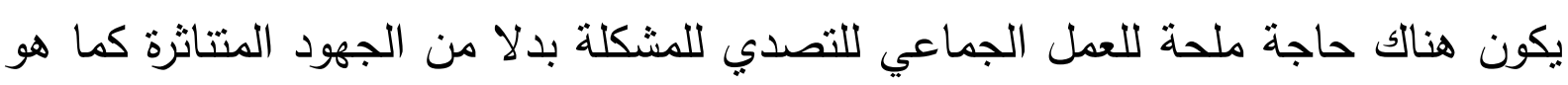
الحال الآن. إنه يجب نحسين إمكانية حصول الإناث على التعليم المؤهل، وصياغة السياسة

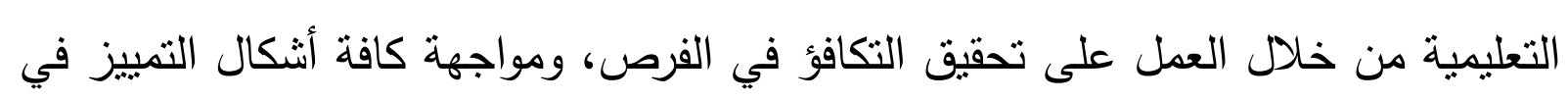

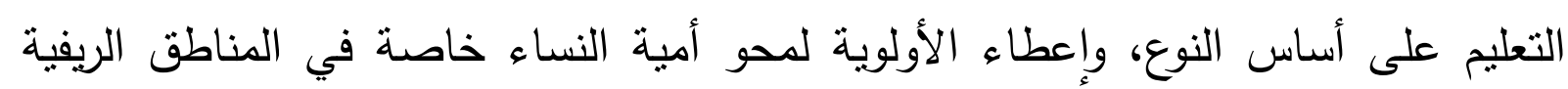

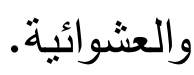


جدول (؛) مؤثرات قياس الأثر لمحور الحماية

\begin{tabular}{|c|c|c|}
\hline المرصودة & السنة & موئشرات قياس الأثر \\
\hline$\% \backslash \wedge$ & $r \cdot 1 \varepsilon$ & 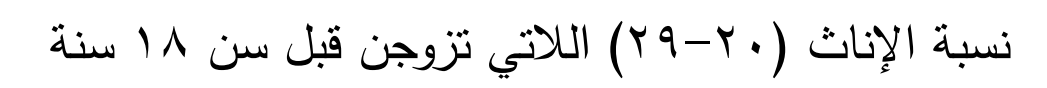 \\
\hline$\%$ \% & $r \cdot I \varepsilon$ & 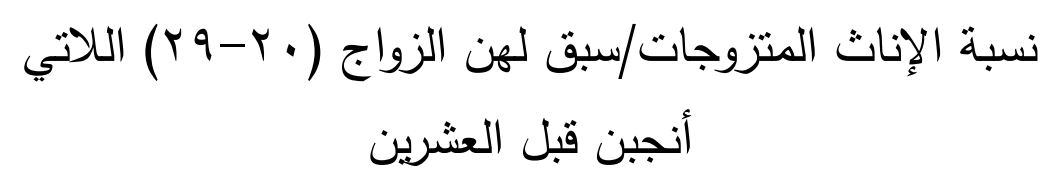 \\
\hline$\%$ & $r .10$ & نسبة الإناث اللاتي تعرضن للتحرش \\
\hline$\% \wedge \vee G$ & $r .10$ & نسبة السيدات (0 1 9 ( ) اللاتي سبق لهن الزواج اللاتي تم \\
\hline$\% 07$ & $r .1 \leq$ & نسبة الفتيات أقل من 19 سنة المتوقع ختانهن \\
\hline$\%$ Yo, & $r \cdot 1 \varepsilon$ & نسبة السيدات اللاتي تعرضن لعنف جسدي من قبل الزوج \\
\hline$\% \backslash \wedge, \wedge$ & $r \cdot 1 \varepsilon$ & نسبة السيدات اللاتي تعرضن لعنف نفسي من قبل الزوج \\
\hline$\left.\% \varepsilon_{6}\right)$ & $r .1 \varepsilon$ & نسبة السيدات اللاتي تعرضن لعنف جنسي من قبل الزوج \\
\hline
\end{tabular}

المصدر: مرصد المرأة المصرية.

إن العنف ضد النساء والفتيات هو أحد أكثر انتهاكات حقوق الإنسان انتشارا واستمرارا

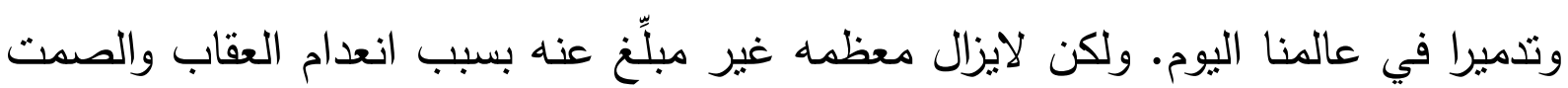
والإحساس بالفضيحة ووصمة العار المحيطة به. على سبيل المثال، في مصر، نثير

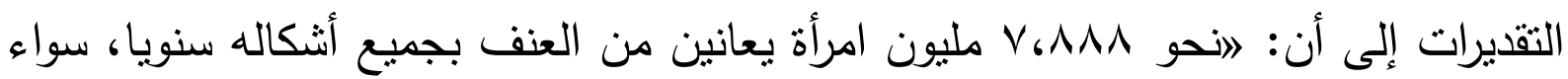
على يد الزوج أو الخطيب، أو أثخاص من الدوائر المقربة لها، أو الغرباء في الأماكن

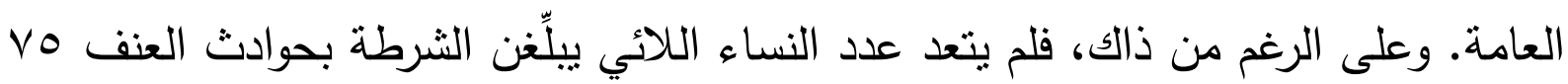
ألف امرأة، وكذلك لا يتعدى عدد النساء اللائي سعين للحصول على خدمات المجتمعات المحلية V آلاف امرأةه (156: UNFPA CAPMAS and NCW, 2016 (UN). وهذه الأرقام قد تشير لضعف الوعي لدى المرأة، أو لعدم انتشار ثقافة الاستعانة بها، أو لاعتقاد

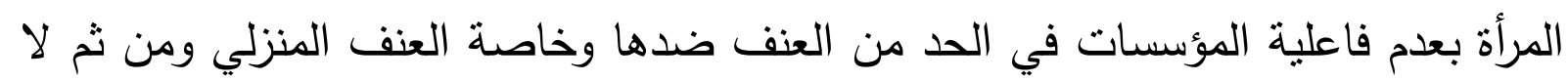
تلجأ إلى هذه المؤسسات. 
لهذا النوع من العنف عواقب بدنية وجنسية ونفسية عديدة، منها ما يصيب الضحية على

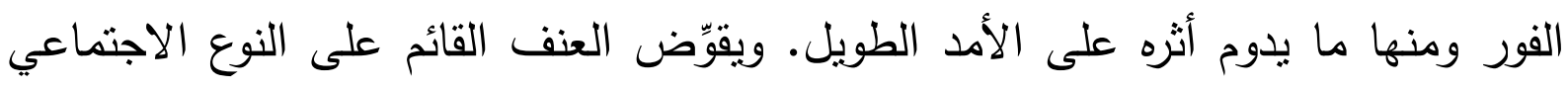

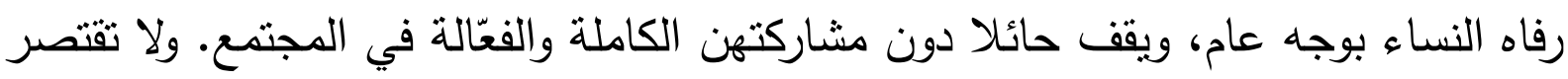

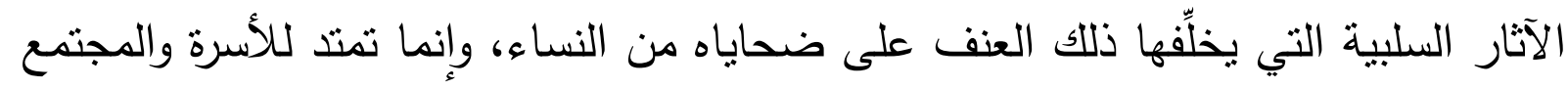

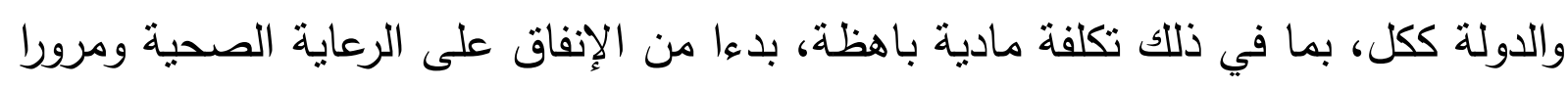

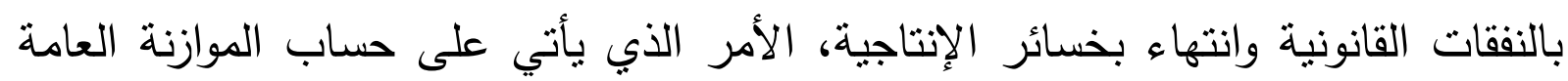

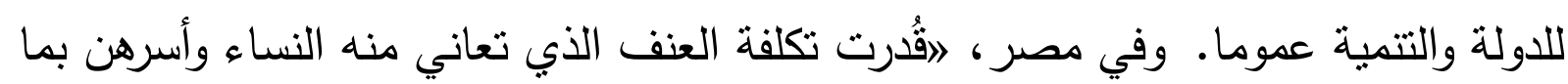

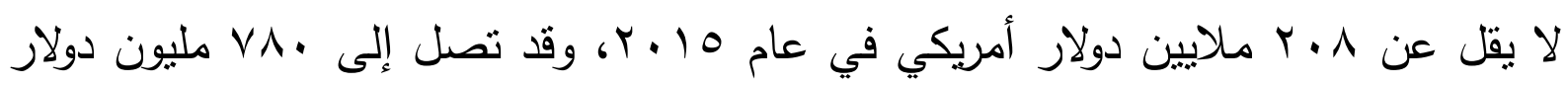
أمريكي" (UNFPA CAPMAS and NCW, 2016:128). وعلى الرغم من الثقام

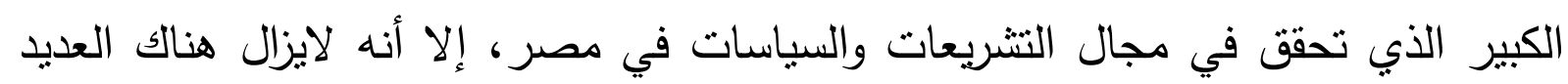
من الثغرات فيما يتعلق بتوفير الحماية الكافية والكاملة للضحايا وتقديم الجناة إلى العدالة، التاليال

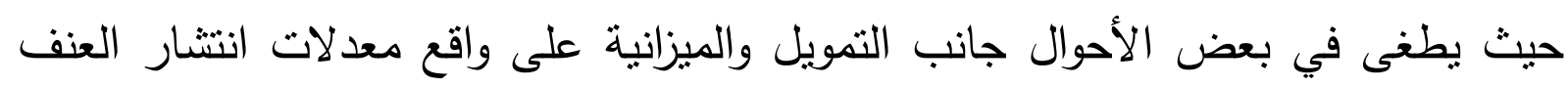

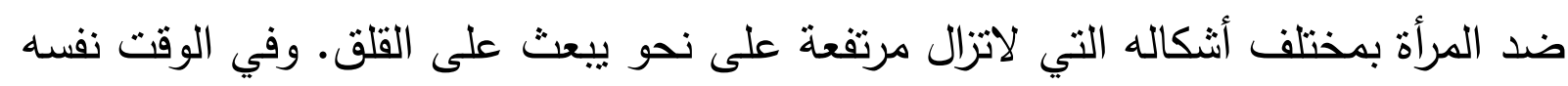

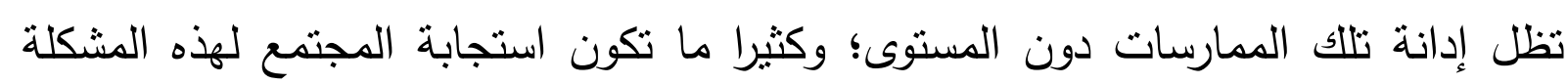

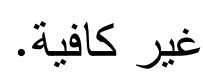
إن الاستراتيجيات الرامية إلى زيادة تمكين المرأة من الناحيتين الاقتصادية والاجتماعية، من

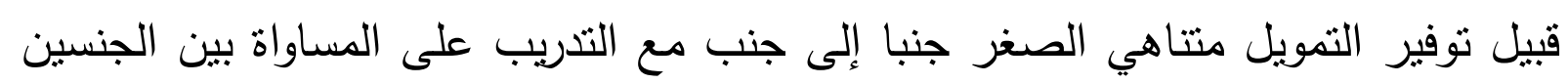

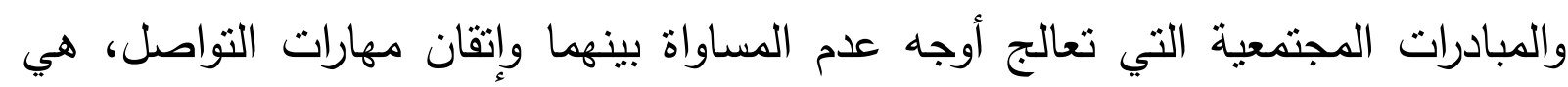

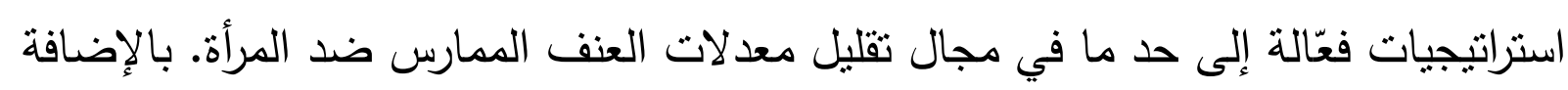
إلى ضرورة تقوية التشريعات والقوانين الخاصة بحماية المرأة والقضاء على كالى كافة أثنكال

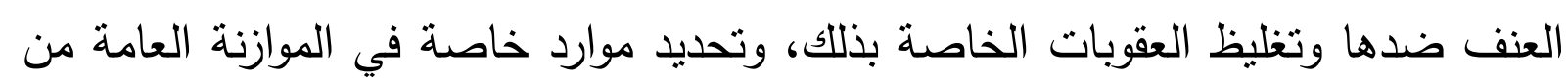
أجل هذا الغرض. والأكثر أهمية من كل ذلك، هو تنظيم حملات نوعية من أجل ترسيخ

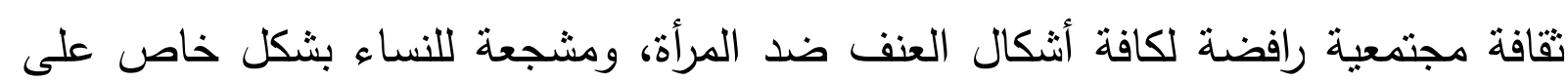
عدم السكوت على مرتكبي العنف أو القبول بإفلات مرتكبيه من العقاب.

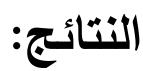
- يثير التعريف العام للنسوية إلى أنها الاعتقاد بأن المرأة لا تعامل على قدم المساواة، لا

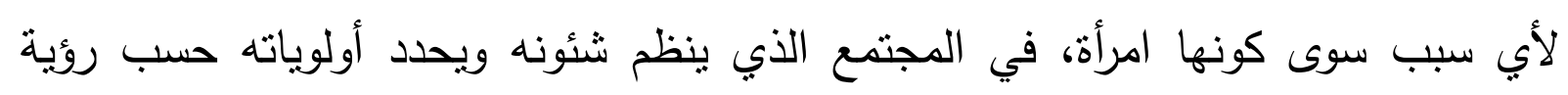
oร 
الرجل واهتماماته. وبذلك يمكن القول إن النسوية هي حركة تعمل على تغيير هذه الأوضاع

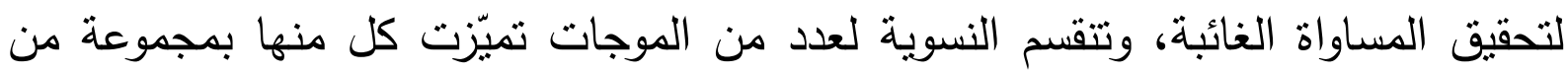
الأفكار والمسارات على المستوى العالمي. - أن التيارات النسوية متعددة الأفكار، نسعى للتغيير الاجتماعي والثقافي، وتغيير بناء التاري العلاقات بين الجنسين، وصولا إلى المساواة المطلقة كهذف استراتيجي، وتتسم أفكارها بالتطرف والثذوذ، وتتبنى العداء والصراع بين الجنسين، وتهدف إلى تقديم قراءات جديدة لللاين واللغة والتاريخ والثقافة. - أن الخطابات النسوية في حاجة ماسة إلى إدراك الاختلافات الكثيرة بين نساء العالم وربط الكاءئ

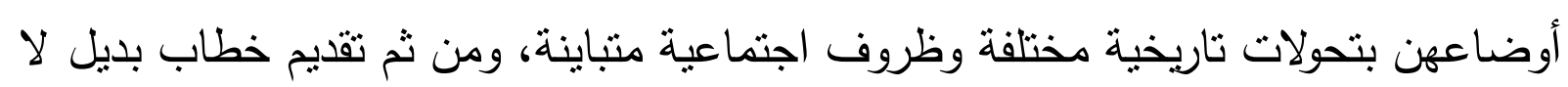

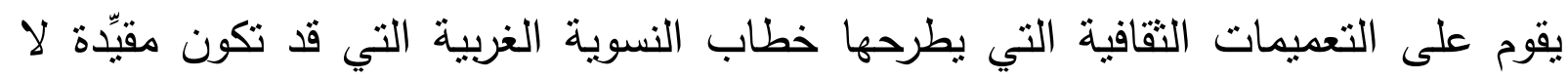

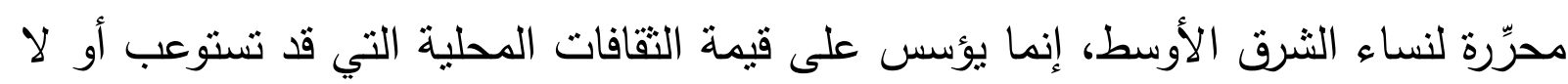
نستوعب أطوار التقدم الغربي. - أن الحركة النسوية في مصر، هي أكثر حركات المرأة في العالم العربي اقترانا بالاستتارة

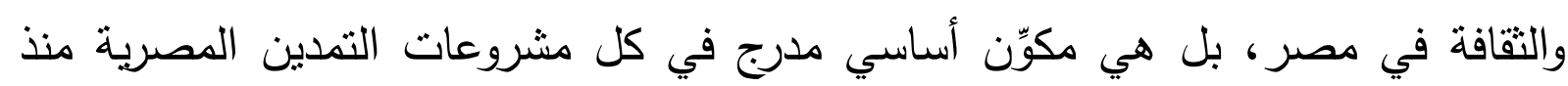

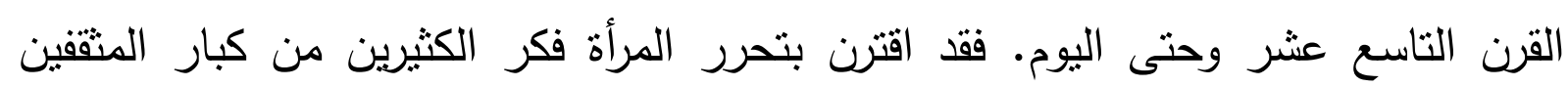
الرواد في مصر الحديثة. - يوجد تواصل عبر أجيال الحركة النسوية المصرية من حيث المطالب المرفوعة وأدوات

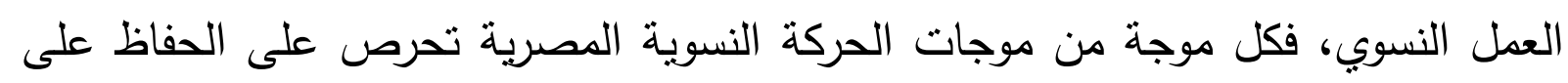

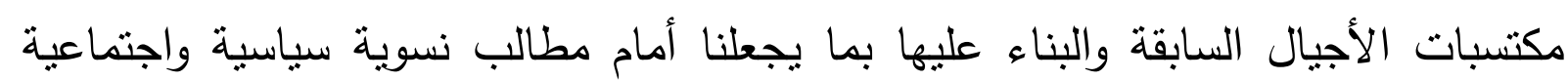

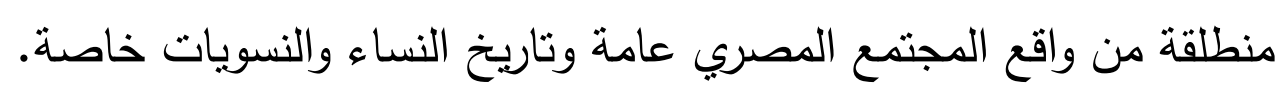

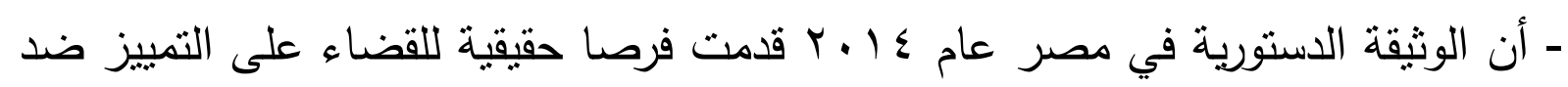

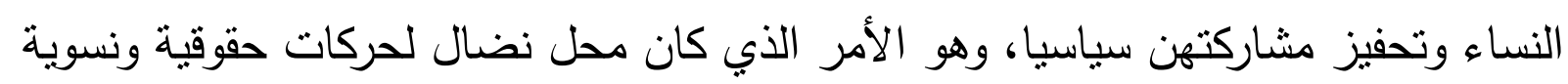

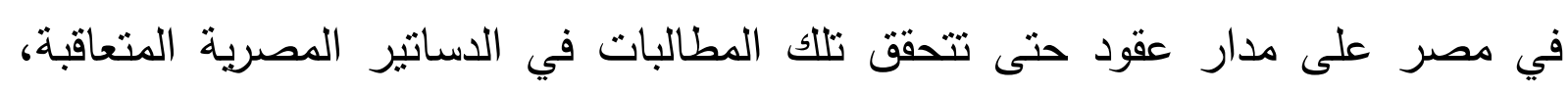
ولكنها لا تعدُ، حتى الآن، إلا حبرا على ورق، ننتظر تطبيقه من خلال تنتريعات تصدر قريبا وتدابير من الدولة تكفل هذه الحقوق. - أن المرأة الدصرية استطاعت الحصول على الكثير من الحقوق الاجتماعية والثقافية

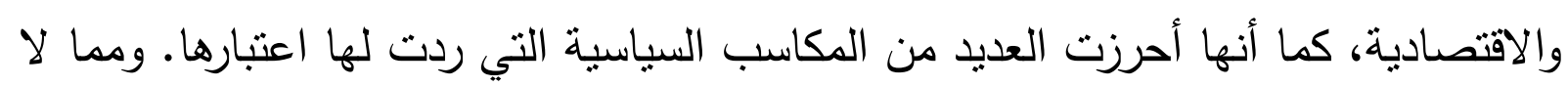


شك فيه أن مصر حققت خلال الخمس سنوات الأخيرة إنجازات هامة على أرض الواقع من

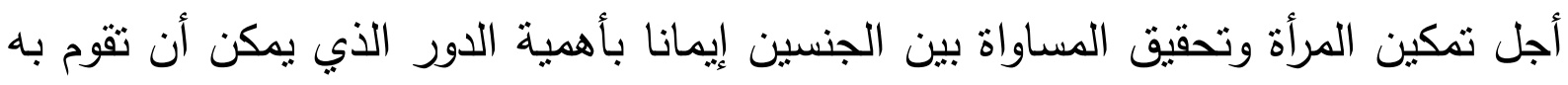

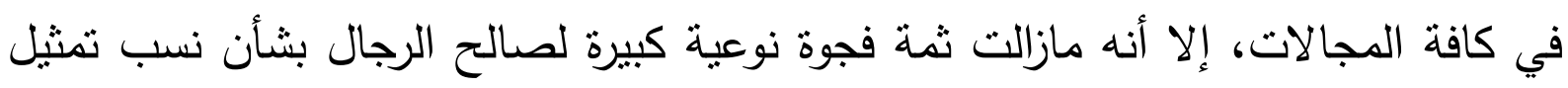
النساء والرجال في مواقع اتخاذ القرار ، سواء في السلطات الثلاثة: (التنفيذية - القضائية التشريعية)، ويرجع ذلك للنقافة الذكورية السائدة في المجتمع التي تتسبب في تعرض النساء لأشكال مختلفة من التمبيز والعنف في المجالين الخاص والعام، تحصر النساء في أدوار نمطية وتقليدية وتستبعدهن من المجال العام وتجعل دورهن الرئيسي داخل الأسرة. التوصيات: - القضاء على جميع أنكال التمبيز ضد النساء والفتيات في كل مكان. - القضاء على جميع أشكال العنف ضد جميع النساء والفتيات في المجالين العام والخاص، بما في ذلك الاتجار بالبشر والاستغلال الجنسي وغير ذلك من أنواع الاستخلال. - القضاء على جميع الممارسات الضارة، من قبيل زواج الأطفال والزواج المبكر والزواج القسري، وتشويه الأعضاء التتاسلية للإناث (ختان الإناث). - الاعنراف بأعمال الرعاية غير مدفوعة الأجر والعمل المنزلي وتقديرها من خلال توفير الإنات الخدمات العامة والبنية التحتية ووضع سياسات الحماية الاجتماعية وتعزيز تقاسم المسئولية داخل الأسرة المعيشية والعائلة، حسبما يكون ذللك مناسبا على الصعيد الوطني. - كفالة مشاركة المرأة مشاركة كاملة وفعّالة وضمان تكافؤ الفرص لها للقيادة على قدم لـان المساواة مع الرجل على جميع مستويات صنع القرار في الحياة السياسية والاقتصادية والعامة. - تعزيز استخدام التكنولوجيا التمكينية، وبخاصة تكنولوجيا المعلومات والاتصالات، من أجل تعزيز تمكين المرأة. - اعتماد سياسات سليمة وتتريعات قابلة للإنفاذ وتعزيز السياسات والتشريعات القائمة من هذا القبيل للنهوض بالمساواة بين الجنسين وتمكين كل النساء والفتيات على جميع المستويات.

- ضمان حصول الجميع على خدمات الصحة الإنجابية، على النحو المتفق عليه وفقا لبرنامج عمل المؤتمر الدولي للسكان والتتمية ومنهاج عمل بكين والوثائق الختامية لمؤتمرات استعراضهما. 
- القيام بإصلاحات لتخويل المرأة حقوقا متساوية في الحصول على الموارد الاقتصادية، ويشمل ذلك حق الملكية والتصرف في الأراضي وغيرها من الممتلكات والنفاذ إلى الخدمات المالية والموارد الطبيعية، والحصول على حقها في الميراث وفقا للقوانين الوطنية. - ضمان حصول كل الفتيات على تعليم أساسي بجودة عالية، والقضاء على الفجوات بين الإناث والذكور في كافة مراحل التعليم ودعم حصول الرأة على التعليم الفني والتنريب.

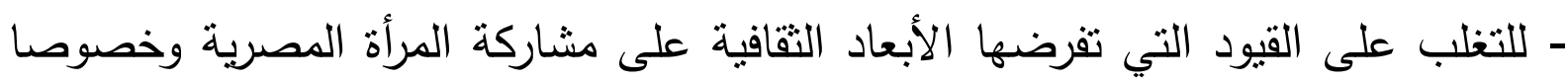
في المجال العام، فلا مناص من العمل مع قطاعات أعرض من النساء في الريف وفي المجتمعات المهمشة، والتعامل بقوة وجسارة مع مشكلات الفقر والعنف والتمييز والممارسات

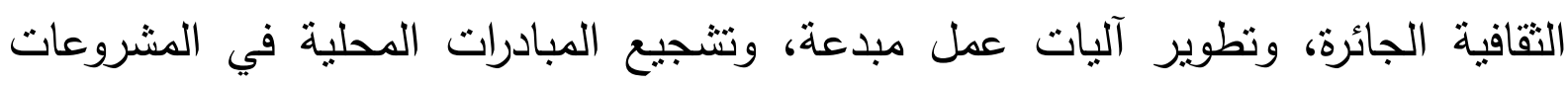

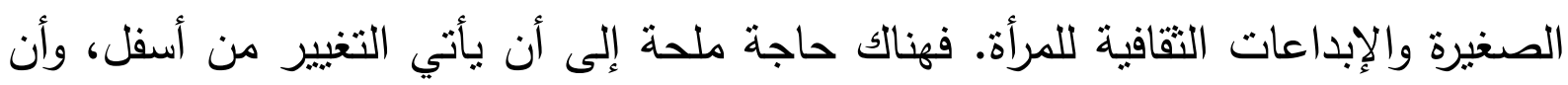

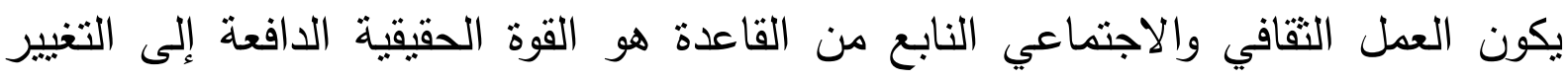

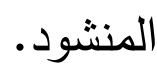

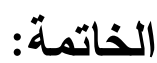

إن الفرضية التي ننطلق منها تقوم على أن المجال العام الآمن يتيح للنساء الدفاع عن

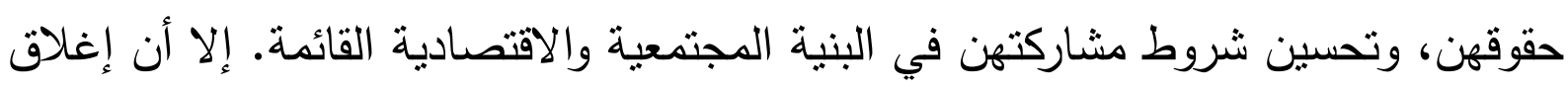

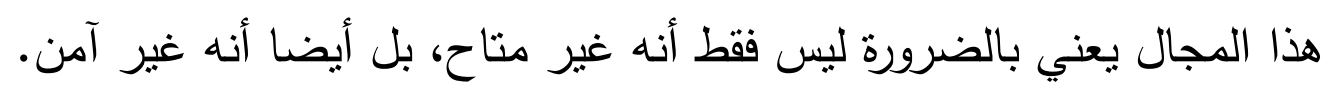

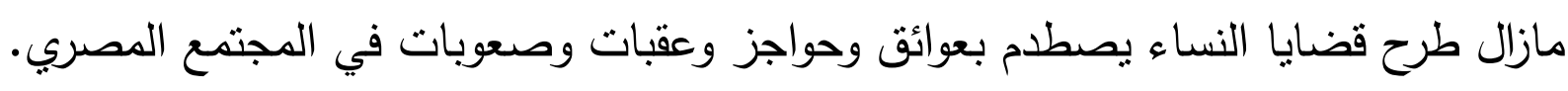

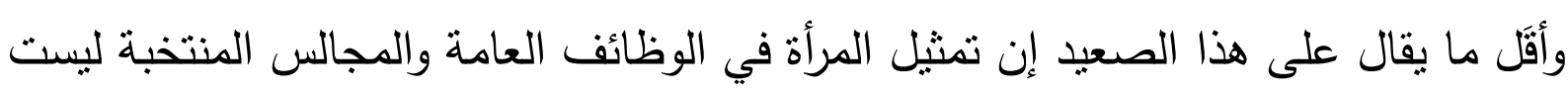

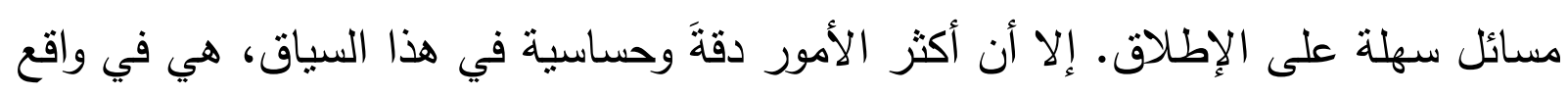

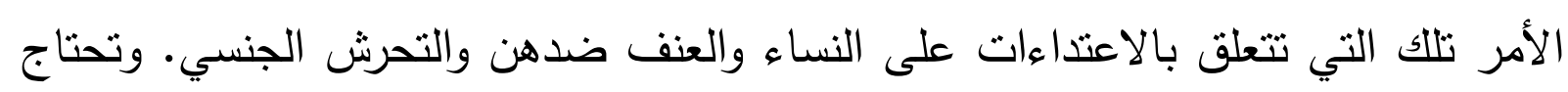
معالجة تلك القضايا إلى أكثر من مجرد الإرادة السياسية، وتتطلب تعميقا لسيادة القانون

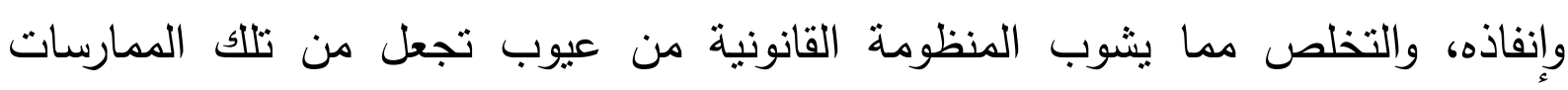

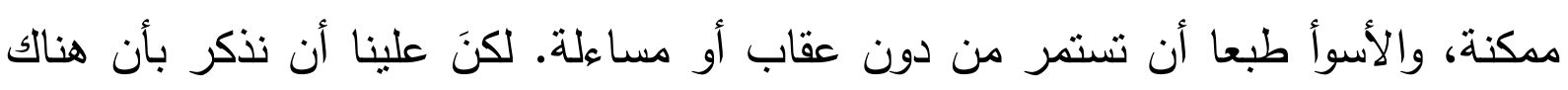
مكاسب تحققت بالفعل في السنوات الأخيرة، يجب أن نعزوها لجملة من الأسباب أهمها:

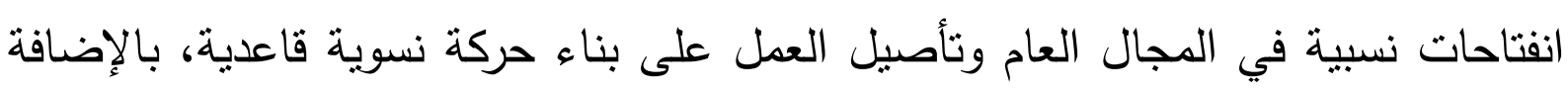
إلى انساع إطار النقاش سياسي الطابع حول القضايا المنعلقة بالنساء. 
وعلى سبيل المثال، ينبغي الإقرار بتحقيق نجاحات مهمة في مواجهة العنف الجنسي ضد المرأة. وكان تعاظم الدور الذي تلعبه مجموعات نسوية شابة ومجموعات داخل الأحزاب السياسية تقوم بالدفع باتجاه الاهتمام بقضايا النساء والدفاع عنها، مما جعل العمل على فتح النقاش وإدراج سياسات أكثر حساسية تجاه هذه القضايا أكبر مما سبق. كما أننا نستحضر باهر

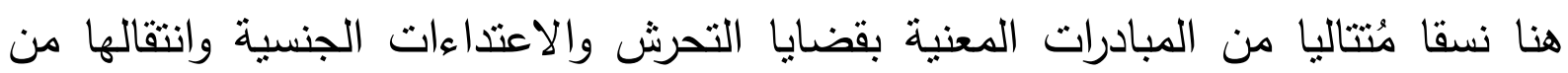
محافظة إلى أخرى، وظهرت على السطح مجموعات لم تكن معروفة في السابق وقامت بتشكيل غرف عمليات للتعامل مع حوادث التحرش الجنسي خلال التجمعات السياسية، التي

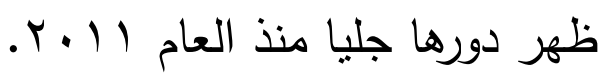

وعلى الرغم من أننا نرى أن قضية العنف ضد المرأة هي قضية مجتمعية بالأساس، وأن صدور القوانين والإصلاح التشريعي وحده غير كافٍ دون تغيير مجتمعي، إلا أن صدور أحكام في قضايا العنف والتحرش الجنسي وتغيير التشريعات المرتبطة بالعنف ضد المرأة وإقرار بعض السياسات يساعد على وصم ذللك الفعل وينزع القبول المجتمي عنه. إن المرأة مرآة المجتمع، فهي التي تعكس مدى تقدمه وتطوره ورقيه، وبقدر مراعاة المجنمع

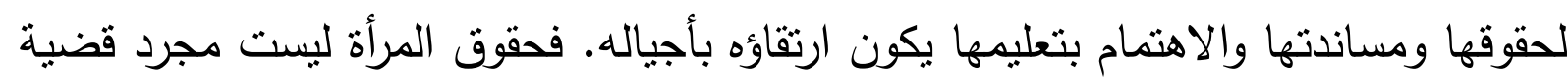
إنسانية بل قضية وطنية ترتبط في مختلف المجالات الفكرية والسياسية والاقتصادية.

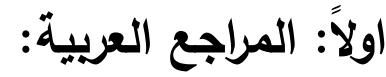

1- الأمم المتحدة، (990 ())، تقرير المؤتمر الدولي للسكان والتتمية (القاهرة، 0-برات سبتمبر ع99 (1))، نيويورك، الولايات المتحدة.

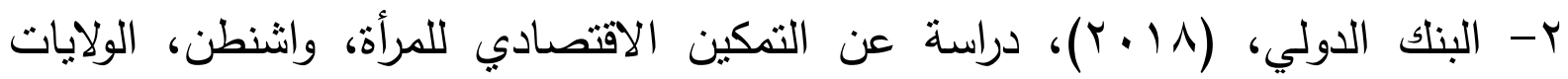
المتحدة.

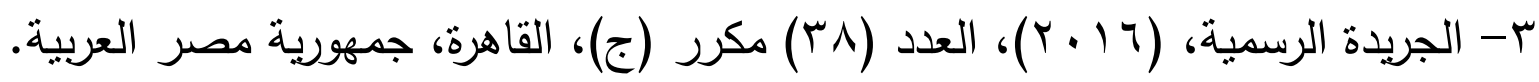

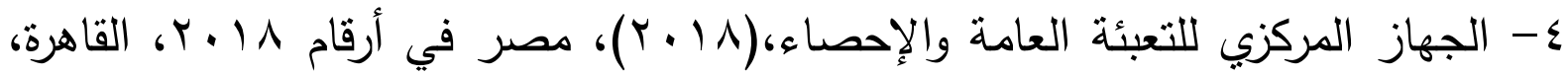
جمهورية مصر العربية. ه- المجلس القومي للمرأة، (Y V • Y)، الاستراتيجية الوطنية لتمكين المرأة المصرية (الروية ومحاور العمل)، القاهرة، جمهورية مصر العربية. 
צ- إلهام عيداروس وخلود جمعة، (ع ( ب)، دليل الكوادر النسائية في الأحزاب الديمقراطية المصرية، نظرة للاراسات النسوية، القاهرة، جمهورية مصر العربية.

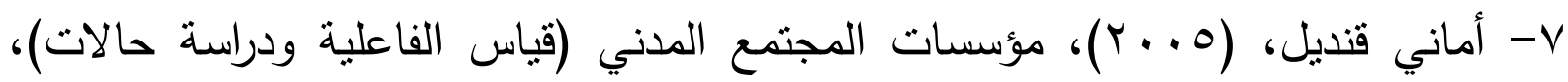
مركز الدراسات السياسية والاستراتيجية بالأهرام، القاهرة، جمهورية مصر العربية.

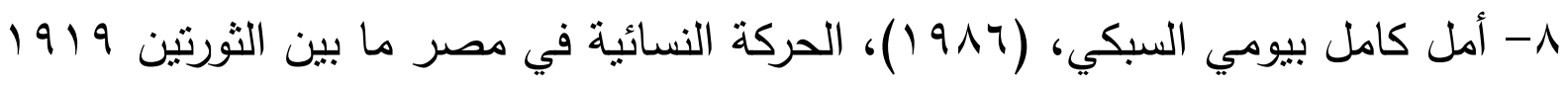
و و 1901، الهيئة المصرية العامة للكتاب، القاهرة، جمهورية مصر العربية. 9- أنهار نشرة غير دورية، (991) (199)، العدد (ץ)، ملتقى الهيئات لتتمية المرأة، القاهرة. جمهورية مصر العربية. • 1- بث بارون، (1999)، النهضة النسائية في مصر (الثقافة والمجتمع والصحافة)، ترجمة: لميس النقاش، المجلس الأعلى للثقافة، القاهرة، جمهورية مصر العربية. 11- بحري دلال، (ع (ب))، النظرية النسوية في التمية، مجلة الففكر، العدد (1)، كلية الحقوق والعلوم السياسية، جامعة محمد خيضر، بسكرة، الجمهورية الجزائرية الديمقراطية الثعبية.

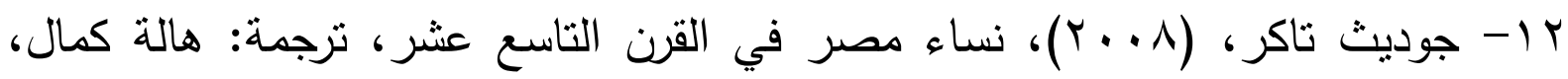
المركز القومي للترجمة، القاهرة، جمهورية مصر العربية. (باهية.

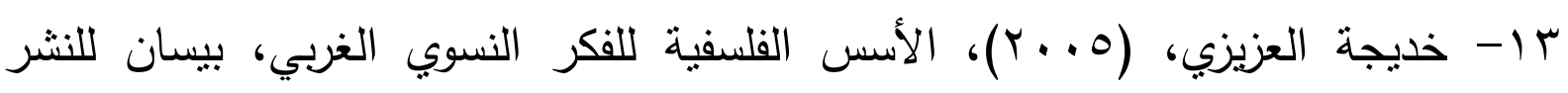
والتوزيع والإعلام، بيروت، الجمهورية اللبنانية.

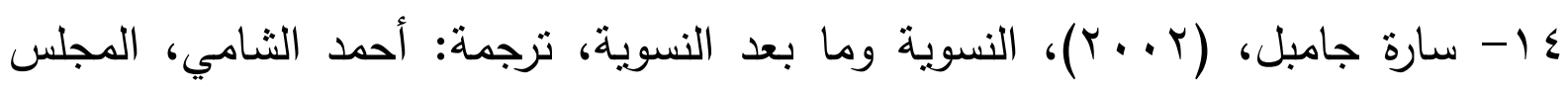
الأعلى للثقافة، القاهرة، جمهورية مصر العربية. 10- سلوى العمد، (ع (ب))، قراءة في تاريخ النسوية الغربية ونظرياتها، مؤتمر فيلادلفيا

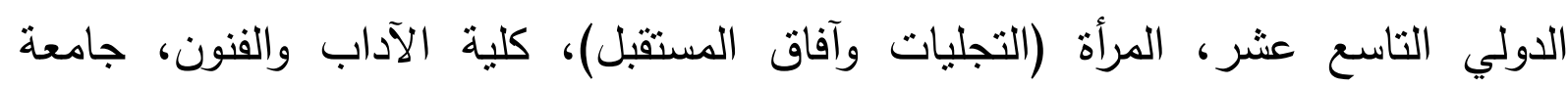
فيلادلفيا، الدملكة الأردنية الهاشمية.

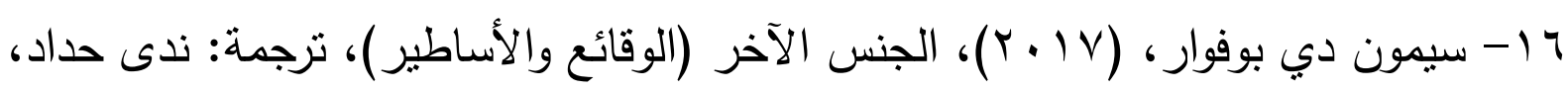
الأهلية للنشر والنوزيع، عمان، المملكة الأردنية الهانمية. 


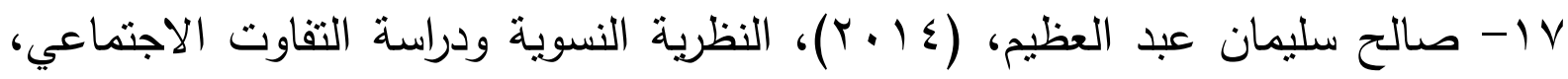
دراسات: العلوم الإنسانية والاجتماعية، المجلد (1)، ملحق (1)، عمادة البحث العلمي البه وضمان الجودة، الجامعة الأردنية، عمان، المملكة الأردنية الهاتشية.

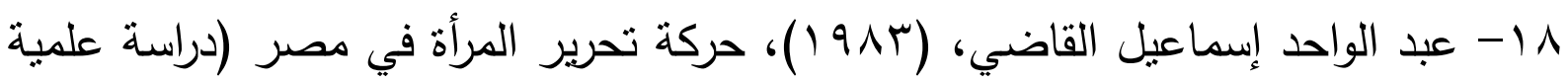
بمفهوم إسلامي)، دار الاعتصام للطبع والنشر والتوزيع، القاهرة، جمهورية مصر العربية.

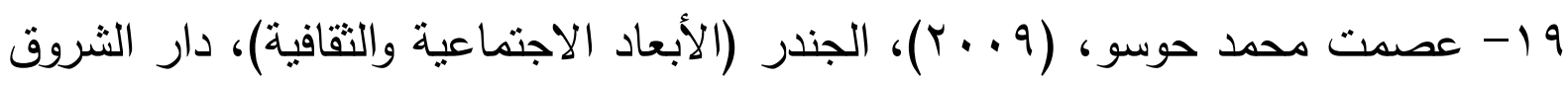
للنشر والتوزيع، عمان، المملكة الأردنية الهاثمية.

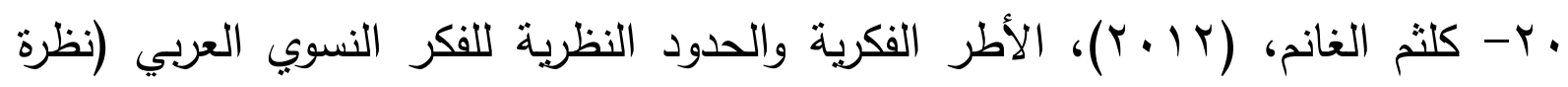

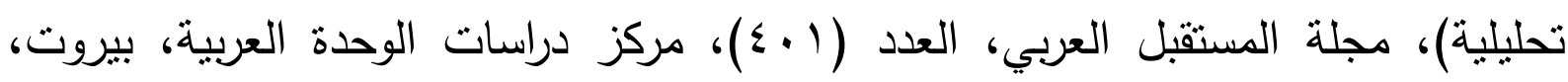
الجمهورية اللبنانية. اب- لينا جزراوي، (1) • (ץ)، صورة الفلسفة النسوية في الفكر العربي المعاصر، دار الآن ناشرون وموزعون، عمان، المملكة الأردنية الهاشمية.

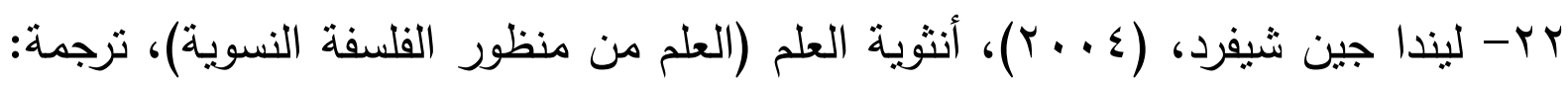

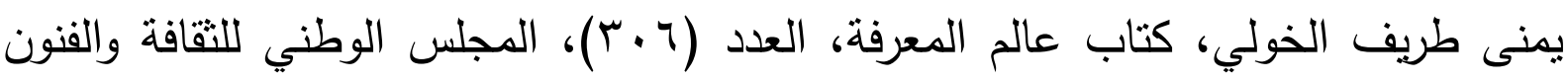
والآداب، الكويت، دولة الكويت.

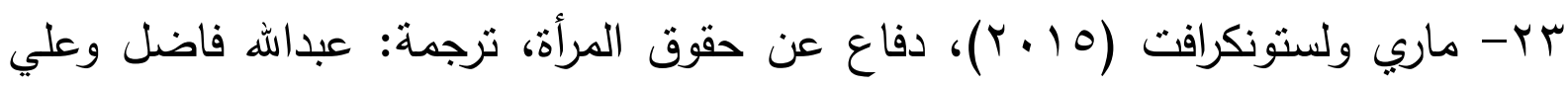
صارم، الرحبة للنشر والتوزيع، دمشق، الجمهورية العربية السورية.

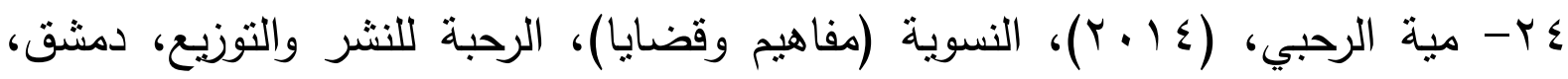
الجمهورية العربية السورية. هץ- هالة شكر الله وآخرون (1991 ()، بحث المرأة في المنظمات الأهلية (حالة مصر)، مركز دراسات المرأة الجديدة، القاهرة، جمهورية مصر العربية العربة

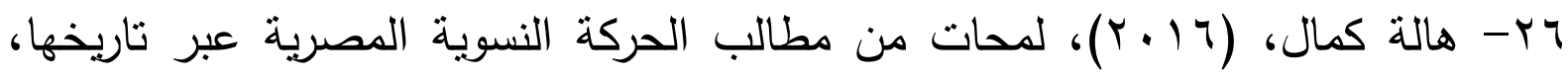
مؤسسة المرأة والذاكرة، القاهرة، جمهورية مصر العربية.

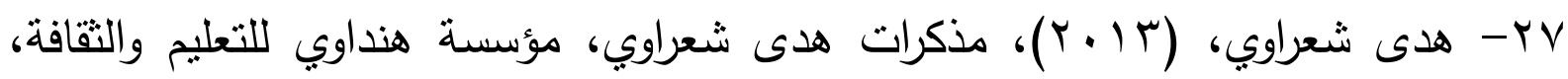
القاهرة، جمهورية مصر العربية.

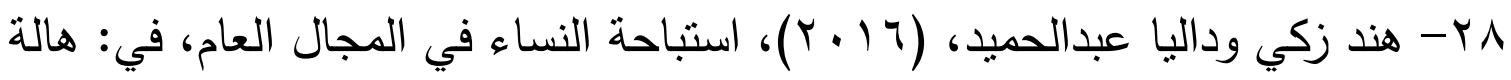
النسوية والجنسانية، ترجمة: عايدة سيف الدولة، سلسلة ترجمات كمال وآية سامي (تحرير)، 7. 
نسوية، العدد (V)، مؤسسة المرأة والذاكرة، القاهرة، جمهورية مصر العربية.

9r- هند محمود وشيماء طنطاوي، (7 (ب)، الدليل للمبادرات النسوية، الإصدار الأول، نظرة للاراسات النسوية، القاهرة، جمهورية مصر العربية.

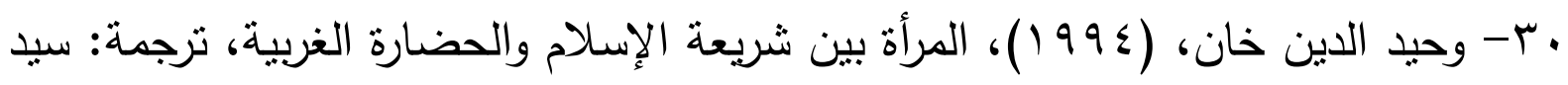

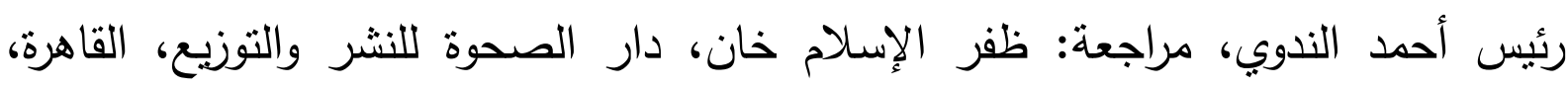
جمهورية مصر العربية. اب- ويندي كيه كولمار وفرانسيس بارتكوفيسكي، (·(+ץ)، النظرية النسوية (مقتطفات مختارة)، ترجمة: عماد إبراهيم، الأهلية للنشر والتوزيع، عمان، المملكة الأردنية الهاشمية.

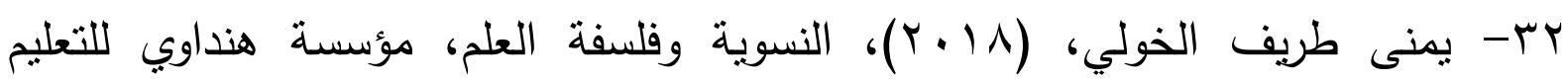
والثقافة، القاهرة، جمهورية مصر العربية.

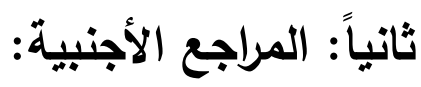

1- Chafetz, Janet Saltzman,(1997), Feminist Theory and Sociology: of Underutilized Contributions for Mainstream Theory, Annual Review Sociology, Vol. (1), No. (23) University of Houston, United States of America. 2- Consalvo, Mia, (2012), Cyberfeminism, Encyclopedia of New Media, Sage Publications, Inc., New York, United States of America. 3- Khater, Akram and Nelson, (1988), Cynthia, Al-Harakah AlNisa'iyya (The Women's Movement and Political Participation in Egypt), Women's Studies International Forum, Vol. 2, No. 5, Amsterdam, Netherlands.

4- Talhami, Ghada Hashem, (1996), The Mobilization of Muslim Women in Egypt, University Press of Florida, United States of America. 
5- United Nations, (1996), Report of the Fourth World Conference on Women (Beijing, 4-15 September 1995), New York, United States of America.

6- UNFPA CAPMAS and NCW, (2016), The Economic Cost of Gender Based Violence Survey Egypt 2015, Cairo, Egypt. 7- World Economic Forum, (2018), The Global Gender Gap Report (Insight Report), Geneva, Switzerland.

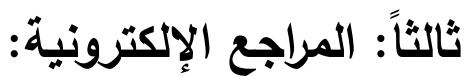

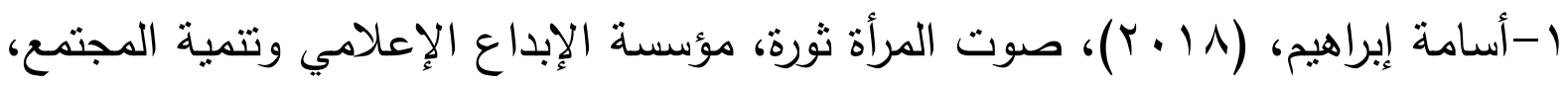

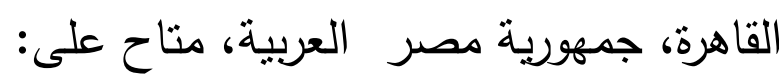
https://mediacreativity.org/article/2019/01/12/939/\%d8\%a3\%d8\%b3\%d8\%a7\%d9\%85\%d8\%a9\%d8\%a7\%d8\%a8\%d8\%b1\%d8\%a7\%d9\%87\%d9\%8a\%d9\%85\%d9\%8a\%d9\%83\%d8\%aa\%d8\%a8:-\%d8\%b5\%d9\%88\%d8\%aa\%d8\%a7\%d9\%84\%d9\%85\%d8\%b1\%d8\%a2\%d8\%a9\%d8\%ab\%d9\%88\%d8\%b1\%d8\%a9/\%d9\%85\%d9\%82\%d8\%a7\%d9\%84\%d8\%a7\%d8\%aa

Y-الفاهم محمد، (10 + ب)، موجات النسوية، صحيفة الاتحاد، الملحق الثقافي، أبوظبي، الإمارات العربية المتحدة، متاح على: https://www.alittihad.ae/article/24787/2015/\%D9\%85\%D9\%88\%D 8\%AC\%D8\%A7\%D8\%AA\%D8\%A7\%D9\%84\%D9\%86\%D8\%B3\% -D9\%88\%D9\%8A\%D8\%A9

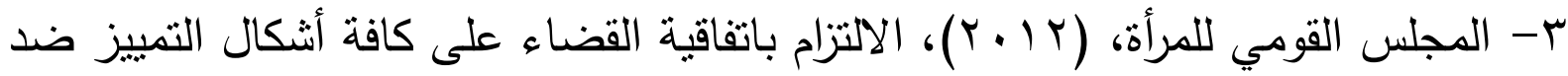

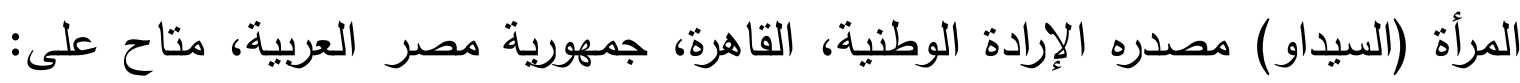
https://ncw.gov.eg/ar/cedawarajustification/ 
ع - أميمة سعودي، (9 (ب)، المرأة المصرية (مائة عام من الوطنية)، الهيئة العامة للاستعلامات، القاهرة، جمهورية مصر العربية، مناح على:

http://www.sis.gov.eg/Story/184154/\%D8\%A7\%D9\%84\%D9\%85\%D 8\%B1\%D8\%A3\%D8\%A9-

\%D8\%A7\%D9\%84\%D9\%85\%D8\%B5\%D8\%B1\%D9\%8A\%D8\%A9..-\%D9\%85\%D8\%A7\%D8\%A6\%D8\%A9-

\%D8\%B9\%D8\%A7\%D9\%85-\%D9\%85\%D9\%86-

\%D8\%A7\%D9\%84\%D9\%88\%D8\%B7\%D9\%86\%D9\%8A\%D8\%A9?la $\mathrm{ng}=\mathrm{ar}$

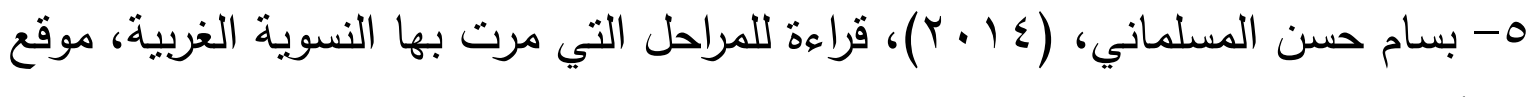

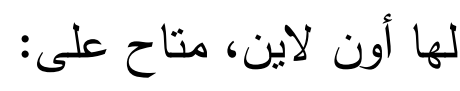
http://www.lahaonline.com/articles/view/44915.htm

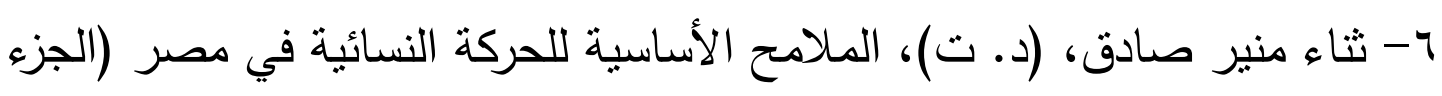

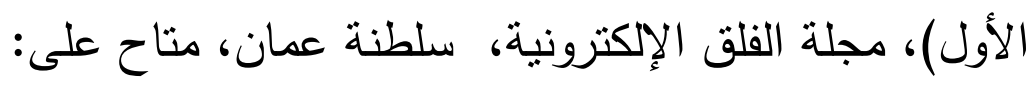
https://www.alfalq.com/?p=1509

https://dostour.eg/2013/topics/basic- دستور مصر، متاح على - - components/state $-15-4 /$

^- سيدة محمود، (د.ت)، المجتمعات العربية من بكين إلى بكين، اللجنة الإسلامية العالمية

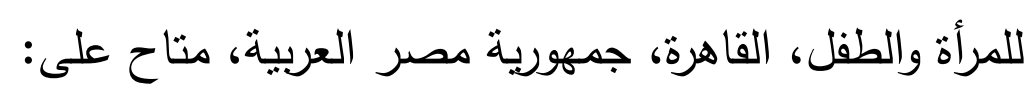
http://iicwc.org/lagna/iicwc/iicwc.php?id=476

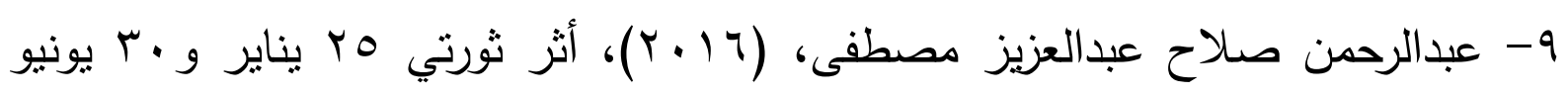

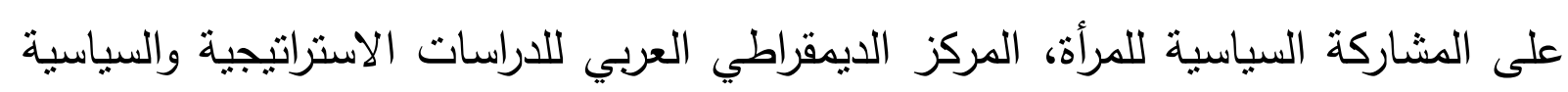

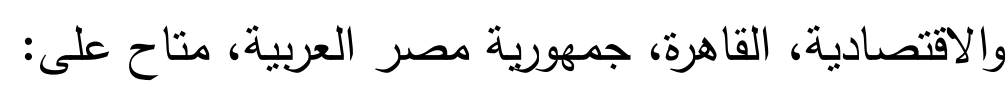
https://democraticac.de/?p=38951

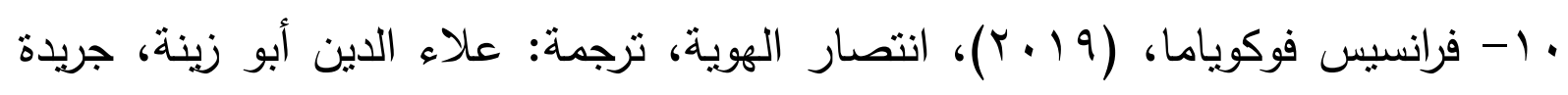

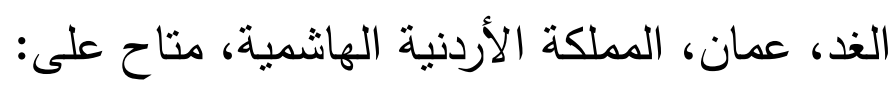


https://alghad.com/\%D8\%B6\%D8\%AF-

\%D8\%B3\%D9\%8A\%D8\%A7\%D8\%B3\%D8\%A9-

\%D8\%A7\%D9\%84\%D9\%87\%D9\%88\%D9\%8A\%D8\%A9-

\%D8\%A7\%D9\%84\%D9\%82\%D8\%A8\%D9\%8E\%D9\%84\%D9\%8A\%

D8\%A9-

\%D8\%A7\%D9\%84\%D8\%AC\%D8\%AF\%D9\%8A\%D8\%AF\%D8\%A9\%D9\%88\%D8\%A3\%D8\%B2\%D9\%85

ا ا - فرناردو ريفيلو لاروتا، (10 • r)، عدسات السايبورج (التكنولوجيا والتجسيد)، مطبوعة اختيار غير الدورية، متاح على:

file://C:/Users/genius/Downloads/Documents/101.pdf r ا- مصطفى محمود وآخرون، (Y (Y)، المرأة تتصدر أولويات القطاع المصرفي وه بنوك تستهدفها، بوابة الوطن الإلكترونية، القاهرة، جمهورية مصر العربية، متاح على: https://www.elwatannews.com/news/details/4101684 r ا - مرصد المرأة المصرية، متاح على: http://www.enow.gov.eg/\%D9\%85\%D8\%AD\%D8\%A7\%D9\%88\%D8 \%B1\%20\%D8\%A7\%D9\%84\%D8\%A7\%D8\%B3\%D8\%AA\%D8\%B1\% D8\%A7\%D8\%AA\%D9\%8A\%D8\%AC\%D9\%8A\%D8\%A9

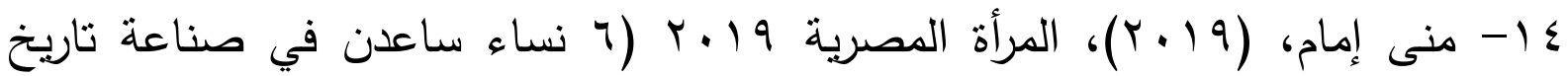
مصر)، بوابة أخبار اليوم، القاهرة، جمهورية مصر العربية، متاح على:

https://akhbarelyom.com/news/newdetails/2818519/1/\%D8\%A7\%D9 \%84\%D9\%85\%D8\%B1\%D8\%A3\%D8\%A9\%D8\%A7\%D9\%84\%D9\%85\%D8\%B5\%D8\%B1\%D9\%8A\%D8\%A92019--6\%C2\%A0\%D9\%86\%D8\%B3\%D8\%A7\%D8\%A1\%D8\%B3\%D8\%A7\%D8\%B9\%D8\%AF\%D9\%86-\%D9\%81\%D9\%8A\%D8\%B5\%D9\%86\%D8\%A7\%D8\%B9\%D8\%A9- 
\%D8\%AA\%D8\%A7\%D8\%B1\%D9\%8A\%D8\%AE-

\%D9\%85\%D8\%B5\%D8\%B1

1 - وزارة التضامن الاجتماعي، متاح على: - https://www.moss.gov.eg/ar eg/Pages/program-details.aspx?pid=10 7 ا 17 - ويكي الجندر ، نسوية راديكالية، متاح على: https://genderiyya.xyz/wiki/\%D9\%86\%D8\%B3\%D9\%88\%D9\%8A \%D8\%A9_\%D8\%B1\%D8\%A7\%D8\%AF\%D9\%8A\%D9\%83\%D8 \%A7\%D9\%84\%D9\%8A\%D8\%A9

IV https://genderiyya.xyz/wiki/\%D9\%86\%D8\%B3\%D9\%88\%D9\%8A \%D8\%A9_\%D9\%85\%D8\%A7\%D8\%B1\%D9\%83\%D8\%B3\%D9\% $8 \mathrm{~A} \% \mathrm{D} 8 \% \mathrm{~A} 9$

$$
\text { 11 - ويكيبيديا الموسوعة الحرة، المرأة في مصر ، متاح على: }
$$

https://www.wikiwand.com/ar/\%D8\%A7\%D9\%84\%D9\%85\%D8\%B1 \%D8\%A3\%D8\%A9_\%D9\%81\%D9\%8A_\%D9\%85\%D8\%B5\%D8\%B 1

$$
9 \text { 19 - ويكيبيديا الموسوعة الحرة ،النسوية في مصر ، متاح على: }
$$

https://ar.wikipedia.org/wiki/\%D8\%A7\%D9\%84\%D9\%86\%D8\%B3\% D9\%88\%D9\%8A\%D8\%A9_\%D9\%81\%D9\%8A_\%D9\%85\%D8\%B5\% D8\%B1

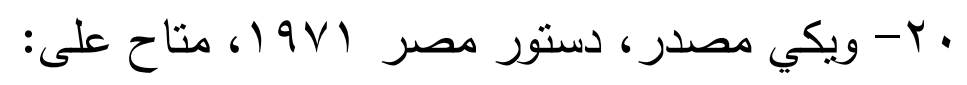

https://ar.wikisource.org/wiki/\%D8\%AF\%D8\%B3\%D8\%AA\%D9\% 88\%D8\%B1_\%D9\%85\%D8\%B5\%D8\%B1_1971

21- Rational Wiki, Radical feminism, Available on:

https://rationalwiki.org/wiki/Radical_feminism 
22.- Wikipedia The Free Encyclopedia, Liberal Feminism, Available on:

https://en.wikipedia.org/wiki/Liberal_feminism 